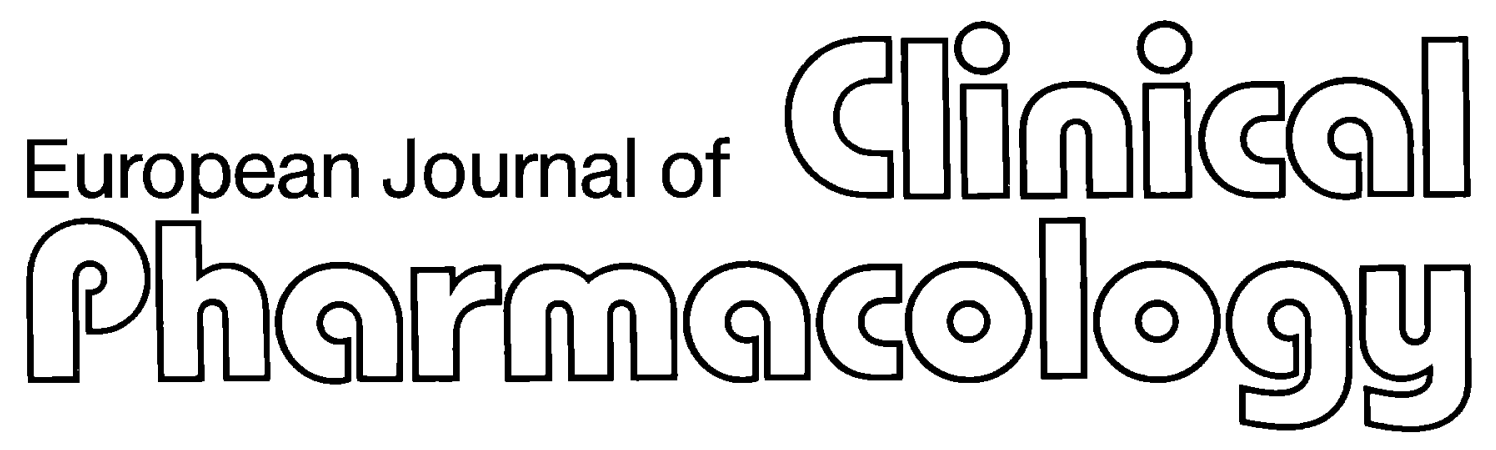

Abstracts of the 4th Annual Meeting of the German Society of Clinical Pharmacology and Therapy Hannover, 14-17 September 1994

\title{
Springer International
}



A 1

DEBRISOQUINE POLYMORPHISM IN PALESTINIANS

${ }^{1}$ Abu Al-Kahia $M$, ${ }^{2}$ Roustom $A$, ${ }^{3}$ Siegmund $W,{ }^{3} Z$ schiesche $M$ and ${ }^{3}$ Franke $\mathrm{G}$.

Thirty-three Palestinians healthy volunteers were phenotyped with debrisquine (DB). Urine was coliected for 6 hours after DB administration. $\mathrm{DB}$ and its metabolite 4-hydroxydebrisoquine 4OHDB was measured in urine by HPLC (2). The metabolic ratio has been calculated (DB/OHDB). The antimode has been excepted by 12.6. No, Poor metabolizer (PM) was found among the phenotyped Palestinians. The commutative exertion of $\mathrm{DB}_{1} 4$ OHDB and total DB was lower in the Palestinians compared with that of the Syrians (1). No correlation was found between sex and hydroxylation-phenotype. These results suggest that the DBhydroxylation may has other behavior in the Palestinians as in the Syrians.

\section{References}

1. Routom $\mathrm{R}$ et al. inter $\mathrm{J}$ clin Pharmacol Ther and Toxicol 30:543544 (1992)

2. Zschiesche $M$ et al. Pharmazie 45:920-921 (1990)
A 2

\section{CAN GRAPEFRUTT JUICE INFLUENCE THE BIOAVAILABILITY OF ETHINYLESTRADIOL ?}

\author{
A. Balogh, A. Weber, G. Klinger
}

Grapefruit juice may considerably increase the systemic bioavailability of drugs as felodipine and nifedipine. This food-drug interaction has potential practical importance because citrus juices are often consumed at breakfasttime when drugs are often taken. It is likely that a plant flavonoid in grapefruit juice, naringenin, is responsible for this effect (inhibition of cytochrome P-450 enzymes in the liver or in the small intestinal wall). Ethinylestradiol $\left(\mathrm{EE}_{2}\right)$, the estrogen of oral contraceptive steroides, shows a high first-pass-metabolism in vivo. Therefore, the purpose of this study is to test the interaction between grapefruite juice and $\mathrm{EE}_{2}$. The area under the serum concentration-time curve $\left(\mathrm{AUC}_{0-24 \mathrm{~h}}\right)$ of $\mathrm{EE}_{2}$ was determined in a group of young healthy women ( $n=13$ ) on day $4 \pm 1$ of menstruale cycle.

To compare intraindividually, the volunteers were randomly allocated to two test days. The female volunteers took $50 \mu \mathrm{g} \mathrm{EE}_{2}$ together with either $200 \mathrm{ml}$ of herb tea or with the same amount of grapefruit juice (content of naringenin $887 \mathrm{mg} / \mathrm{l}$ ). Furthermore, on the day of testing the women drank 4 times $200 \mathrm{ml}$ of the corresponding fluid every three hours up to four times.

The $\mathrm{AUC}_{0-24 \mathrm{~h}}$ of $\mathrm{EE}_{2}$ amounts to $1110.5 \pm 637.7 \mathrm{pg} \mathrm{x} \mathrm{ml}^{-1} \mathrm{x} \mathrm{h}$ after the administration of the drug with grapefruit juice; that means $28 \%$ higher in comparison to $868.0 \pm 490.0 \mathrm{pg} \mathrm{x} \mathrm{ml}^{-1} \mathrm{x} \mathrm{h}$ after concomitant intake of tea. Also, the mean $\mathrm{C}_{\mathrm{max}}$-value increases to $37 \%, \mathrm{p} \leq 0.01$ (117.5 $\pm 53.2 \mathrm{pg} \mathrm{x} \mathrm{ml}^{-1}$ and $85.5 \pm 32.9 \mathrm{pg} \mathrm{x} \mathrm{ml}^{-1}$, respectively).

This result shows that the systemic bioavailability of $\mathrm{EE}_{2}$ increases after intake of the drug with grapefruit juice.

The extent of this effect is lower than the extent of known interindividual variability.

Institue of Clinical Pharmacology, Bachstr. 18, 07740 Jena, FDR

\section{A 4}

TIRACIZINE DISPOSITION: DOES IT DEPEND ON URINARY PH ?

Annette Berndt, R. Oertel. Th. Gramatté, K. Richter, B. Terhaag, and W. Kirch

The present investigation was carried out to obtain information on the circadian variations of the phannacokinetics of the antiarrhythmic agent tiracizine (AWD Dresden $\mathrm{GmbH}$ ) and its pharmacological active metabolites $\mathrm{Ml}$ and M2. During a 7 day multiple dose study period (100 mg tiracizine b.i.d.) in eight healthy volunteers a significant lower mean steady state total urinary recovery during day-time compared to night-time ( $A e_{\text {tot }}=42.0 \pm 15.7 \%$ vs. $A e_{\text {tottn }}=51.2 \pm 19.6 \%$ ) had been observed. This difference was mainly due to a substantial increase of M1 and a smaller increase of M2 urinary recovery by night. Through serum levels of MI and M2 tended to be higher at 7 p.m. compared to 7 a.m.. Circadian variations of drug absorption, metabolism as well as glomerular filtration could not explain our observations.

The $\mathrm{pH}$-dependence of the in vitro n-octanol/water partition coefficient of tiracizine and metabolites (pKa about 8 ) was determined. It could be shown that the ratio non-ionic/ionic form of M1 and $\mathrm{M} 2$ is highly dependent on $\mathrm{pH}$ in the range of $\mathrm{pH} 5-\mathrm{pH} 7$. Therefore, the observed circadian variations might be attributed to alterations of ionisation, i.e. non-ionic tubular reabsorption of the metabolites due to the well known circadian differences in urinary $\mathrm{pH}$

Considering the narrow therapeutic index of class I antiarrhythmics the present results indicate that the effect of alterations of urinary $\mathrm{pH}$ on the pharmacokinetics of tiracizine and its metabolites should be investigated in vivo. 
EXERCISE INCREASES SYSTEMIC NITRIC OXIDE PRODUCTION IN UNTRAINED AND ENDURANCE-TRAINED HEALTHY HUMAN SUBJECTS.

Stefanie M. Bode-Böger, Rainer H. Böger, Jürgen C. Frölich.

The effects of submaximal exercise on systemic nitric oxide (NO) formation, as assessed by measuring the urinary excretion rates of $\mathrm{NO}_{3}{ }^{-}$and of cyclic GMP, were compared in 10 endurance-trained and 6 untrained male subjects. Urinary excretion rates of $\mathrm{NO}_{3}{ }^{-}$(by gas chromatography) and cyclic GMP (by radio-immunoassay) were assessed before and after a $30 \mathrm{~min}$ exercise test at $60 \%$ of each subject's individual maximal work capacity in hourly intervals. Urinary $\mathrm{NO}_{3}{ }^{-}$excretion in untrained and trained subjects was comparable at rest $(104 \pm 35$ vs. $110 \pm 19 \mu \mathrm{mol} / \mathrm{mmol}$ creatinine, $p=$ n.s.). It more than doubled during exercise in both groups (to $236 \pm$ $88 \mu \mathrm{mol} / \mathrm{mmol}$ creatinine in untrained and to $252 \pm 39 \mu \mathrm{mol} / \mathrm{mmol}$ creatinine in trained subjects, each $p<0.01$ ) and rapidly decreased to baseline within 2 hours after the test. Resting urinary cyclic GMP excretion was fourfold higher in the athletes than in the untrained subjects ( $21 \pm 5$ vs. $6 \pm 1 \mathrm{nmol} / \mathrm{mmol}$ creatinine, $p<0.05$ ). During exercise it increased about twotold in both groups (to $52 \pm 12$ and 10 $\pm 1 \mathrm{nmol} / \mathrm{mmol}$ creatinine, respectively, each $p<0.01$ ), and returned to baseline after its end. There was a correlation between urinary cyclic GMP and $\mathrm{NOs}^{-}$excretion $(p<0.05)$ in both groups. We conclude that acute submaximal exercise increases the formation of $\mathrm{NO}$ in man, as reflected by the increased urinary excretion of $\mathrm{NO}_{3}{ }^{-}$ and cyclic GMP. This may contribute to the vasodilation during physical exercise, and at least partly explain the beneficial effects of physical training in patients with cardiovascular diseases.

Institute of Clinical Pharmacology, Medical School, Hannover, Germany.
HEMODYNAMIC AND BIOCHEMICAL EFFECTS OF A SINGLE INTRAVENOUS DOSE OF L-ARGININE OR PROSTAGLANDIN E1 IN PATIENTS WITH PERIPHERAL ARTERIAL DISEASE.

Stefanie M. Bode-Böger, Rainer H. Böger, Heiko Alfke ${ }^{\star}$, Doris Heinzel, Klaus Alexander*, Jürgen C. Frölich.

Prostaglandin $E_{1}$ (PGE1) is used for the treatment of patients with peripheral arterial disease, and probably effective due to its vasodilator and antiplatelet effects. L-arginine is the precursor of endogenously synthesized nitric oxide (NO). In healthy human subjects, Larginine also induces peripheral vasodilation and inhibits platelet aggregation due to an increased NO production. In the present study the influence of a single intravenous dose of L-arginine $(30 \mathrm{~g}, 60 \mathrm{~min})$

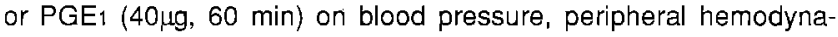
mics (femoral artery Duplex sonography), and urinary $\mathrm{NO}_{3}^{-}$and cGMP excretion rates was assessed in ten patients with peripheral arterial disease (Fontaine III - IV). Blood flow in the femoral artery was significantly increased by L-arginine by $68 \%(p<0.01)$, and by PGE1 by $25 \%(p<0.05)$. L-arginine more strongly decreased systolic and diastolic blood pressure than PGE1. Plasma arginine concentration was increased 4 -fold by L-arginine, but unaffected by PGE1. Urinary excretion of $\mathrm{NO}_{3}^{-}$increased by $118 \%$ after L-arginine $(p<$ 0.05 ), and by $78 \%$ after PGE1 ( $p=n . s$.). Urinary cGMP excretion increased by $76 \%$ after L-arginine and by $43 \%$ after PGE1 (each $p=$ $n$.s.). We conclude that intravenous $L$-arginine decreases peripheral arterial resistance, resulting in enhanced blood flow and decreased blood pressure in patients with peripheral arterial disease. These effects were paralleled by increased urinary $\mathrm{NO}_{3}{ }^{-}$excretion, indicating that systemic NO production was enhanced by the infusion. Increased $\mathrm{NO}_{3}-$ excretion may be a sum effect of $\mathrm{NO}$ synthase substrate provision (L-arginine) and increased shear stress (PGE1 and L-arginine).

Institutes of Clinical Pharmacology and *Anglology, Medical School, Hannover, Germany.

\section{A 8}

INCREASED PROSTACYCLIN PRODUCTION DURING SUBMAXIMAL EXERCISE IN TRAINED AND UNTRAINED SUBJECTS: EFFECT OF LOW-DOSE ASPIRIN ADMINISTRATION.

Rainer H. Böger, Stefanie M. Bode-Böger, Dimitrios Tsikas, Jürgen C. Frölich.

The influence of submaximal exercise on the urinary excretion of 2,3-dinor-PGF1a (the major urinary prostacyclin metabolite), 2,3dinor-TXB2 (the major urinary thromboxane A2 metabolite), and PGE2 (originating from the kidney), and on platelet aggregation was assessed in 6 untrained and 10 endurance-trained male subjects before and after 7 days of $50 \mathrm{mg} /$ day of aspirin. Urinary 2,3-dinor-TXB2 excretion was significantly higher in the athletes at rest $(p<0.05)$. Submaximal exercise increased urinary 2,3-dinor-6-keto-PGF10. excretion without affecting 2,3-dinor-TXB2 or PGE2 excretion or platelet aggregation. Aspirin treatment induced an $~ 80 \%$ inhibition of platelet aggregation and 2,3-dinor-TXB2 excretion in both groups. However, urinary 2,3 -dinor-6-keto-PGF $1 \alpha$ was inhibited by only $24 \%$ in the untrained, but by $51 \%$ in the trained group $(p<0.05)$. Urinary PGE2 was unaffected by aspirin in both groups, indicating that cyclooxygenase activity was not impaired by a systemic aspirin effect. After low dose aspirin administration, the same selective stimulatory effect of submaximal exercise on urinary 2,3-dinor-6-keto-PGF $1 \alpha$ excretion was noted in both groups as before. The ratio of 2,3-dinor-6-ketoPGF1 1/2,3-dinor-TXB2 was increased by exercise; this effect was potentiated by aspirin $(p<0.05)$. Our results suggest that the stimulatory effect of submaximal exercise on prostacyclin production is not due to an enhanced prostacyclin endoperoxide shift from activated platelets to the endothelium, but rather the result of endothelial prostacyclin synthesis activation from endogenous precursors. 50 $\mathrm{mg} /$ day of aspirin potentiates the favorable effect of submaximal exercise on endothelial prostacyclin production by selectively blocking platelet cyclooxygenase activity.

Institute of Clinical Pharmacology, Medical School, Hannover, Germany. 
A 9

\section{EFFECT OF CONSENSUS CONFERENCES ON CLINICAL PRESCRIBING HABITS IN A GERMAN UNIVERSITY HOSPITAL. Rainer H. Böger, Stefanie M. Bode-Böger, Jürgen C. Frölich.}

Demand for cost-effectiveness in medical treatment in general, and especially in pharmacotherapy, has been increasing in recent years. During the same time period, an increasing number of new, expensive drugs has been introduced into clinical practice. Therefore, mechanisms need to be installed to maintain quality of treatment and, at the same time, to reduce costs produced by the inadequate use of drugs. Arriving at a consensus how to use drugs in different departments of a hospital may contribute to this process, by standardizing the way patients are treated and by placing clinical pharmacotherapy on a more rational basis. We have introduced a therapeutic consensus conferences concept into our hospital as a means of finding a consensus about pharmacotherapeutic concepts for our clinics, and of defining accepted indications and refuting misuses of certain drugs.

The first consensus conference focused on differential volume therapy with albumin or colloidal solutions. Consensus was recorded in a therapeutic guideline which was disseminated in our hospital. In the 12 months period following the consensus conference, savings of some 0.8 million DM (or $27 \%$ of the expenses for volume therapy in the previous year) were recorded. The second consensus conference established a therapeutic guideline for the prophylactic and therapeutic use of intravenous immunoglobulins, and resulted in a sharp reduction of the use of hyperimmunoglobulins, as well as in a $\sim 24 \%$ reduction of costs in the following 6 months period.

These results show that consensus conferences are a useful means for reducing the inadequate use of drugs in a university hospital. This results in considerable reductions in the costs of drug treatment and may thus be an important tool for a more rational and a mors costeffective clinical pharmacotherapy.

Institule of Clinical Pharmacology, Medical School, Hannover, Germany.

\section{A 11}

RECOMBINANT OVEREXPRESSION OF A FUNCTIONAL SOLUBLE GUANYLYL CYCLASE IN THE BACULOVIRUS / INSECT CELL SYSTEM

\section{W. A. Buechler, J. Aktas, S. David, J.-M. Heim and R. Gerzer}

Soluble guanylyl cyclases (GC-S) are heterodimeric hemeproteins consisting of two protein subunits $(70 \mathrm{KDa}, 82 \mathrm{KDa})$. The enzyme is activated by nitric oxide (NO) and catalyzes the formation of the signal molecule "cGMP" (cyclic guanosine-3'5'-monophosphate) from GTP. Numerous physiological effects of cGMP are already very well characterized. However, detailed insights in the NO-activation mechanism of this enzyme have been described to date only in a hypothetical model (1). Recently, this concept was supported by experimental data using sitedirected mutagenesis to create a NO-insensitive soluble guanylyl cyclase mutant (2). It is generally accepted that the prostethic heme-group plays a crucial role in the activation mechanism of this protein. Nonetheless, some interesting questions with regard to structure and regulation of soluble guanylyl cyclases still need to be uncovered (e.g. activation with other free radicals, such as carbon monoxide). Since this kind of studies is limited so far by isolating large quantities of a biologically active enzyme with conventional purification techniques, the recombinant protein was expressed in the baculovirus / insect cell system. We describe here the construction and characterization of recombinant baculoviruses, harboring the genes that encode both protein subunits of the soluble guanylyl cyclase. Insect cells infected with these recombinant baculoviruses produce between $20-30 \%$ (as related to total cell protein) of functional soluble guanylyl cyclase. Positive infection was monitored as a change in morphology of the cells and by production of the respective recombinant viruses detected by polymerase-chain-reaction (PCR). So far examined, the recombinant enzyme exhibits similar physicochemical characteristics as the "natural" protein. Exogenous addition of several heme analogues to the infected cells is able to either stimulate or inhibit the enzymatic activity of GC-S. We are confident to purify milligram amounts of the recombinant protein in the near future.

Dr.Wolfgang A. Buechler, Abtlg. Klinische Pharmakologie, Med. Klinik, Klinikum Innenstadt, Ziemssenstrasse 1, D-80336 München

(1) Ignarro L.J., Biochemical Soc. Transactions 20,465-469, 1992

(2) Wedel et al., PNAS 91,2592-2596, 1994
A 10

EFFICACY OF THE KININ B2-RECEPTOR ANTAGONIST HOE 140 IN MEN. G.Bönner, H.Rütten, R.Chrosch, R.Müller, M.Steffen, E.Krause, W.Krone

Bradykinin (BK) induces a dose related fall in systemic blood pressure (BP) which is due to direct vasodilation and will be mediated by endothelial NO. Bradykinin has no direct effect on the pulmanary artery pressure (PAP). In our' here reported study we tested the dose of HOE 140, a new kinin $B_{2}$-receptor antagonist, which is needed to inhibit the BP lowering effect of exogenous BK completely. In a second trial we investigated whether HOE 140 itself has any effects on systemic or pulmonary circulation.

In both studies we investigated $8(4 \mathrm{~m} / 4 \mathrm{f})$ normotensive healthy volunteers under standard conditions (diet, day time, supine position). In the first study we looked for complete inhibition of exogenous bradykinin by infusion of 0.5 , $1,2,4,8 \mu \mathrm{g} / \mathrm{kg} \mathrm{BW}$ over $10 \mathrm{~min}$ i.v.. BK $(1 \mu \mathrm{g} / \mathrm{kg} \mathrm{BW})$ was injected before and after $\mathrm{HOE} 140$ as a bolus $(10 \mathrm{ml})$ in $\mathrm{NaCl}$ solution; $10 \mathrm{ml}$ of pure saline served as control. In the second study the hemodynamic effects of HOE $140 \quad 16$ $\mu \mathrm{g} / \mathrm{kg} \mathrm{BW}$ over $10 \mathrm{~min}$ i.v.) itself was studied. In both experiments BP was measured by Finapres (Ohmeda), PAP and cardiac output (CO) by Swan-Ganz thermodilution catheter, heart rate (HR) by ECG. BP, PAP and HR were determined continuously.

BK decreased mean BP $\{-19.1 \pm 3.1 \mathrm{mmHg})$ and increased $\mathrm{HR}(+24.4 \pm 3.6$ $\mathrm{min}^{-1}$; both $\left.p<0.001\right)$ and $\mathrm{CO}(+3.4 \pm 0.5 \mathrm{l} / \mathrm{min} ; \mathrm{p}<0.01)$ by reduction of peripheral vascular resistance (PVR) $\left(-492.0 \pm 42.6 \mathrm{dyn}^{*} \mathrm{~s}^{*} \mathrm{~cm}^{-5} ; \mathrm{p}<0.001\right)$. The hemodynamic effects of BK were inhibited almost completely by $8 \mu \mathrm{g} / \mathrm{kg}$ BW HOE 140 and totally abolished by $16 \mu \mathrm{g} / \mathrm{kg}$ BW HOE 140 . HOE 140 itself increased basal MAP by $+3.9 \pm 1.1 \mathrm{mmHg}$, MPAP $+0.6 \pm 0.1 \mathrm{mmHg}$, total pulmonary resistance (TPR) $+9.5 \pm 2.7 \mathrm{dyn}^{*} \mathrm{~s}^{*} \mathrm{~cm}-5$ (all $\mathrm{p}<0.01$ ) and peripheral vascular resistance (PVR) clearly about $+68.8 \pm 42.0 \mathrm{dyn}^{*} \mathrm{~s}^{*} \mathrm{~cm}^{-5}$. Our data show that HOE 140 is able to antagonize the hemodynamic effects of BK on systemic and pulmonary circulation in a dose-dependent manner. These results lead to the conclusion that bradykinin develops its hemodynamic effects only via $B_{2}$-receptors and that HOE 140 is a potent kinin-receptor antagonist in men. Inhibition of endogenous kinins by HOE 140 results in an increase in BP and PAP by raising TPR and PVR. These new data in men suggest that kinins might play an important role in physiological regulation of basal blood pressure.

Prof.Dr.med.G.Bönner, Department II of Internal Medicine, University of Cologne, Merheim Hospital, Ostmerheimer Straße 200, D-51109 Köln.

\section{A 12}

NONINVASIVE MEASUREMENT OF BETA-ADRENOCEPTORS BY PET. Paolo G Camici. MRC Clinical Sciences Centre and Royal Postgraduate Medical School, Hammersmith Hospital, London (UK).

PET studies of myocardial pharmacology have principally concerned the sympathetic nervous system and tracers have been developed to probe the integrity of both pre- and post-synaptic sites. The sympathetic nervous system plays a crucial role in the control of heart rate and myocardial contractility as well in the control of the coronary circulation. Alterations of this system have been implicated in the pathophysiology of a number of .cardiac disorders, in particular, heart failure, ventricular arrhythmogenesis, coronary artery disease, idiopathic dilated and hypertrophic cardiomyopathy. Several beta blockers have been labelled with carbon-11 for imaging by PET. The most promising of these is CGP 12177 which is a non-selective beta adrenoceptor anatagonist particularly suited for PET studies due to its high affinity and low lipophilicity, thus enabling the functional receptor pool on the cell surface to be studied. Studies in our institution in a group of young healthy subjects have yielded $B \max$ values of $10.4 \pm 1.7 \mathrm{pmol} / \mathrm{g}$ myocardium. These data are consistent with literature values of Bmax for beta adrenoceptors in human ventricular myocardium determined by a variety of in vitro assays. A recent study in patients with hypertrophic cardiomyopathy has shown that myocardial beta adrenoceptor density is decreased by approximately $25-30 \%$ relative to values in normal subjects. The decrease in receptor density occurs in both hypertrophied and nonhypertrophied portions of the left ventricle. These data are consistent with the hypothesis that sympathetic overdrive might be involved in the phenotypic expression of hypertrophic cardiomyopathy. A further decrease of myocardial beta adrenoceptor density (to levels well below 76.5-7.7 pmol/g) has been observed in those patients with hypertrophic cardiomyopathy who procede to ventricular dilatation and heart failure.

MRC Clinical Sciences Centre, Hammersmith Hospital, Du Cane Road, London W12 ONN, (UK). 
CYTOCHROME P4501A1 (CYP1A1) AND GLUTATHIONE-STRANSFERASE $\mu$ (GSTM1 type $A$ and B): ASSOCIATION TO LUNG CANCER SUSCEPTIBILITY

I. Cascorbi, J. Brockmöller, R. Kerb, P. Mrozikiewicz, E. Müller, and I. Roots

CYP1A1 hydroxylates polycyclic aromatic hydrocarbons such as benzo(a)pyrene occurring e.g. in cigarette smoke. Two hereditary mutations are discovered: $m 1, a \mathrm{~T}$ to $\mathrm{C}$ transition $1,194 \mathrm{bp}$ downstream of exon $7 ; \mathrm{m} 2$, located at position 4,889 in exon 7 representing an $A$ to $G$ transition resulting an isoleucine to valine substitution in the heme-binding region. Recently we could demonstrate in Caucasians that carriers of the m2-mutation possess an increased risk towards lung cancer (Drakoulis et al. Clin.Investig. $72: 240,1994)$, whereas the $m 1$-mutation shows no such association. The Phase-II enzyme GSTM1 catalyses the conjugation of glutathione to electrophilic compounds such as products of CYP1A1. GSTM1 is absent in $50.9 \%$ of the Caucasian population due to base deletions in exon 4 and 5 of the gene. We found no contrariety in the GSTM1 distribution, including frequencies of type $A(\mu)$ and type $B(\psi)$ among lung cancer patients (odds ratio $=1.01, \mathrm{n}=117$; Cancer Res. 53:1004,1993).

149 lung cancer patients and 408 reference patients were investigated for mutations of CYP1A1 and GSTM1 by allele-specific PCR and RFLP. A statistically significant higher risk for lung cancer among carriers of the $m 2-$ trait was found (odds ratio $=2.63, P=0.001$ ). Interestingly, amid lung cancer, $m 2$-alleles were less often linked to $m 1$ than in controls (odds ratio $=9.50,95 \%$-confidence limits $=1.50-99.7, P=0.0054)$. However, the frequency of CYP1A1 mutations did not differ among active and defective GSTM1 types. Consequently, we could not confirm in the Caucasian population the synergistic effects of CYP1A1 mutations (especially m2) and deficient GSTM1 as combined susceptibility factors for lung cancer as described among the Japanese (Cancer Res. 55:2994,1993).

Institute of Clinical Pharmacology, Charité, Humboldt-University Berlin, Schumannstr. 20/21, D-10098 Berlin, Germany

\section{A 15}

Spontaneous Changes of ST-SEgment Depression, Heart Rate AND BLOOD PRESSURE IN HYPERTENSIVES WITHOUT CORONARY ARTERY DISEASE: EFFECTS OF BETA - BLOCKADF M. Christ, P. Rauen, T. Krüger, V. Klauss, A. Frey, K. Theisen, M. Wehling

Pectanginal pain and signs of silent myocardial ischemia frequently occur in hypertensives, even in the absence of coronary artery disease (CAD) and/or left ventricular hypertrophy, probably due to a reduced coronary flow reserve. Since the oxygen ex traction of the heart is nearly maximal during rest, increases of oxygen demand cannot be balanced by increases of myocardial perfusion: To assess the frequency of ischemic type ST-segment depressions in this patients and to determine the influence of heart rate (HR) and blood pressure (BP), simultaneous $24 \mathrm{~h}$ Holter- and $24 \mathrm{~h}$ ambulatory BP monitoring were performed in 18 hypertensives (age $43-71$ years, $9 \mathrm{f}, 9 \mathrm{~m}$ ) without $C A D$ before and after four weeks on therapy with the $\beta$ - blocker betaxolol.

25 episodes of significant ST-segment depressions ( $\geq 0.1 \mathrm{mV}, \geq 1 \mathrm{~min})$ of a total length of $470 \mathrm{~min}$ could be demonstrated in $9 / 18$ patients $(50 \%)$ without antihypertensive therapy. Systolic BP significantly increased from $139 \pm$ $13.9 \mathrm{mmHg}$ (mean $\pm \mathrm{SD}, \mathrm{p}<0.05$ ) 60 min before to a maximum of $191 \pm$ $44.5 \mathrm{mmHg}$ during the ischemic episodes, HR and rate-pressure product (RPP) increased from $76 \pm 6.3 \mathrm{~min}^{-1}$ and $100.6 \pm 20.9 \mathrm{mmHg} \mathrm{x} \mathrm{min}-1 \mathrm{x}$ $10^{2}$ to $138 \pm 16.8 \mathrm{~min}^{-1}$ and $230.4 \pm 88.9 \mathrm{mmHg} \times \mathrm{min}^{-1} \times 10^{2}(\mathrm{p}<0.05)$. The extent of ST-segment depressions significantly correlated with $H R$ and RPP ( $<<0.05$ ). Drug therapy with $10-20 \mathrm{mg} / \mathrm{d}$ betaxolol for 4 weeks significantly decreased mean $\mathrm{HR}$, systolic and diastolic BP $(\mathrm{p}<0.05)$. 6 ischemic episodes of a total length of 38 min were recorded only in 4 of 15 hypertensives $\left(26.7 \% ; p<0.05 ; \chi^{2}\right.$-test).

In conclusion, increases of HR and systolic BP seem to be the most important factors which induce myocardial ischemia in hypertensives without $\mathrm{CAD}$. As silent ischemia is a independent risk factor for sudden cardiac death and other cardiac events, specific antihypertensive therapy should not only be aimed to normalize blood pressure, but should also address reduction of ischemic episodes as demonstrated here.

Dr. M. Christ, Med. Klinik, Klinikum Innenstadt der LMU - München, Ziemssenstraße 1, D - 80336 München.
EFFECTS OF OCREOTIDE AND GLUCAGON ON BPLANCHNIC HEMODYNAYICS IN HEALTHY VOLONTEERS.

J. Chemnitz, A. von zur Mühlen and T.H. Schürmeyer

In healthy subjects the effect of gastrointestinal hormones like somatostatin and glucagon on splanchnic hemodynamics is not well defined due to the invasiveness of the direct measurement of e.g. portal vein (PV) wedged pressure.

Methods : Now, we applied Duplex sonography (3.5 $\mathrm{MHz}$ ) and color coded flow mapping to compare the effects of ocreotide $(100 \mu \mathrm{g} s c)$, a long acting somatostatin agonist, and glucagon ( $1 \mathrm{mg}$ iv) on the hemodynamics of the $\mathrm{PV}$, superior mesenteric artery (SMA) and common hepatic artery (HA) in 14 healthy volunteers $(130,1 \% ; 25 \pm 2 y ; x \pm$ sem).

Results: Basal values of PV flow (12.9 \pm 0.8 $\mathrm{cm} / \mathrm{s}), \mathrm{PV}$ flow volume $(549 \pm 50 \mathrm{ml} / \mathrm{min})$, SMA systolic (sF: $195 \pm 13 \mathrm{~cm} / \mathrm{s}$ ) and diastolic flow (dF: 28 $\pm 4 \mathrm{~cm} / \mathrm{s})$, SMA Pourcelot index (PI) $(0.86 \pm 0.01)$, $\mathrm{HA} \mathrm{SF}(80 \pm 8 \mathrm{~cm} / \mathrm{s})$ and $\mathrm{dF}(19 \pm 1 \mathrm{~cm} / \mathrm{s})$ and $\mathrm{HA} \mathrm{PI}$ $(0.75 \pm 0.01)$ well agreed with previously reported results.

Within 15 min ocreotide resulted in a decrease of SMA SF $(-32 \pm 4 \%)$ SMA dF $(-31 \pm 4 \%)$, HA SF $(-18 \pm$ $5 \%)$ and $\mathrm{HA} d F(-24 \pm 7 \%)$. Maximum drop of PV flow $(-33 \pm 3 \%)$ and flow volume $(-34 \pm 7 \%)$ occurred at $30 \mathrm{~min}$. All effects diminished at $60 \mathrm{~min}$. No significant change of vessel diameter and PI was seen. 5 min following its application glucagon caused a highly variable, only short lasting increase of $P V$ flow volume $(+51 \pm 18 \%)$ and SMA dF $(+49 \pm 17 \%)$. HA Fd $(+14 \pm 4 \%)$ showed a tendency to rise (ns). We conclude that in clinical pharmacology Duplex sonography is a valuable aid for measuring effects of hormones and drugs on splanchnic hemodynamics.

PD Dr. T.H. Schürmeyer, Abt. Klin. Endokrinologie, Medizinische Hochschule, D-30625 Hannover, Germany

\section{A 16}

\section{EFFECTS OF THE PHOSPHODIESTERASE INHIBITOR PIROXIMONE ON PLATELET FUNCTION IN VITRO AND IN VIVO IN PATIENTS WITH HEART FAILURE} T. Cyrus, M. Buerke, J. Meyer, H. Darius

Phosphodiesterase inhibitors exert their positive inotropic effects by inhibiting CAMP degradation and increasing the intracellular calcium coucentration in cardiomyocytes. An identical phosphodiesterase type III has been demonstrated in platelets and vascular smooth muscle cells. We studied the influence of piroximone on platelet function in vitro and ex vivo and the hemodynamic effects of a bolus application of piroximone in patients with severe heart failure (NYHA III-IV) using a Swan -Ganz-Catheter. In order to study the influence of piroximone on platelet function in vitro, platelet rich plasma from healthy volunteers was incubated with piroximone (10-100 $\mu \mathrm{mol} / \mathrm{l})$ from 1 minute to 2 hours and aggregation was induced by addition of ADP. For the ex vivo experiments platelet rich plasma was obtained from patients who received piroximone in doses of $0.25,0.5,1.0$ or $2.0 \mathrm{mg} / \mathrm{kg}$ bw. Blood samples were drawn immediately before and 30, 60, 90, 120 and 240 minutes after bolus application.

The ADP-induced platelet aggregation was inhibited time- and dosedependently. The $\mathrm{IC}_{50}$ value for piroximone in vitro amounted to $67 \pm 14$ $\mu \mathrm{mol} / \mathrm{l}$. In the ex vivo experiments the maximal inhibition of ADP-induced aggregation was obtained in PRP from patients who had received $2 \mathrm{mg} / \mathrm{kg}$ bw piroximone 60 minutes before. The administration of piroximone resulted in a marked hemodynamic improvement with a dose-dependent increase in cardiac index and decreases in pulmonary artery pressure and resistance.

Dr T. Cyrus, II. Medizinische Klinik der Johannes Gutenberg-Universität, Langenbeckstr. 1, 55131 Mainz, Germany 
A 17

\section{PHARMACOECONOMIC ISSUES IN CRITICAL CARE. \\ J.F. Dasta}

Intensive care unit (ICU) patients often require many drugs to treat conditions associated with acute and chronic multiorgan dysfunction. Studies indicate patients receive approximately ten drugs, on average during their ICU stay, from several drug classes. Commonly prescribed drugs include narcotics, sedatives, antibiotics, antiarrhythmics, antihypertensives, drugs for stress ulcer prophylaxis, diuretics, vasopressors, and inotropes. Reports suggest surgical ICU patients cost the hospital an average of $\$ 18,000 /$ patient in un-reimbursed costs under fixed-price reimbursement. Furthermore, patients with the greatest drain in revenue received catecholamines, triple antibiotics, or antifungal agents. Thrombolytics, antibiotics, plasma expanders, and benzodiazepines account for nearly twothirds of the cost of drugs prescribed in medical and surgical ICUs. Agents with considerable economic impact include biotechnology drugs for sepsis. Pharmacoeconomic data in ICU patients suggest increased attention should be directed towards several areas, including patients with pneumonia, intraabdominal sepsis, nosocomial bloodstream infections, optimizing sedation and analgesic therapy, preventing persistent paralysis from neuromuscular blockers, preventing stress ulcers, treating hypotension, and providing optimal nutritional support. Studies are needed to assess the impact of strategies to improve ICU drug prescribing on length of stay and quality of life. If expensive drugs are shown to decrease the length of ICU stay, then their added costs can have positive economic benefits to the health care system.

Ohio State University, College of Pharmacy, Columbus, $\mathrm{OH}$ 43210, USA

\section{A 19}

$B 1$ - and B2-adrenergic contributions to B-adrenergic inodilatory responses in healthy man

C. de Mey, K. Erb, R. Butzer, G.G. Belz

The responses to $10 \mathrm{~min}$ iv. infusions of the $B 1-$ and $B 2$-adrenoceptor agonist isoprenalin (ISO) and the $\beta_{2}$ - (and $\alpha$-) adrenoceptor agonist adrenalin (ADR) at constant rates of $1 \mu \mathrm{g} / \mathrm{min}$ were evaluated noninvasively after pretreatment (pre-Tr) with placebo (PL), $100 \mathrm{mg}$ of the $\beta 1$-selective adrenoceptor antagonist talinolol (TAL) and $80 \mathrm{mg}$ of the non-selective $B$ antagonist propranolol (PRO) in 12 healthy subjects. The following were analysed: heart rate $(\mathrm{HR}, \mathrm{bpm})$, pre-ejection time (PEP, ms), ejection time (VET, ms), HR-corrected electromechanical systole (QS2c, ms), impedance-cardiographic estimates of stroke volume ( $\mathrm{SV}, \mathrm{ml}$ ), cardiac output (CO, $1 / \mathrm{min}$ ) and peripheral resistance (TPR, dyn.s. $\mathrm{cm}^{-5}$ ) calculated from CO and mean blood pressure (SBP and DBP according to auscultatory Korotkoff-I and -IV sounds). The average responses are detailed here below:

\begin{tabular}{|c|c|c|c|c|c|c|c|c|}
\hline Agonist & pre-Tr & TPR & HR & SV & CO & PEP & VET & QS2c \\
\hline ISO & PL & -345 & +19.3 & +28.5 & +4.5 & -47 & -34 & -40.6 \\
\hline ISO & TAL & -346 & +8.9 & +23.9 & +2.6 & -25 & -4 & -10.5 \\
\hline ISO & PRO & -99 & +2.8 & +5.7 & +0.6 & -9 & -1 & -4.1 \\
\hline ADR & PL & -277 & +9.9 & +16.6 & +2.3 & -29 & 0 & -8.1 \\
\hline
\end{tabular}

This indicates that 1 ) about half the rise of $\mathrm{HR}$ and $\mathrm{CO}$ and half the shortening of PEP is $B 1$ - respectively $B 2$ - determined, 2) that predominant B2- adrenergic responses, whilst not affecting VET, take optimal benefit from the inodilatory enhancement of pump performance, 3 ) that an additional $B 1$-adrenergic stimulation is proportionally less efficient, as VET is dramatically shortened, thus blunting the gain in SV so that the rise in $\mathrm{CO}$ relies substantially on the amplified increase of HR and 4), VET is more sensitive than QS2c in expressing additional B1-adrenoceptor agonism and 5) prime systolic time intervals provide a less speculative and physiologically more meaningful represenation of cardiac pump dynamics than HR-corrected ones.

Zentrum für Kardiovaskuläre Pharmakologie, Mathildenstraße 8, 55116 Mainz, BRD
A 18

PULMONARY EXTRACTION OF DOBUTAMINE IN SURGICAL ICU PATIENTS. J. Dasta, C. Klem, T. Reilley, L. Flancbaum

The lung is known to be an organ for metabolism of several catecholamines. However, no data concerning pulmonary extraction of dobutamine (DBU) exist. Patients admitted to the surgical ICU who were receiving DBU and had pulmonary and arterial catheters in place were eligible. A set of paired blood samples were obtained for DBU concentrations simultaneously from the arterial (Ca) and distal port $(\mathrm{Cv})$ of the pulmonary artery catheter after at least a $30 \mathrm{~min}$ infusion at a constant rate. DBU concentrations were determined by HPLC (CV $=9 \%$ at concentrations of $50-500 \mathrm{ng} / \mathrm{mL}$ ). Total clearance (Cl) was calculated by Dose/Css, pulmonary extraction by (Cv$\mathrm{Ca}) / \mathrm{Cv}$. Eleven patients $(4 \mathrm{M}, 7 \mathrm{~F}), 64 \pm 16$ years, $71 \pm 24 \mathrm{~kg}$ were studied. Four patients had ARDS. DBU was administered at $7.8 \pm 5.4 \mu \mathrm{g} / \mathrm{kg} / \mathrm{min}$ for $8.5 \pm 10.5 \mathrm{hrs}$ before DBU concentrations were obtained. Ca averaged 172 $\pm 178 \mathrm{ng} / \mathrm{mL}$, while Cv was $178 \pm 187 \mathrm{ng} / \mathrm{mL}$ (ns by t-test). DBU total clearance averaged $82 \pm 63 \mathrm{~mL} / \mathrm{kg} / \mathrm{min}$. The absolute \% extraction was $3.6 \pm 23.0$. Correlation between $\%$ extraction and $\mathrm{Cv}$ was $\mathrm{r}=0.003$. The $\%$ extraction for most patients could be explained by the coefficient of variation of the assay. A wide range of DBU concentrations were seen. The pulmonary extraction of DBU is low suggesting a minimal first-pass elimination of drug through the lung.

The Ohio State University, College of Pharmacy, Columbus, OH 43210, USA.

\section{A 20}

Regression between blunting of ergometric rise of heart rate and B1adrenoceptor occupancies in healthy man C. de Mey, D. Palm, K. Breithaupt-Grögler, G.G. Belz

The HR-responses to supine bicycle ergometry ( $4 \mathrm{~min}$ at appr. $200 \mathrm{Watt}$ ) were investigated at several time points after the administration of propranolol (PRO: 40, 80, $160 \mathrm{mg}$ ), carvedilol (CAR: 12.5, 25, 50, $100 \mathrm{mg}$ ), talinolol (TAL: 25, 50, 100, $400 \mathrm{mg}$ ), metoprolol (MET: $600 \mathrm{mg}$ ) and celiprolol (CEL: $1200 \mathrm{mg}$ ) to healthy man. The effects of the agents (= difference of the ergometric response for active drug and placebo) were analysed for both the end values (END) and the increments (INC) from resting values immediately before ergometry up to END. The effects were correlated with the \%-ß1-adrenoceptor occupancies estimated using a standard Emax-model (sigmoidicity=1) from the concentrations of active substrate in plasma determined by $\beta 1$-adrenoceptor specific radioreceptor assay. The respective intercepts (I), slopes (S) and correlation coefficients ( $\mathrm{r}$ ) are detailed here below:

\begin{tabular}{||l|c|c|c|c|c||}
\hline \hline END & PRO & CAR & MET & TAL & CEL \\
\hline $\mathrm{I}$ & 0.853 & -1.874 & -6.444 & -7.162 & -9.113 \\
\hline $\mathrm{S}$ & -0.313 & -0.232 & -0.310 & -0.257 & -0.056 \\
\hline $\mathrm{r}$ & 0.942 & 0.873 & 0.996 & 0.878 & 0.429 \\
\hline INC & PRO & CAR & MET & TAL & CEL \\
\hline $\mathrm{r}$ & 2.931 & 0.506 & -7.290 & -5.091 & -7.357 \\
\hline $\mathrm{S}$ & -0.284 & -0.224 & -0.274 & -0.338 & -0.179 \\
\hline $\mathrm{r}$ & 0.954 & 0.898 & 0.991 & 0.941 & 0.865 \\
\hline
\end{tabular}

This indicates that 1) additional $\alpha$-Blockade does not distort the relationship (CAR vs. PRO), 2) MET and TAL had lower intercepts but similar slopes as PRO suggesting an "ergometric bonus", which could not be explained by their relative B1-adrenoceptor selectivity as it was maintained up to high doses where selectivity is impaired and 3) CEL's flat END-relationship regains its steepness when the slight increase of HR at rest is taken into account (as shown for INC). Mechanistically the INC-format might be more suitbale for the analysis of complex effect constellations. Therapeutically though, the END-format might be more relevant. 


\section{A 21}

INHIBITION OF LEUKOTRIENE PRODUCTION BY FISH OIL. C. Denzlinger, T. Kless, C. Haberl, C. Lemmen, O. Adam, and W. Wilmanns

Inhibition of leukotrienes is a promising approach to the treatment of several diseases because excess formation of these lipid mediators has been shown to play an important role in a wide range of pathophysiological conditions. Since until recently we were not able to obtain specific drugs suppressing leukotriene biosynthesis or action for clinical practice, we started investigating the effects of putative natural modulators of leukotriene biosynthesis such as fish oil:

10 healthy male volunteers were supplemented for 7 days with fish oil providing $40 \mathrm{mg}$ eicosapentaenoic and docosahexaenoic acid per $\mathrm{kg}$ body weight and day. The urinary concentration of leukotriene $\mathrm{E} 4$ plus $\mathrm{N}$-acetyl leukotriene $\mathrm{E} 4$ served as a measure for the endogenous leukotriene production.

Treatment resulted in a significant increase in the eicosapentaenoate concentration in red blood cell membranes. Fish oil reduced the endogenous leukotriene generation in 8 of the 10 volunteers. The effect was associated with a decrease in urinary prostaglandin metabolites, determined as tetranorprostanedioic acid. In contrast to what was expected from published in vitro and ex vivo experiments, no endogenously generated cysteinyl leukotrienes of the 5 series could be identified. The inhibitory effect of fish oil on the endogenous leukotriene generation was not synergistic to the effect of vitamin $E$, which also exhibited some suppressive activity.

Early clinical data on the effects of fish oil on leukotriene production in patients with allergy or rheumatoid arthritis are not yet conclusive.

We conclude that fish oil exhibits some inhibitory activity on leukotriene production in vivo. The effectivity of fish oil may be attenuated by concomitant modulation of other mediator systems e.g. up-regulation of tumor necrosis factor production. Medizinische Klinik III, Klinikum Grosshadern, LudwigMaximilians Universität, D-81377 München and Staatliche Orthopädische Klinik, D-81547 München

\section{A 23}

\section{MELOXICAM INHIBITS PREFERENTIALLY COX-2}

G. Engelhardt

The potency of Meloxicam (Mell, a new anti-inflammatory drug (NSAID), in the rat is higher than that of well-known NSAIDs. In adjuvant arthrtitis rats, Mel is a potent inhibitor of the local and the systemic signs of the disease. Mel is also a potent inhibitor of PG-biosynthesis by leukocytes found in pleuritic exudate in rats. Conversely, the effect of Mel on PG-biosynthesis in isolated enzyme preparations from bull seminal vesicle in vitro, the effect on intragastric and intrarenal PG-biosynthesis and the influence on the $\mathrm{TXB}_{2}$-level in rat serum is weak. In spite of the high antiinflammatory potency in the rat, Mel shows a low gastrointestinal toxicity and nephrotoxicity in rats. - Cyclooxygenase-2 (COX-2) has been recently identified as a isoenzyme of cyclooxygenase. NSAIDs are anti-inflammatory through inhibition of PG-biosynthesis by inducible COX-2 and are ulcerogenic and nephrotoxic through inhibition of the constitutive COX-1. We have investigated the effects of Mel and other NSAIDs on COX-1 of non stimulated and on COX-2 of LPS-stimulated guine pig peritoneal macrophages. Cells were cultured with and without LPS for 6 hrs together with the NSAID. Arachidonic acid was then added for further 20 mins, the medium removed and $\mathrm{PGE}_{2}$ measured by RIA.

\begin{tabular}{|c|c|c|c|c|c|c|}
\hline \multicolumn{6}{|c|}{ IC $_{50}$ values (nmol/I) of NSAIDs on COX-1 and COX-2 } \\
\hline NSAID & Meloxicam & Piroxicam & Tenoxicam & Tanidap & Dielofenac & Indomethacin \\
\hline COX-1 & 5.8 & 5.3 & 20 & 393 & 0.86 & 64 \\
COX-2 & 1.9 & 175 & 322 & 47800 & 1.9 & 6810 \\
\hline
\end{tabular}

The high potency of Mel against the COX-2 explains the high anti-inflammatory activity of this compound in spite of the good gastrointestinal and renal tolerance.

G. Engelhardt, Department of Pharmacological Research,

Dr. Karl Thomae GmbH, D-88397 Biberach/Riss, Germany

\section{A 22}

\section{EFFECT OF ACETYLSALICYLIC ACID ON HUMAN THROMBOXANE AND PROSTACYCLN RECEPTORS M. Dobler, H. Bergmann, J. Michael-Hepp, J. Meyer, H. Darius}

The number and affinity of platelet thromboxane $\left(\mathrm{TXA}_{2}\right)$ and prostacyclin $\left(\mathrm{PGI}_{2}\right.$ )-receptors are regulated by several factors. We studied the influence of oral intake of acetylsalicylic acid (ASA) on ex-vivo binding studies with human platelet membranes on the binding of the specific thromboxane $A_{2}$ antagonist ${ }^{3} \mathrm{H}-\mathrm{SQ}-29548$ and the $\mathrm{PGI}_{2}$ agonist ${ }^{3} \mathrm{H}$-noprost. The number of receptors ( $\left.\mathbf{B}_{\max }\right)$ and the binding affinity $\left(K_{d}\right)$ were calculated using Scatchard's plot analysis. In healthy male volunteers no significant difference was seen following intake of $500 \mathrm{mg} / \mathrm{d}$ of ASA for 14 days (mean \pm SEM):

\begin{tabular}{|l|l|l|l|l|}
\hline & $\begin{array}{l}\mathrm{B}_{\max } \mathrm{TXA}_{2} \\
\text { fmol/mg prot. }\end{array}$ & $\begin{array}{l}\mathrm{K}_{\mathrm{d}} \mathrm{TXA}_{2} \\
\mathrm{nM}\end{array}$ & $\begin{array}{l}\mathrm{B}_{\max } \text { PGI }_{2} \\
\text { pmol/mg prot. }\end{array}$ & $\begin{array}{l}\mathrm{K}_{\mathrm{d}} \mathrm{PGI}_{2} \\
\mathrm{nM}\end{array}$ \\
\hline Placebo & $1.48 \pm 0.17$ & $46.6 \pm 4.3$ & $0.82 \pm 0.12$ & $31.2 \pm 3.2$ \\
\hline 500 mg ASA & $1.69 \pm 0.22$ & $39.5 \pm 4.2$ & $0.98 \pm 0.11$ & $33.3 \pm 3.1$ \\
\hline
\end{tabular}

In patients with stable coronary artery disease treatment without or with 40 , 100 or $500 \mathrm{mg} / \mathrm{d}$ of ASA for 6 months showed now significant difference on PGI2 receptors ( mean \pm SEM):

\begin{tabular}{|l|l|l|l|}
\hline $\begin{array}{l}\text { ASA } \\
\mathbf{m g} / \text { day }\end{array}$ & $\mathbf{n}$ & $\begin{array}{l}\mathbf{K}_{\mathbf{d}} \\
\mathbf{n M}\end{array}$ & $\begin{array}{l}\mathbf{B}_{\max } \\
\mathbf{p m o l} / \mathbf{m g} \text { protein }\end{array}$ \\
\hline 0 & 6 & $45 \pm 3.6$ & $1.7 \pm 0.09$ \\
\hline 40 & 7 & $37 \pm 6.1$ & $1.6 \pm 0.14$ \\
\hline 100 & 5 & $38 \pm 4.6$ & $1.6 \pm 0.21$ \\
\hline 500 & 8 & $35 \pm 3.3$ & $1.4 \pm 0.14$ \\
\hline
\end{tabular}

ASA at clinically relevant doses, did not show any significant influence on the number or affinity of thromboxane $\mathrm{A}_{2}$ oder $\mathrm{PGI}_{2}$ receptors on platelets of human volunteers or patients with coronary artery disease.

Dr. Michael Dobler, II. Medizinische Klinik der Johannes GutenbergUniversität, Langenbeckstr. 1, 55131 Mainz, Germany

\section{A 24}

CARDIOVASCULAR EFFECTS OF BIMAKALIM, DILTIAZEM AND THEIR COMBINATION IN HEALTHY VOLUNTEERS K. Erb, C. de Mey, S. Roll, A. Köhnlein, W. Ungethüm*', G. Leopold*', G. G. Belz, Center for Cardiovascular Pharmacology, Mainz, "E. Merck, Darmstadt, Germany

Bimakalim, EMD 52692, is a new investigational $\mathrm{K}^{+}$-channel activator with vasodilating properties. Single peroral doses of $0.2 \mathrm{mg}$ bimakalim, $60 \mathrm{mg}$ diltiazem, either alone or in combination, were investigated in 13 healthy male supine volunteers ( 20 to 28 years of age) in a placebo-controlled, periodbalanced, randomised, double-blind, 4way cross-over design. Point estimates of the global effects of bimakalim $[K]$, diliazem $[D]$ and their interaction $[K \times D,=0$ in case of mere additivity] incl. $95 \%$ confidence intervals (Cl) were analysed for systolic and diastolic blood pressure (SBP. DBP; $\mathrm{mmHg}$ ), heart rate (HR; bpm), PQ (ms), systolic time intervals (PEP, QS2c, LVETc; ms), cardiac output (CO I. $\left.\mathrm{min}^{-1}\right)$, total peripheral resistance (TPR; dyn.s. $\left.\mathrm{cm}^{-5}\right)$, Heather index $\left(\mathrm{HI} ; \Omega . \mathrm{s}^{-2}\right)$; $1.5 \mathrm{~h}$ after dosing, "statistically significant at $\alpha=0.05$ :

\begin{tabular}{|c|c|c|c|c|c|}
\hline Variable & [K] & $95 \%-\mathrm{Cl}$ & [D] & $95 \%$-Cl & 95\%-Cl [KXD] \\
\hline SBP & 1 & -2 to 5 & -4 & -7 to -1 & -4 to 3 \\
\hline DBP & -6 & -10 to -2 & -4 & -8 to 0 & -3105 \\
\hline $\mathrm{HR}$ & 6.0 & 3.3 to 8.6 & 3.2 & 0.5 to 5.9 & -3.4 to 1.9 \\
\hline$P Q$ & -2.2 & -5.7 to 1.3 & 8.3 & 4.9 to 11.8 & -3.9 to 3.1 \\
\hline PEP & -8.3 & $-11.810-4.8$ & -4.7 & -8.2 to -1.2 & -5.3 to 1.6 \\
\hline QS2c & -1.9 & -5.5 to 1.6 & -1.6 & -5.1 to 2.0 & -4.8 to 2.3 \\
\hline LVETC & 4.0 & -0.7 to 8.7 & 1.8 & -2.9 to 6.6 & -3.9 to 5.6 \\
\hline $\mathrm{CO}$ & 0.73 & 0.23 to 1.23 & 0.25 & -0.25 to 0.75 & -0.66 to 0.35 \\
\hline TPR & -143 & -225 to -61 & -79 & -161103 & -74 to 90 \\
\hline $\mathrm{HI}$ & 0.62 & 0.01 to 1.22 & 0.53 & -0.07 to 1.14 & -0.50 to 0.71 \\
\hline
\end{tabular}

Afterload reduction and a drop in DBP occurred with bimakalim associated with a rise in HR and mild increase in cardiac performance, diltiazem (slightly) decreased afterload and BP with little (reflectory) accompanying changes and had a negative dromotropic effect. The combination caused additive effects.

Center for Cardiovascular Pharmacology, ZeKaPha GmbH, Mathildenstr. 8, 55116 Mainz, Germany. 
A 25

\section{ENHANCED EXCRETION OF LEUKOTRIENE E 4 IN PATIENTS WITH RHEUMATOID ARTHRITIS}

J. Fauler, D. O. Stichtenoth, H. Zeidler and J.C. Frölich

Rheumatoid arthritis (RA) is characterized by an immunological mediated inflammatory reaction in affected joints. Infiltration of granulocytes and monocytes is the pathophysiological hallmark within the initial phase of inflammation. These cells are able to synthesize leukotrienes. LTB $_{4}$ is a potent chemotactic factor and therefore could be responsible for the influx of granulocytes from the circulation. Cysteinyl leukotrienes $L T C_{4}, D_{4}$ and $\mathrm{E}_{4}$ augment vascular permeability and are potent vasoconstrictors. $\mathrm{LTB}_{4}$ and cysteinyl leukotrienes have been detected in synovial fluid of patients with RA. However, these results are difficult to interprete, because the procedure is invasive and artificial synthesis cannot be excluded. We used a different, noninvasive approach by assessing the excretion of $\mathrm{LTE}_{4}$ into urine. Studies with ${ }^{3} \mathrm{HLTC}_{4}$ have demonstrated that $\mathrm{LTE}_{4}$ is unchanged excreted into urine and is the major urinary metabolite of cysteinyl leukotrienes in man. Urinary $L T E_{4}$ was isolated from an aliquot of a 24 hour urine collection by solid phase extraction followed by HPLC and quantitated by RIA. Nine patients were enrolled in the present study. All met the American College of Rheumatology criteria for RA. Patients were treated with nonsteroidal inflammatory drugs and disease modifying drugs. Therapy with prednisolon was started after collection of the initial 24 hour urine sample. Disease activity was assessed by CRP (mean $59 \pm 22 \mathrm{mg} / \mathrm{L}$ ) and ESR (mean $57 \pm 37 \mathrm{~mm} /$ hour). Patients with RA excreted $97.7 \pm 71$ $n \mathrm{nol} / \mathrm{LTE}_{4}$ into urine which was significantly $(\mathrm{p}<0.008)$ more than the 13.6 $\pm 3.1 \mathrm{nmol} \mathrm{LTE}_{4} / \mathrm{mol}$ creatinine excreted by comparable healthy volunteers. Prednisolon in a mean dose of $25 \mathrm{mg} /$ day significantly $(p<0.04)$ reduced $\mathrm{LTE}_{4}$ excretion within 7 days by more than $50 \%$.

The present data demonstrate an enhanced synthesis of cysteinyl leukotrienes in RA. Furthermore, we show an inhibition of this synthesis by prednisolon

Institute of Clinical Pharmacology and Department of Rheumatology Hannover Medical School, D-30623 Hannover, Germany

\section{A 27}

\section{A PHARMACOKINETIC DATABASE}

\section{T. Frankewitsch, D. Zellner, T. Schromm, D. Nave, M. Giehl,} F. Keller

Drug databases on computers are commonly textfiles or consist of tables of generic-names or prices for example. Until now pharmacokinetic data are not easily available for regular use, because searching parameters in a textfile is time consuming and personal intensive. On the other hand these pharmacokinetic data are the fundamental background of every dosage regimen and individual dosage adjustment. For many drugs elimination is dependent on the patients renal function. Renal failure leads to accumulation, possibly up to toxic plasma concentrations.

Therefore, the decision was to build up a pharmacokinetic database. The aim is to achieve simplicity and effectiveness by using the basic rules. Only three parameters are needed to describe the pharmacokinetics: clearance (Cl), volume of distribution (Vd) and half-life $\left(\mathrm{T}_{1 / 2}\right)$. Moreover, with two parameters the third can be calculated and controlled by the equation:

$$
\mathrm{Cl}=\mathrm{Vd} * 0,693 / \mathrm{T}_{1 / 2}
$$

According to the Dettli-Equation and the Bayes' theorem estimation of individual pharmacokinetic parameters will be done by a computer program.

The advantage is that the impact of therapeutic drug monitoring can be increased. Using the population data and the Bayesian approach, only one measurement of serum drug concentrations might be enough to achieve an individual dosage regimens (El Desoky et al., Ther Drug Monitor 1993, 15: 281)

Higher therapeutic security for the patient can be achieved. There is also a major pharmacoeconomic aspect: adapting drug dosage reduces costs (Susanka et al., Am J Hosp Pharm 1993, 50:909)

The basic database for future pharmacokinetic clinical desicions is going to be built up.

T. Frankewitsch, Sektion Nephrologie, Univeritätsklinik Ulm, Robert-Koch-Str. 8, D-89069 Ulm

\section{A 26}

NEW APPROACHES TO THE INHIBITION OF PLATELET AGGREGATION (IIb/llla INHIBITORS). Desmond Fitzgerald.

Platelet aggregation is mediated by the binding of an adhesive protein, fibrinogen, to a surface receptor, the platelet glycoprotein Ilb/lla. GPIIb/llla is one of a family of adhesion receptors, integrins, which consist of a Ca ${ }^{++}$-dependent complex of two distinct protein subunits. Under resting conditions, GPIlb/llla has a low affinity for fibrinogen in solution. However, activation of platelets by mast agonists, including thrombin, ADP and thromboxane results in a conformational change in the receptor and the expression of a high affinity site for fibrinogen. Binding of fibrinogen to platelets is a common end-point for all agonists and therefore is a potential target for the development of antiplatelet drugs. These have included chimeric, partially humanised antibodies (7E3), peptides and peptidomimetics that bind to the receptor and prevent fibrinogen binding. The peptides often include the sequence RGD, a sequence that is present in fibrinogen and is one of the ligand's binding sites. When administered in vivo, antagonists of GFllb/llla markedly suppress platelet aggregation in response to all known agonists, without altering platelet shape change, a marker of platelet activation. They also prolong the bleeding time in a dose and perhaps drug dependent manner, often to more than $30 \mathrm{~min}$. In experimental models of arterial thrombosis, GPIlb/llla antagonists have proved highly effective and are more potent than aspirin. Studies in man have focused on coronary angioplasty, unstable angina and coronary thrombolysis and have given promising results. 7E3 given as a bolus and infusion combined with aspirin and heparin reduced the need for urgent revascularisation in patients undergoing high-risk angioplasty, although bleeding was more common. Some compounds have shown oral bioavailability raising the possibility that these agents could be administered chronically. Antagonists of the platelet GPIIb/lla provide a novel and potent approach to antithrombotic therapy.

Centre for Cardiovascular Science and Department of Clinical Pharmacology, Royal College of Surgeons in Ireland, St. Stephens Green, Dublin 2, Ireland.

\section{A 28}

RENAL EXCRETION OF NARINGENIN AND ITS CONJUGATED METABOLITES FOLLOWING GRAPEFRUIT JUICE INTAKE U. Fuhr and A. Kummert

The pharmacokinetic interactions with grapefruit juice reported for many drugs are attributed to the inhibition of cytochrome P450 enzymes by naringenin, which is the aglycone of the bitter juice component naringin. However, only circumstantial evidence exist that naringenin is indeed formed when grapefruit juice is ingested, and the lack of drug interaction when naringin solution is given instead of the juice is still unexplained. We investigated the pharmacokinetics of naringin, naringenin and its conjugated metabolites following ingestion of $20 \mathrm{ml}$ grapefruit juice per $\mathrm{kg}$ body weight, containing $621 \mu \mathrm{M}$ naringin, in 3 male and 3 female healthy adults. Urine was collected $0-2,2-4$, $4-6,6-8,8-10,10-12,12-16$ and $16-24$ hours after juice intake. Naringin and naringenin concentrations were measured by reversed phase HPLC following extraction using ethyl acetate, with a limit of quantitation of $300 \mathrm{nM}$. Conjugated metabolites in urine were transformed by incubation with glucuronidase $(28000 \mathrm{U} / \mathrm{ml}) /$ sulfatase $(733 \mathrm{U} / \mathrm{ml})$ from abalone entrails for $4 \mathrm{~h}$ at $\mathrm{pH} 3.8$ and determined as parent compounds. Additionally, naringin and naringenin concentrations were measured in plasma samples from grapefruit juice interaction studies conducted previously.

Neither naringin nor its conjugated products were detected in any of the samples. Naringenin was not found in plasma. Small amounts of naringenin appeared in urine after a median lag time of 2 hours and reached up to $0.365 \%$ of the dose (measured as naringin). After treatment with glucuronidase / sulfatase, up to $57 \%$ of the dose was recovered in urine:

\begin{tabular}{|c|c|c|c|c|}
\hline & $\begin{array}{c}A_{e, \text { urng }}(\% \text { of } \\
\text { dose) naringenin }\end{array}$ & $\begin{array}{c}T_{1 / 2 \text { ol.,uring }}(h) \\
\text { naringenin }(n=3)\end{array}$ & $\begin{array}{c}A_{\text {, urna }}(\% \text { of } \\
\text { dose) conjugate }\end{array}$ & $\begin{array}{c}T_{1 / 2 \text { el, urlne }}(h) \\
\text { conjugate }\end{array}$ \\
\hline & 0.012 & 1.19 & 4.98 & 2.25 \\
\hline & 0.087 & 2.87 & 9.35 & 2.57 \\
\hline & 0.365 & 7.23 & 57.1 & 3.39 \\
\hline
\end{tabular}

The absence of naringin and its conjugates and the lag time observed for naringenin to appear in urine suggests that cleavage of the sugar moeity may be required before the flavonoid can be absorbed as the aglycone. Naringenin itself undergoes rapid phase II metabolism. Whether the conjugated metabolite is a potent cytochrome P450 inhibitor is unknown but not probable. The pronounced variability of naringenin excretion provides a possible explanation for apparently contradictory results in grapefruit and/or naringin interaction studies. 
GRAPEFRUIT JUICE INCREASES ORAL NIMODIPINE BIOAVAILABILITY U. Fuhr, A. Maier, H. Blume*, W. Mück*, S. Unger*, A. H. Staib

Grapefruit juice increases the oral bioavailablity of almost any dihydropyridine tested, presumably due to inhibition of first-pass metabolism mediated by the cytochrome P450 isoform CYP3A3/4. The mean extent of increase was up to threefold, observed for felodipine, and more pronounced drug effects were also reported. Thus, a such interaction may be of considerable clinical relevance. No data are yet available for nimodipine.

We conducted a randomized cross-over interaction study on the effects of concomitant intake of grapefruit juice on the pharmacokinetics of nimodipine and its metabolites M11 (pyridine analogue), M10 (demethylated) and M8 (pyridine analogue, demethylated).

8 healthy young men ( 4 smokers / 4 nonsmokers) were included into the investigation. Nimodipine was given as a single $30 \mathrm{mg}$ tablet (Nimotop) with either $\mathbf{2 5 0} \mathrm{ml}$ of water or $250 \mathrm{ml}$ of grapefruit juice (Döhler $\mathrm{GmbH}$, Darmstadt, $751 \mathrm{mg} / \mathrm{l}$ naringin). Concentrations of nimodipine and its metabolites in plasma withdrawn up to 24 hours postdose were measured by GC-ECD, and model independent pharmacokinetic parameters were estimated. The study was handled as an equivalence problem, and ANOVA based $90 \%$ confidence intervals were calculated for the test (=grapefruit period) to reference (= water period) ratios. The absence of a relevant interaction was assumed if the $\mathrm{Cl}$ were within the 0.67 to 1.50 range:

$\begin{array}{lccccc} & \begin{array}{c}C_{\text {max }} \\ \text { nimodipine }\end{array} & \begin{array}{c}\text { AUC } \\ \text { nimodipine }\end{array} & \begin{array}{c}\text { AUC ratio } \\ \text { M11 to } \\ \text { nimodipine }\end{array} & \begin{array}{c}\text { AUC ratio } \\ \text { M10 to } \\ \text { nimodipine }\end{array} & \begin{array}{c}\text { AUC ratio } \\ \text { Ma to }\end{array} \\ \text { lower limit } & 0.76 & 1.14 & 0.81 & 0.70 & 0.55 \\ \text { point estimator } & 1.24 & 1.51 & 0.92 & 0.85 & 0.69 \\ \text { upper limit } & 2.01 & 2.00 & 1.04 & 1.03 & 0.86\end{array}$

Thus, the null hypothesis "no relevant interaction" was rejected for AUC $\mathrm{C}_{\max }$ and the ratio $\mathrm{AUC}_{\mathrm{M} \theta} / \mathrm{AUC}_{\text {nimatipine }}$ Nimodipine effects should be carefully monitored when the drug is taken concomitantly with grapefruit juice.

Department of. Clinical Pharmacology, University Hospital, Th.-Stern -Kai 7 , 60590 Frankfurt, Germany; *Bayer AG, Clinical Pharmacology International Aprather Weg, 42096 Wuppertal, Germany

\section{A 31 \\ REDUCED ERYTRHROMYCIN RELEASE AND BIOAVAILABILITY FROM FILM TABLETS STORED UNDER ARID CONDITIONS M.Gerhartz 1), A.F.Rump2), R.Süverkrüp1), M.Theisohn 2)}

The physical stability of erythromycin stearate film tablets was studied according to a $2^{3}$ factorial design with experimental variables temperature, relative humidity, and storage time

After one half year of storage at $40^{\circ} \mathrm{C}$ and $20 \%$ relative humidity, the fraction of dose released within $30 \mathrm{~min}$ in a USP XXI paddle apparatus under standard conditions decreased from $93 \%$ for the reference stored at ambient temperature in intact blister packages to $13 \%$ for the stress-tested specimens. Chemical degradation of the active ingredient did not become apparent before 12 months of storage. Under all other storage conditions, no effects of physical aging upon drug release were found.

The bioequivalence of reference and stress-tested samples was studied in six healthy volunteers. The extent of relative bioavailability of the test product was markedly reduced (mean: $8.5 \%$, range: $6-12 \%$ ), mean absorption times of the test product were significantly prolonged.

The results indicate that the product tested can undergo physical alterations upon storage under unfavourable conditions, and lose its therapeutic efficacy. It can be expected that this phenomenon is reduced by suitable packaging, but the magnitude of deterioration may cause concern. On the other hand, incomplete drug release is in this case easily detected by dissolution testing.

Whether similar correlations exist for other erythromycin formulations remains to be demonstrated.

1) Pharmazeutisches Institut der Universität Bonn, An der Immenburg 4, D-53121 Bonn and 2) Institut für Pharmakologie der Universität Köln, Gleueler Str. 24, D-50931 Köln
NO EFFECT OF GRAPEFRUIT JUICE ON THEOPHYLLINE PHARMACOKINETICS.

U. Fuhr, A. Maier, A. Keller*, V. W. Steinijans*, R. Sauter*, A. H. Staib

Grapefruit juice was reported to inhibit the metabolism of a variety of drugs, including dihydropyridines, verapamil, terfenadine, cyclosporine, and caffeine. These drugs are metabolized mainly by the cytochrome P450 isoforms CYP1A2 (caffeine and, in part, verapamil) and CYP3A (others). Theophylline has a therapeutic range of $5-20 \mathrm{mg} / \mathrm{l}$ and is also in part metabolized by CYP1A2. Therefore, we conducted a randomized changeover interaction study on the effects of concomitant intake of grapefruit juice on the pharmacokinetics of theophylline.

12 healthy young male nonsmokers were included. Theophylline was given as a single dose of $200 \mathrm{mg}$ in solution (Euphyllin ${ }^{\ominus} 200$ ), diluted by either $200 \mathrm{ml}$ of water or $200 \mathrm{ml}$ of grapefruit juice (Döhler $\mathrm{GmbH}$, Darmstadt, $751 \mathrm{mg} / \mathrm{l}$ naringin). Subsequently, additional fractionated $0.8 \mathrm{I}$ of either juice or water were administered until 16 hours postdose. Theophylline concentrations in plasma withdrawn up to 24 hours postdose were measured by HPLC, and pharmacokinetics were estimated using compartment model independent methods. The study was handeled as an equivalence problem, and ANOVA based $90 \%$ confidence intervals were calculated for the test (=grapefruit period) to reference (= water period) ratios ( $T_{\max }$ : differences). Lack of interaction was assumed if the $90 \% \mathrm{Cl}$ were within the 0.80 to 1.25 equivalence range:

$\begin{array}{lccccc} & \mathbf{C}_{\max } & \text { AUC } & \mathbf{C}_{\max } / A U C & \mathrm{~T}_{y_{\text {eel. }}} & \mathbf{T}_{\max } \\ \text { lower limit } & 0.81 & 0.95 & 0.81 & 0.98 & -0.11 \mathrm{~h} \\ \text { point estimator } & 0.90 & 1.02 & 0.88 & 1.03 & 0.15 \mathrm{~h} \\ \text { upper limit } & 1.00 & 1.11 & 0.95 & 1.09 & 0.41 \mathrm{~h}\end{array}$

Thus, no inhibitory effect of grapefruit juice on theophylline pharmacokinetics was observed. The lower contribution of CYP1A2 to primary theophylline metabolism or differences in naringin and/or naringenin kinetics are possible explanations for the apparent contradiction between the effects of grapefruit juice on caffeine and on theophylline metabolism.

Department of. Clinical Pharmacology, University Hospital, Th.-Stern -Kai 7, 60590 Frankfurt, Germany; *Byk Gulden Pharmaceuticals, Byk-GuldenStr. 2, 78467 Konstanz, Germany

\section{A 32}

REAL-TIME COMPLIANCE MEASUREMENT: ITS CONTRIBUTION TO IMPROVE DATA QUALITY IN CLINICAL TRIALS D. Göthel

The efficacy of a drug therapy is considerably influenced by patient compliance. Within clinical trials the effects of poor compliance on the interpretation of study results frequently leads to underestimating the efficacy of the treatment.

In the evaluation of the "Lipid Research Clinics Primary Coronary Prevention Trial" and the "Helsinki Heart Study" special attention was focused on compliance with medication. The strong influence of compliance on clinical outcome and the dilutional effect of poor compliance on the efficacy of the respective drugs occured in both these trials.

There are indirect (e.g. pill-count, patient interview) and direct methods (e.g measurement of drugs, metabolites or chemical markers in body fluids) used to assess compliance with drug therapy. The indirect methods mentioned are commonly considered as unreliable. The direct methods can prove dose ingestion a short time before the sample is taken, however, they cannot show the time history of the drug use.

An advanced method of measuring compliance is to use electronic devices. The integration of time/date-recording microcircuity into phamaceutical packaging, so as to compile a time history of package use, provides real-time data as indicative of the time when dosing occurred. This method supports a precise, quantitative definition of "patient compliance" as: the extent to which the actual time history of dosing corresponds to the prescribed drug regimen.

By taking real-time compliance data into account the results from clinical trials show not only clearer evaluations of drug efficacy and dose-reponse-relationship but also a better understanding of dose dependant adverse drug reactions.

Dietrich Göthel, M.D

APREX LTD. European Operations

Heinrich-Heine-Weg 41

D-30880 Laatzen 
A 33

TREATMENT OF IMPOTENCE BY ERODERM CREAM

A.A. Gomaa, M.A. Shalaby, H.N. Anmed, M.E. Osman, A.E. AbdelMenam and M.M. Abdellah

A new type of topical applied drugs (Eroderm creams) for impotence is presented. Eroderm creams contain vasoactive drugs. These drugs have ability to penetrate the penile cutaneous tissue and facilitate erection. Three different preparations (Eroderm 1,2 and 3) were made in Pharmacology Depart. Fac. of Med. Assiut Univ. In the present study, we examined the usefulness of Eroderm-1 and Eroderm-2. Seventy five impotent men, 24 to 65 years old, participated in the present trial. The patients were classified into 3 groups, 25 patients each. The first group was treated by cream containing only co-dergocrine mesilate (Eroderm-1), the second received a cream containing isosorbide dinitrate, isoxsuprine $\mathrm{HCL}$ and co-dergocrine mesilate (Eroderm-2), while the third used a cream containing placebo. The cream was applied to penile shaft and gland $1 / 2-1 \mathrm{hr}$ before sexual stimulation and intercourse. The patients were asked to report their experience via questionnaire after one week. The results of treatment are as follows: Seven patients (28\%) who applied Eroderm-1 indicated a full erection and successful intercourse. The use of Eroderm-2 restored potency in 14 patients $(56 \%)$ of the second group. Three men (12\%) of psychogenic type reported overall satisfaction with placebo cream. Treatment of impotence with Eroderm cream was most successful in patients with psychogenic disorders which are often coincident with minor vascular or neurological disorders. Fair results were reported by patients afflicted by moderate neurological disorders. Except for one case of drug allergy following the use of Eroderm-2, no side effects were reported. We believe that Eroderm cream has obvious advantages and may be a suitable treatment before the use of non-safe method as intracavernous medication.

Prof. Adel A. Gomaa, Department of Pharmacology, Faculty of Medicine, Assiut University, Assiut, Egypt

\section{A 35}

MOLSIDOMINE (M) IN PULMONARY HYPERTENSION

w. GroBe-Heitmeyer, T. Huber

We investigeted the effect of $8 \mathrm{mg} M$ iv. in 15 patients: 6 pat. $(3 \mathrm{f}, 3 \mathrm{~m} ; 41 \pm 2 \mathrm{Y}$.) suffering on precapillary pulmonary hypertension (group 1) with a mean pulmary artery pressure (PAPM) of $50.2 \pm 19.7$

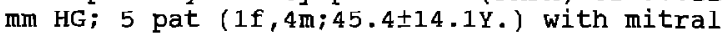
valve stenosis (group 2) with a PAPm of $44.4 \pm 15.1$ mmHG and 4 pat. $(4 \mathrm{~m} ; 48.7 \pm 9,7 \mathrm{Y})$ with left

ventricular heart failure (group 3) with a PAPM of $36.5 \pm 11.5 \mathrm{mmHG}$.

PAPM, right ventricular pressure (RVP), cardiac index (CI), heart rate (HR) and blood pressure (BP) were measered before and $10,20,30,40,50$ and $60 \mathrm{~min}$. after a bolus of $8 \mathrm{mg} \mathrm{M}$ iv.

PAPm decrerased in group $218 \%$ and group $332 \%$, whereas in group 1 only $3 \%$. CI increased in group $3(+24 \%)$, decreased in group $2(-14 \%)$ and was not changed in group 1 . In all patients we observed a decrease of BP and RVP.

Thus we conclude that there is a benefit on the pulmonary hypertension due to left ventricular heart failure and due mitral valve stenosis caused by the reduction of preload, but we could not observe a No-related effect on the pulmonary vascular system in pat. with precapillary pulmonary hypertension.

PD Dr. med w. Große Heitmeyer

Abt. Kardiologie / Innere Medizin

st. Bonifatius-Hospital

Wilhelmstr. 13

49808 Lingen/Ems
A 34

TOPICAL THERAPY OF ERECTILE DYSFUNCTION

A.A. Gomaa, M.A. Shalaby, M.E. Osman, M.A. Eissa, A.E. AbdelMenam and M.M. Abdellah

A new type of topically applied drugs (Eroderm creams) for impotence is presented. Eroderm creams contain vasoactive drugs. These drugs have ability to penetrate the penile cutaneous tissue and facilitate erection. In the present study, we examine the usefulness of Eroderm- 3 in the treatment of erectile dysfunction. Eroderm-3 contains tiemonium methylsulfate, A.F. piperazine and isosorbide dinitrate. A randomized, double blinded control trial on 36 patients was performed. The etiology of impotence was investigated. All patients received Eroderm-3 and placebo cream. The patients randomized into 2 groups of 18 . The first group received Eroderm-3 on day 1 and placebo cream on day 2, however, group two received placebo on day 1 . The patients were advised to apply the cream on the penile shaft $1 / 2-1 \mathrm{hr}$, before sexual stimulation and intercourse. The patients reported their experience via questionnaire. Overall 70 percent of patients demonstrated a response with Eroderm-3. The other responders reported a partial erection and tumescenous. Three men $(8 \%)$ reported a full crection and satisfied intercourse with either cream. These patients were psychogenic impotence. Neither Eroderm-3 nor placebo cream produced marked response in 11 patients. Four patients were venous leakage which were advised to use tourniquet at the base of penis after $1 / 2 \mathrm{hr}$. of cream application. Only one of them indicated a good response. The highest activity proved to occur in psychogenic impotence. Less rate of success was observed in patients with minor to moderate neurological and/or arterial disorders. No marked side effects were recorded. For these reasons Eroderm-3 may be proposed as first line therapy of erectile dysfunction.

Prof. Adel A. Gomaa, Department of Pharmacology, Faculty of Medicine, Assiut University, Assiut, Egypt

\section{A 36}

MODULATION OF CELL PROLIFERATION BY PROSTAGLANDINS AND LEUKOTRIENES. C. Haberl, L. Hültner, M. Falk, D. Egger, S. Geuenich, K. Dittmann, W. Wilmanns, and $C$. Denzlinger

Control of cell proliferation is a basic homeostatic function in multicellular organisms. We studied the effects of some prostaglandins and leukotrienes and of their pharmacological inhibitors on cell proliferation in murine mast cells and mast cell lines, in a human promyelocytic cell line (HL-60 cells) and in Burkitt's lymphoma cell lines. In addition, prostaglandin and leukotriene production was investigated in mast cells, representing putative endogenous sources of these lipid mediators.

Murine mast cells were derived from bone marrow of Balb/c mice. Proliferation of cells was estimated using a colorimetric assay (MTT-test). Production of Prostaglandin D2 (PGD2), PGJ2, delta-12-PGJ2, Leukotriene C4 (LTC4) and LTB4 by mast cells was determined by combined use of high performanceliquid chromatography and radioimmunoassay.

PGD2 and its metabolites PGJ2 and delta-12-PGJ2 exhibited significant antiproliferative effects in the micromolar range in mast cells, mast cell lines, HL-60 and Burkitt's lymphoma cell lines whereas inhibition of cyclooxygenase by indomethacin was without major effects. LTC4 and LTB4 had a small stimulatory effect on cell proliferation in $\mathrm{HL}-60$ celis. Degradation and possibly induction of cell differentiation may have attenuated the actions of leukotrienes. The leukotriene biosynthesis inhibitors AA-861 and MK-886 reduced proliferation of HL-60 and lymphoma cells significantly but had no major effects on mast cell growth. On the other hand, mast cells stimulated with calcium ionophore produced PGD2 and its metabolites, as well as LTB4 and LTC4 in significant amounts. From our data we conclude that prostaglandins and leukotrienes may play an important role in the control of cell proliferation.

Medizinische Klinik III, Klinikum Grosshadern, LudwigMaximilians Universität, and Forschungszentrum für Umwelt und Gesundheit, D-81377 München 
DRUG UTILIZATION REVIEW IN GERMAN HOSPITALS

S.Harder, R.Böger, S.Bode-Böger, B. Drewelow, J.Krappweis, J.P.Marschner, K.H.Molz, A.Plangger, T.Szucs, J.Tepper, M.Theison, P.Thürmann (Study group „Pharmacoeconomics and Rational Pharmacotherapy“, GKPharm)

We compared the pattern of drug expenditures of several hospitals in 1993 (size: 1000 to 1400 beds). A, B are university hospitals in the ,old"and C,D,E are university hospitals in the ,new" German countries, $\mathrm{F}$ is a community based institution in an „old "German country. Main data source were lists comprising all drugs according to their expenditures in a rank order up to $100 \%$. Items were classified into I) pharmaceutical products including immunoglobulines, II) blood and -derived products (cell concentrates, human albumin, clotting factors) and III) contrast media (x-ray). With regard to group I) the highest expenditures occured in hospitals $\mathrm{A}$ and $\mathrm{B}$ whereas drug costs in $\mathrm{C}$ - $\mathrm{E}$ were $1 / 3$ less and came to only $20 \%$ in hospital $\mathrm{F}$. The main groups of drugs which together account for $>50 \%$ of these expenditures are shown in the table.

Table: percent of the overall expenditures $(100 \%)$ pharmaceuticals in 1993 Agents

Antibiotics

$\begin{array}{llllll}\text { A } & \text { B } & \text { C } & \text { D } & \text { E } & \text { F }\end{array}$

$\begin{array}{llllll}19.3 & 18.3 & 20.4 & 20.7 & 11.2 & 20.0\end{array}$

$\begin{array}{lllllll}\text { Virustatics/Antimycotics } & 7.6 & 6.1 & 3.7 & 7.5 & 3.1 & 1.8\end{array}$

Immunoglobulines

Cytokines/Immunosuppr

$\begin{array}{llllll}7.6 & 6.1 & 3.7 & 7.5 & 3.1 & 1.8 \\ 7.5 & 4.9 & 5.6 & 9.9 & 10.5 & 2.8\end{array}$

Infusion solutions

$\begin{array}{lllll}7.1 & 6.7 & 3.6 & 7.5 & 5.2\end{array}$

Cytostatics

Heparins

$\begin{array}{llllll}6.9 & 6.5 & 10.1 & 7.9 & 0.8 & 10.9\end{array}$

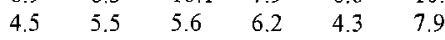

$\begin{array}{llllll}2.5 & 25 & 2.9 & 2.7 & 1.5 & 60\end{array}$

$5 \mathrm{HT}_{3}$-Antagonists

$\begin{array}{lllll}1.4 & 1.8 & 2.2 & 4.4 & 3.1\end{array}$

Expenditures for group II) products were about $20 \%$ up to $40 \%$ of group I and highest in hospitals A, B and E, but about $1 / 3$ lower in hospitals $\mathrm{C}$ and $\mathrm{D}$. These results suggest meaningful differences in the drug utilization between the old and new countries as well as between university institutions and community based hospitals. However, although all hospitals provide oncology and traumatology services and all university hospitals offer NTX, differences in other

subspecialities e.g. bone marrow and liver transplantation and treatment of patients with haemophilia must be considered, too.

Dr.med.Sebastian Harder, Dept.Clinical Pharmacology, University Hospital Frankfurt, Theodor Stem Kai 7, 60590 Frankfurt/Main FRG

\section{A 39}

COMPARATIVE BIOAVAILABILITY OF ACETYLSALICYLIC ACID FROM ACESAL ${ }^{\oplus}$, ACESAL $^{\oplus}$ EXTRA, MICRISTIN ${ }^{\oplus}$ AND MINIASAL ${ }^{\oplus}$

Claudia Hoffmann, M. Zschiesche, W. D. Krüger, Rita Sauter, G. Franke, $W$. Siegmund, and $V$. W. Steinijans

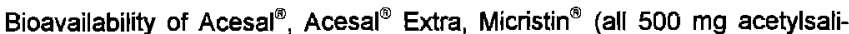
cylic acid - ASA), and Miniasal ${ }^{\boxplus}$ (30 mg ASA), OPW Oranienburg, relative to respective listed references was studied in female and male healthy volunteers (age 18-35 y, weight 48-90 kg, height 161-198 cm). ASA and salicylic acid (SA) were measured using an HPLC method validated from 50 $\mathrm{ng} / \mathrm{ml}$ to $60 \mathrm{\mu g} / \mathrm{ml}$. Extent of absorption was assessed by AUC (bioequivalence range 0.8-1.25), rate by $C_{\text {max }} / A U C$ (bioequivalence range $0.7-1.43$ ). Geometric means and $90 \%$-confidence limits of the ratios Test/Reference (multiplicative model) are shown in the Table.

\begin{tabular}{|c|c|c|c|c|c|}
\hline Formulation & & $\mathbf{N}$ & AUC & $C_{\max } / A U C$ & $t_{1 / 2}$ \\
\hline Acesal $^{(1)}$ & ASA & 24 & $1.05(0.97,1.13)$ & $1.16(1.00,1.34)$ & $0.85(0.74,0.98)$ \\
\hline Acesal ${ }^{\text {(i) }}$ Extra & & 24 & $1.13(1.05,1.22)$ & $1.72(1.49,1.99)$ & $0.74(0.64,0.85)$ \\
\hline Micristin $^{\text {बi }}$ & & 19 & $1.02(0.92,1.14)$ & $0.83(0.73,0.94)$ & $1.27(1.04,1.56)$ \\
\hline Miniasal $^{\mathbb{B}}$ & & 12 & $1.04(0.86,1.26)$ & $0.68(0.57,0.82)$ & $1.36(1.11,1.66)$ \\
\hline Acesal $^{\Phi}$ & SA & 24 & $1.02(0.96,1.07)$ & $1.02(0.98,1.07)$ & $1.00(0.97,1.04)$ \\
\hline Acesal ${ }^{18}$ Extra & & 24 & $1.05(0.99,1.11)$ & $1.07(1.02,1.12)$ & $1.00(0.96,1.03)$ \\
\hline Micristin $^{\text {3 }}$ & & 24 & $0.98(0.91,1.04)$ & $0.93(0.88,0.97)$ & $1.00(0.91,1.10)$ \\
\hline Miniasal $^{(3)}$ & & 12 & $1.00(0.94,1.08)$ & $0.80(0.75,0.85)$ & $1.09(1.03,1.15)$ \\
\hline
\end{tabular}

Acesa ${ }^{\oplus}$ and Micristin ${ }^{\oplus}$ were bioequivalent in rate and extent of absorption with the reference formulations. The fast liberating Acesal ${ }^{(i)}$ Extra was bioequivalent with respect to extent only. ASA from Miniasa ${ }^{\text {(a) }}$ was absorbed more slowly than from an ASA solution $\left(\mathrm{C}_{\max }(68 \%\right.$-range): $264-536 \mathrm{ng} / \mathrm{ml}$ and $387-726 \mathrm{ng} / \mathrm{ml} ; \mathrm{t}_{\max }$ (min-max): 0.33-2.0 h and 0.17-0.5 h).

ASA from Micristin ${ }^{(1)}$ and the corresponding reference was absorbed more slowly than from Acesa ${ }^{(1)}$ and Acesa $\left.\right|^{(i)}$ Extra. This was accompanied by decreased $A \cup C_{A S A}$ (increase of first pass metabolism) and increased apparent $t_{1 / 2}$ (absorption being rate limiting). All ratios of $A \cup C_{S A} / A \cup C_{A S A}$ after administration of $500 \mathrm{mg}$ ASA were markedly higher than after $30 \mathrm{mg} \mathrm{ASA}$. Thus, the formation of salicyluric acid from SA might be capacity limited at doses of $500 \mathrm{mg} \mathrm{ASA}$.
ORGANIC NITRATE METABOLISM AND NITRIC OXIDE RELEASE IN VASCULAR TISSUE AND IN PLATELETS

M. Hönicka, R. Spahr, M. Feelisch, and R. Gerzer

Organic nitrates like glyceryl trinitrate (GTN) act as prodrugs and release nitric oxide (NO), which corresponds to the endogenously produced endothelium-derived relaxing factor. In the vascular tissue, NO induces relaxation of smooth muscle cells, whereas in platelets it shows an antiaggregatory effect. Both activities are mainly mediated via stimulation of soluble guanylyl cyclase (sGC) by NO In contrast to compounds which release NO spontaneously, a membrane-associated biotransformation step is thought to be required for NO release from organic nitrales. Glutathione-S-transferases and cytochrome P-450 enzymes have been shown to metabolize organic nitrates in the liver, but little is known as to whether these enzymes are involved in the metabolic conversion of organic nitrates in the vasculature. Furthermore, it is still unclear whether or not platelets are capable of metabolizing organic nitrates to NO. We isolated the microsomal fraction of bovine aorta in order to characterize the activities towards organic nitrates using the guanylyl cyclase reaction as an indirect and the oxyhemogiobin-technique as a direct measure for NO liberation. GTN was metabolized to NO by the microsomal fraction under aerobic conditions already in the absence of added cofactors. This activity was not influenced by the cytochrome P-450 inhibitors cimetidine and metyrapone In contrast, the glutathione S-transferase substrate 1-chloro-2,4-dinitrobenzene and the glutathione S-transferase inhibitors sulfobromophthalein and ethacrynic acid did not affect NO release, but potently inhibited sGC activity. Blocking of microsomal thiol-groups resulted in a decreased NO release from GTN. Homogenates of human plateles isolated by thrombapheresis and stabilized by addition of $5 \mathrm{mM} \mathrm{N}$-acelylcysteine did not show NO-release from GTN as determined by the stimulation of the platelet SGC even after addition of the possible cosubstrates glutathione and NADPH. These data demonstrate (1) that bovine aortic microsomes exhibit an organic nitrate metabolizing and NO-releasing activity whose properties are clearly different from classical cytochrome P-450 enzymes and from giutathione S-transferases, and (2) that human platelets itself are nol capable of bioactivating organic nitrates and therefore require organic nitrate metabolism in the vessel wall for antiaggregation to occur.

M. Hönicka, Medizinische Klinik, Klinikum Innenstadt der Universität, Abteilung für Klinische Pharmakologie, Ziemssenstr. 1, 80336 München, FRG

\section{A 40}

Impacts of 1993 Reform Law in Germany on Ambulatory Primary Health Care.

M. Hoopmann, F.W. Schwartz, J. Weber

In the study wPhysicians' Assessment of Internal Practice-Conditions and Regional Health-Services-Conditions in Accordance with Ambulatory Patient-Managemente a sample of 130 primary care physicians - comprising GPs and internists - provide data for continuous analyses of ambulatory health care quality and structure. Focussing on the tinuous analyses of ambulatory health care quality and structure. Focussing on the physicians' drug prescription, the impacts of 1993 reform law (Gesundheilsstrukturgeset2 GSG) upon primary care providers and their therapeutic decisions were examined in 1993 Four different surveys were carried out during the year, dealing with frequent patients reasons for encounter in GPs' offices. After a pretest was carried out, physicians reported

For every therapeutic change patients received, the reasons for the change were recorded (e.g. reform law, medical indication) and above the physicians ${ }^{2}$ expectations towards three criteria to measure the quality:

1) physicians' assessment of the patients's satisfaction,

2) adverse drug effects,

3) therapeutic benefit.

According to therapeutic changes due to 1993 reform law (drug budgets, blacklist) it can be stated:

1) Therapeutic changes due to reform law were carried out with relevant frequency.

2) The reform law was of different concern regarding the different reasons for encounter we invescigated

3) The impacts' strengch of the legal control mechanisms differed annong several groups of physicians: Those who already have been liable to recourse before 1993 more of ten carried out therapeutic changes according to fixed drug budget. Different multivariate logistic regression-models yield an estimation of the odds-ratio of about 3 .

4) Therapeutic changes in accordance with the 1993 reform law having been carried out at the beginring of the year more often suffered from negative expectations lowards the therapeutic quality than changes during the actual encounter, e.g. "joint pains $26 \%$ decrease of the therapeutic benefit in contrast to $7 \%$. During the year a decrease of negative expectations is noticable.

5) Patients overestimating the severity of their own health problem in comparison to the physician more often suffered from negative expectations towards the therapeutic change than other patients, e.g. concerning the therapeutic benefit ( $29 \%$ in contrast to 3\%). Generally speaking, firstly the reform law led to insecuricies - particularly in the introduc-
tion phase - among susceptible subgroups of physicians and patients, regarding the four tion phase - among susceptible subgroups of physicians and patients, regarding the fou investigated reasons for encounter. Secondly, there is evidence of a loss of quality in amderably subsided within the field phase duration from May to November, 1993.

The presented analyses give evidence of the practicability of sudies assessing effects of legally-initiated mechanisms to control health costs upon primary health care quality.

Postanschrift: ISEG, Bissendorfer Str. 9, D-30625 Hannover 
A 41

COMPARATIVE STUDY OF INHIBITION OF PROTEIN GLYCATION BY DRUGS WITH AMINO AND SULFHYDRYL GROUPS V.Jakus, Y.Keita, E.Stay, N.Rietbrock

The cellular and biochemical mechanisms that lead to the longterm complications of diabetes mellitus are poorly understood.

Glycation is a multireaction beginning with a condensation reaction between reducing sugars and reactive amino groups of proteins. The accumulation of the glycated products of various proteins may contribute to the development of the complications of diabetes and aging. In order to find suitable non-toxic glycation inhibitors we used sulfur deriva-tives (penicillamine, captopril and alpha-lipoic acid) and amino derivatives (aminoguani-dine and aminoguanidine propionic acid) and postulated the mechanisms involved. The inhibitory effect of the drugs on the early (Amadori product) and advanced glycation products (AGE) determined by affinity chromatography, deglycation inethod. HPLC and fluorescence spectroscopy, differs markedly depending on the drug used and is greatest (up to $80 \%$ ) with aminoguanidine and penicillamine (20 mM) and smallest with alpha-lipoic acid

Aminoguanidine propionic acid had no inhibitory effect on the glycation process. The ability of penicillamine to inhibit both the formation of Amadori products and AGE was demonstrated by isolation of the adducts of penicillamine with ribose, glucose, glucosa-mine and p-tolylglucosamine, a standard for glycated protein. Their structures were characterized using IR- and $\mathrm{l}_{\mathrm{H}-\mathrm{NMR}}$ and ${ }^{13} \mathrm{C}-\mathrm{NMR}$ spectroscopy. The oxidative deg-radation of glycated human serum albunin in the presence of copper (II), forming the carboxymethyllysine, was inhibited by the sulfur derivatives. The in vitro formation of pentosidine, a crosslinking product was influenced by all drugs used.

However captoptil, alpha-lipoic acid and aminoguanidine propionic acid do not condense with sugar derivatives. The mechanism by which captopril and alpha-lipoic acid inhibit the formation of AGE may be involve radical formation, where a spontaneus thiol/disul-fide intercliange between drug and protein takes place. Complications can appear at any lime in diabetic patients The cause of these complica-tions in some cases may be due glycation and/or axidation. The clinical applications of substances which are able to prevent these events may have advantages These results and the mechanism proposed show that the amino and sulfhydryl groups of drugs reduce glycalion and postglycation of proteins and thus have potential value in this regard.

Dr.pharm. Vladinir Jakus, Depı Clinical Pharmacology, University Hospital Frankfurt, Theodor Stern Kai 7, 60590 Frankfurt/Main FRG

\section{A 43}

EFFECTS OF INTRAVENOUS ANISOYLATED PLASMINOGEN STREPTOKILIASE ACTIVTOF COMPLEX OH LEFT VENTRICULAR FUNCTION AFTER ACUTE MYOCARDIAL INFARCTION.

\author{
T. Karow, W. Große-Heitmeyer, E. Bienstein, T. Huber
}

The effect of anisoylated plasminogen streptokinase activator complex (APSAC) on left ventricular ( $\mathrm{LV}$ ) function was investigated in is patients with acute myocardial infarction (AM).

A dose of 30 units APSAC was given intravenousiy to patients with AMl within 4 hours after onset of pain. Patienis underwent cardiac angiography at 90 minutes and at day 28 .

Wail motion was measured by the global ejection fraction and by the centerline methed in the infarct and noninfarct regions and expressed in units of standard deviations below normai, as defined in 50 normai patients.

Group A with successful thrombolysis (TiMi 2 and 3 ) was compared with group $B$ without successfui thrombolysis (Tindi 0 and 1). At 90 minutes there was no significant difference in giobal ejection fraction between both groups. By using the regional wall motion by the centerline method group A showed a significant improvement of $L V$ function ( $p$ < 0.05 ). The benefit of successful thrombolysis was more marked in the peripheral infarct region than in the central infarct region.

Thus early reperfusion is an important factor in maintaining good LV function at̂er AfAi. The rogional wall motion in the infarct region seems to be more sensitive than the global ejection fraction to show sarly differences in LV function after AMAit.

T. Karow

St. Bonifatius Hiospital Lingen, Department of Cardiology

Witheimstr. 13

49808 Lingen (Ems)
A 42

INHIBITION OF NON-ENZYMATIC GLYCATION OF HUMAN SERUM ALBUMIN BY VARIOUS DRUGS

V. Jakus, U. Fuhr, N. Rietbrock

Non-enzymatic glycation starts by covalent binding of single sugars to $\alpha$ or $\varepsilon$ amino groups of proteins. In subsequent reactions a number of early glycation products like Schiff bases or Amadori products, and of advanced glycation endproducts (AGEs) is formed. Glycation is increased in a variety of proteins in diabetic patients [Schleicher E (1992) Diabetes und Stoffwechsel 1: 274] including human serum albumin (HSA), the red cell membrane, hemoglobin, collagen, laminin, immunoglobulin G, low- and high-density lipoproteins. The process is supposed to be a key mechanism in the pathogenesis of diabetic complications and in tissue ageing [Vlassara $\mathrm{H}$ et al. (1994) Lab Invest 70: 138]. Inhibition of glycation may therefore be important for the prevention of late diabetic complications.

We investigated the in vitro glycation of human serum albumin (HSA) and its inhibition by aminoguanidine, penicillamine, captopril and $\alpha$-lipoic acid $(20 \mathrm{mM})$. HSA $(40 \mathrm{~g} / \mathrm{l})$ was glycated by incubation with $20 \mathrm{mM}$ glucose in $0.1 \mathrm{M}$ phosphate buffered saline, $\mathrm{pH} 7.4$, at $37{ }^{\circ} \mathrm{C}$ for 28 days under sterile conditions in the presence of $0.1 \%$ natrium azide. The glycation rate was determined by two different methods:

Deglycation - measures Amadori products based on the colorimetry of 2-ketoglucose which is released from the glycated protein (ketoamine) on heating with hydrazine [Kobayashi K et al.(1993) Biol Pharm Bull 16: 195]

Fluorescence spectroscopy - measures advanced glycation endproducts.

All drugs tested reduced the glycation rate of HSA

Decrease by: Amadori products aminoguenid

$\begin{array}{lc}32 \% & 37 \% \\ 73 \% & 64 \%\end{array}$
$\begin{array}{cc}25 \% & \boldsymbol{\alpha} \text {-lipoic acid } \\ 21 \%\end{array}$ $\begin{array}{lllll}\text { AGEs } & 73 \% & 64 \% & 67 \% & \text { no effect }\end{array}$

The results provide evidence for a possible role of the investigated drugs in the prevention of the formation of early and late glucose-protein adducts in vivo.

Dept. Clinical Pharmacology, University Hospital Frankfurt, Theodor Stern Kai 7, 60590 Frankfurt am Main, Germany

A 44

MODULATION OF BAY X 1005 MEDIATED 5-LOX INHIBITION IN HUMAN GRANULOCYTES BY ARACHUDONIC ACID.

R.Kast*, A.Hatzelmann\#, R.Kupferschmidt\#, R.Fruchtmann*, and R.Müller-Peddinghaus* *Bayer AG, Pharma Research Center, Wuppertal and \#Byk Gulden Pharmaceuticals, Konstanz, Germany

The quinoline derivative Bay X 1005 ((R)-2-[4-(quinolin-2-yl-methoxy)phenyl]-2cyclopentyl acetic acid) is a selective inhibitor of $\mathrm{LTB}_{4}$-biosynthesis in various in vitro and in vivo models. It acts via binding to the integral nuclear membrane protein FiveLipoxygenase Activating Protein (FLAP), which has been shown to be an essential component of the cellular leukotriene synthesis machinary. The function of FLAP is only poorly understood, but recently it has been shown that a radiolabeled photoaffinity-analog of arachidonic acid binds specifically to FLAP. Consequently, a role of FLAP in the substrate transfer to 5-lipoxygenase (5-LOX) has been suggested.

Using intact and fractionated human polymorphonuclear leukocytes (PMNL), we present data showing that exogenously added arachidonic acid diminishes dose-dependently binding of $\left[{ }^{14} \mathrm{C}\right]$-Bay X 1005 to its target. This effect correlates with the reduction of Bay X 1005 mediated intibition of $\mathrm{LTB}_{4}$ synthesis after stimulation of intact PMNL with the calcium ionophore A23187 in the presence of increasing extracellular arachidonic acid concentrations. In addition, enhancing the release of intracellular arachidonic acid from phospholipids after activation of phospholipase $\mathrm{A}_{2}\left(\mathrm{PLA}_{2}\right)$ with increasing $\mathrm{A}_{23187}$ concentrations or after prolonged incubalion of the cells with the ionophore results in a loss of Bay X 1005 potency. To further study the effect of arachidonic acid on the Bay X 1005 mediated $\mathrm{LTB}_{4}$ synthesis inhibition, human PMNL were stimulated with PAF, C5a or fMLP in the presence of exogenous arachidonic acid. Under such conditions, LTB synthesis is significantly enhanced in response to PAF, C5a or AMLP, which are only weak activators of cell-associated PLA2 The effect of extracellular arachidonic acid is dosedependently inhibited by Bay X 1005. Coincubation of the cells with arachidonic acid and PAF, C5a or AMLP, respectively, enhances synergistically the translocation of 5-LOX from the cytosol to the membrane fraction. Again, this effect is inhibited by Bay X 1005. In sumnary, using Bay X 1005, we provide evidence, that FLAP is involved in the utilization of the 5-LOX substrate arachidonic acid from exogenous or endogenous sources for the agonist-induced leukotriene biosynthesis.

R.Kast, Bayer AG, Pharma Research Center, Aprather Weg 18a, 42096 Wuppertal, Germany 
A 45

THE INFLUENCE OF HEMATOPOIETIC GROWTH FACTORS ON VINCRISTINE ACCUMULATION AND CYTOTOXICITY IN THE HL60/VINC AML CELL-LINE.

A. Keese, S. Harder, B.G. Woodcock

Hematopoietic growth factors have a yet to be established place in chemotherapy schedules of patients with acute myeloid leukemia (AML). These agents stimulate the incorporation of ara-C into DNA of AML blasts in vitro (C. Reuter et al. [1993] In: Drug resistance in leukemia and lymphoma. (Eds. G.J.K. Kaspers et al.), Harwood, Switzerland, pp. 215-226) but their effect on the expression and function of the multiple drug resistance gene product has not been studied in detail. We have therefore examined the effect of GM-CSF and G-CSF on the uptake and toxicty of vincristine with and without the chemosensitizers R-verapamil and norverapamil in the Pglycoprotein-containing vincristine-resistant cell-line, $\mathrm{HL}-60 /$ vir Following a $48 \mathrm{~h}$ pre-incubation with $10 \mathrm{ng} / \mathrm{ml}$ G-CSF or GM-CSF, cells were washed and reincubated in RPMI medium with ${ }^{3} \mathrm{H}$ vincristine and the modulators for 4 hours. The uptake of ${ }^{3} \mathrm{H}$ vincristine was increased up to 2 -fold and this effect was equally marked when the vincristine-uptake was stimulated with the chemosensitizers in the range of $2.5 \mu \mathrm{g} / \mathrm{ml}$ to $10 \mu \mathrm{g} / \mathrm{ml}$. Although cytokine-pretreatment increased the accumulation of vincristine, we could not show an increase in vincristine toxicity over $72 \mathrm{~h}$ with the same concentrations of vincristine and chemosensitizers. It is concluded that the effects of cytokines on vincristine accumulation are compensated by a positive effect on cell-survival or cell-growth.

Department of Clinical Pharmacology, University Clinic, Frankfurt, Theodor Stern Kai 7, 60590 Frankfurt, Germany.

\section{A 46}

COST-BENEFIT-ANALYSIS OF DRDGS - AN EXAMPLE FROM SECONDARY PREVENTION OF STROKE

A. Kempel, I. Kempf

From the economic point of view people often tend only to regard the price of a product. Savings for the health care system as a whole which could be gained by use of these drugs and which could more than compensate the high costs of medication are not considered. The cost-benefit-analysis enables a comprehensive analysis of the economic effectiveness of a pharmaceutical. The relevant cost factors such as the costs for in- and out-patient treatment depending on the therapeutic success and the inability to work are compared to the costs of medications. Using the example of stroke prevention, it was possible to show that prophylaxis with an expensive but effective pharmaceutical is economically better than standard medication. According to the TASS study Ticlopidine can prevent at least 3 more strokes per 100 treated patients than ASS. On the basis of this study cost savings of up to DM 92,000 per 100 treated patients can be reached including higher costs of Ticlopidine. Projected onto 100,000 patients up to DM 92,000 per year can be saved for the German health care system by the use of Ticlopidine in secondary prophylaxis after TIA.

Dr. Angela Kempel

Pharmametrics $\mathrm{GmbH}$

Rötebuckweg 9

D - 79104 Freiburg

\section{A 47}

CLINICAL PHARMACOKINETICS OF HYPERICIN AND PSEUDOHYPERICIN R. Kerb, J. Brockmöller, W.-D. Hübner*, S. Bauer and I. Roots

The naphthodianthrones Hypericin $(\mathrm{H})$ and Pseudohypericin $(\mathrm{PH})$ were proved to be effective in mild depressive disorders. Recently they were discovered to exhibil high in vitro activity against enveloped viruses fostering clinical trials in infections with HIV or herpes viruses. For studying the pharmacokinetics of $\mathrm{H}$ and $\mathrm{PH}$ a solidified extract from St. John's Wort (Hypericum perforatum $L$ ) was orally administered to 12 healthy male volunleers in three single doses of 250,750 , and $1500 \mu \mathrm{g}$ of $\mathrm{H}$ and 526,1578 , and $3156 \mu \mathrm{g}$ of $\mathrm{PH}$, followed by a 14-days course of multiple dosing of $250 \mu \mathrm{g} \mathrm{H}$ and $526 \mu \mathrm{g}$ of $\mathrm{PH}$ tds. Plasma concentrations were delermined by HPLC, the quantification limit was $0.2 \mu \mathrm{g} / \mathrm{l}$ (Staffeldh et al., Nervenheilkunde 12(1993): 331). Singledose kinetics. H showed a median lagtime of 1.9 (range: $1.4-2.3$ ) $h$, which was significantly longer compared to 0.38 (range: $0.5-1.0) \mathrm{h}$ of PH. $\mathrm{H}$ was eliminated with a median half-life of 36 (range: $12-56$ ) $h$, and in case of PH the half-life ranged between 5.0 and 36 (median: 16.5) h. Median $C_{\max }$ levels were 1.3, 7.2, 16.6 $\mu \mathrm{g} / \mathrm{l}$ for $\mathrm{H}$ and $3.4,12.1,29.7 \mu \mathrm{g} / \mathrm{l}$ for $\mathrm{PH}$ for the three single-dose levels given above, respectively. Lowest dose $\mathrm{C}_{\max }$ and $\mathrm{AUC}$ of $\mathrm{H}$ was lower then expected from medium and highest dose, which was statistically significantly for $\mathrm{C}_{\max } \quad(\mathrm{p}=0.049$, Anova; $p=0.0156$, Bonferroni/Dunn), indicating nonproportionality of pharmacokinetic response may exist in the lower dosing range. Multiple-dose kinetics. During long-term dosing steady-stale trough levels $\left(\mathrm{C}_{\text {trough }}\right.$ ) of 7.9 (range: 3.4 - 13.6) $\mu \mathrm{g} /$ lor $\mathrm{H}$ and 4.9 (range: 12 - 10.9) $\mu \mathrm{g} / \mathrm{l}$ for $\mathrm{PH}$ were reached after 4 days for both. $\mathrm{C}_{\max }$ after 14 days of treatment were 8.8 (range: 5.8 - 22.1) $\mu \mathrm{g} / \mathrm{f}$ for $\mathrm{H}$ and 8.5 (range: $4.3-20.7$ ) for $\mathrm{PH}$, this is about $2 / 3$ of the $\mathrm{C}_{\max }$ reached after the corresponding single-dose of $250 \mu \mathrm{g} \mathrm{H}$ and $526 \mu \mathrm{g} \mathrm{PH}$. The AUC for one dosing interval of 187 (range: $98.5-337$ ) $\mu \mathrm{g} \cdot \mathrm{h} / \mathrm{l}$ for $\mathrm{H}$ and 121 (range: 41.7 244) $\mu \mathrm{g} \cdot \mathrm{h} / \mathrm{I}$ for $\mathrm{PH}$ is statistically not significant different to the corresponding singledose AUC (interpolated to the same dosing interval) of 207 (range: $135-44 B$ ) and 137 (range: $84.9-466) \mu \mathrm{g} \cdot \mathrm{h} / \mathrm{l}$ for $\mathrm{H}$ and $\mathrm{PH}$, respectively. Therefore acceleration of firstpass-metabolism due to enzyme induction is unlikely during steady-state treatment in the dosing-range investigated. Plant extracted versus chemically synthesized $H$. To investigate the influence of galenics or other substances in the plant extract one single-dose of $750 \mu \mathrm{g}$ of chemically synthesized $\mathrm{H}$ (in a $10 \%$ alcoholic solution) was given to one of the volunteers. $\mathrm{C}_{\max }$ and $\mathrm{AUC}$ were $2.6 \mu \mathrm{g} / \mathrm{l}$ and $73.6 \mu \mathrm{g} \cdot \mathrm{h} / \mathrm{l}$, respectively, compared to 7.7 $\mu \mathrm{g} / \mathrm{l}$ and $145.6 \mu \mathrm{g} \cdot \mathrm{h} / \mathrm{l}$ after the equivalent dose of solidified extract. No difference was noticed in the lagtime ( $\mathrm{H}$ in plantal extract: $1.35 \mathrm{~h}$ versus chemically synthesized $\mathrm{H}: 1.5 \mathrm{~h}$ ). Different sites of inlestinal $\mathrm{H}$ and $\mathrm{PH}$ absorption may give an explanation, but this remains to be experimentally proven.

Institut für Klinische Pharmakologie, Universitätskklinikum Charité, Humboldt-Universität zu Berlin, Schumannstraße 20, D-10098 Berlin;" "Lichtwer Pharma GmbH, Berlin

\section{A 48}

Cost-Benefit-Analysis in the Healthcare system of the FRG - Cost-Effectiveness of prevention of NSAID-induced ulcers. C. Kori-Lindner, R. Eberhardt

The Healthcare Restructure Act (1993) changed the evaluation of drugs from efficacy to cost effectiveness: therapeutic necessity, utility, purpose; medical progress and economic utility have to be considered. Criterias and suroundings of pharmacooeconomic evaluations and studies according to the Healthcare Restructure act are demonstrated by an example: "Costs of NSAID-induced gastro-duodenal ulcers and prevention with misopiostol".

Methods: Cost-utility, cost-benefit, legal requirements, decision-model and decision-tree, basic calculation and the transfer to the socialsystem of the FRG. Premissions: rate of ulcers without prevention $21,7 \%$, with prevention $5,6 \%$; rate of compliance $70 \%$, rate of hospitalisation $20 \%$ and duration of hospitalisation 16,6 days. Results: basic calculation: Costs of prevention 62,77 DM / patient per 3 months. Transferred to the spezial circumstances in the FRG: rate of hospitalisation $30 \%$ and duration of hospitalisation 18,8 days for the elderly leads to a costsaving of $32,55 \mathrm{DM} /$ patient per 3 months. Literatur: C. Kori-Lindner, R. Eberhardt: KostenNutzen-Bewertungen von Arzneimitteln und pharmako -ökonomische Studien. Pharm.Ind. 56, Nr. 5 (1994) 419-424.

Dr. med. C. Kori-Lindner, Heumann Pharma Postfach 2260 , D-90009 Nürnberg

Dr. med. R. Eberhardt, Pharmalog-Institut Frauenlobstr. 28, D-80337 Múnchen 
A 49

DRUG EXPENDITURE OF RHEUMATIC DISORDERS IN OUTPATIENTS

J. Krappweis, L. von Ferber, W. Kirch

Rheumatic disorders have become a frequent reason for services in ambulatory care. Therefore the use of drugs which are administered in rheumatic complaints is widespread. Data of the Sientific Institute of Statutory Health Insurances (Arzneimittelindex 1992) demonstrate that the group of antirheumatics/analgetics held the first rank due to the number of prescriptions. With regard to the costs this drug class were amongst the top three. Apart from antirheumatics and analgetics different other drug classes are used for the treatment of rheumatic disorders for example corticoids. To estimate the total expenditure for drug utilization in out-patients suffer from musculoskeletal disorders data of the statutory health insurance Dortmund (AOK Dortmund) were investigated. A 5\% random sample of insurees $(n=6478)$ was analysed for diagnoses and drug therapy. The data were collected in a individual-related way for an observation period of one year (1988). The results demonstrate the high frequency of rheumatic disorders among out-patients: the 12-month prevalence of musculoskeletal disorders was about $40 \%$ in the studied population of whom one half suffered from back pain. Approximately $80 \%$ of the patients were prescribed any drugs for treatment of rheumatic disorders. As might be expected nonsteroidal antiinflammatory drugs were used most frequently. The extensive use of topical products was a considerable factor of costs. More than one half of the patients received drugs for topical application. Further details will be presented. Diachronous data of statutory health insurences that have been gathered in a person-related way permit the estimation of drug expenditure in outpatients with regard to the several musculoskeletal disorders.

Institut für Klinische Pharmakologie

Medizinische Fakultät der Technischen Universität Dresden

Fiedlerstr. 27, D 01307 Dresden, Germany

\section{A 51}

\section{BIOAVAILABILITY OF TOPICAL ETOFENAMATE PRODUCTS IN RHEUMATOID ARTHRITIS PATIENTS}

M. Kurowski and A. Dunky†

Etofenamate is one of the most frequently applied topical NSAIDs in Germany. It can be regarded as a lipophilic prodrug of flufenamic acid, which is liberated after transdermal absorption and cleavage of the ester. We compared several topical NSAIDs in patients suffering from osteoarthrosis or rheumatoid arthritis with concomitant knee joint effusions. The products contained between 5 and $10 \%$ of etofenamate and were administered according to the recommended dosage schedule. Following multiple applications of defined doses we obtained synovial fluid and plasma specimen in order to measure the concentrations and to compare the bioavailability of several products. The analysis of synovial fluid and plasma samples was achieved by HPLC. Following the addition of other N-phenylanthranilic acid derivatives as internal standards the samples were extracted twice with a 5 -fold volume of acetonitrile/methanol (1:1). The diluted extracts were concentrated with the use of preconditioned ODS-columns and subsequently eluted with methanol. The separation of the products was pertormed on a reversed phase column with an elution medium of methanol/water/acetic acid (72:27.9:0.1).

The highest synovial fluid and plasma concentrations were measured after 3 hours following the final administration of etofenamate. The concentrations reached average maximum values of $60.5 \mathrm{ng} / \mathrm{ml}$ of flufenanamic acid in plasma and $45.1 \mathrm{ng} / \mathrm{ml}$ in synovial fluid. The bioavailability could be estimated from the area under the concentration time interval between 0.5 and 3 hours, during which samples were obtained. They served for the comparison of the topical products. From in vitro data of cyclooxygenase or lipoxygenase inhibition with N-phenylanthranilic acid derivatives it can be concluded, that the synovial fluid levels of etofenamate and its metabolites are unsufficient to produce effects relying on this mechanism. It can not be excluded, however, that other effects contribute to the clinical improvements observed by other investigators.

*Institut für Klinische Pharmakologie, Universitätsklinikum Charité, HumboldtUniversität zu Berlin, Schumannstraße 20, D-10098 Berlin;

†Wilhelminenspital der Stadt Wien, 5. Medizinische Abteilung, Montleartstr. 37, A1171 Wien.
A 50

PHARMACOKINETICS OF DEXAMETHASONE IN LIVER DIBEABE. S. Kütemeyer, A.von zur Mühlen and T.H. Schürmeyer. Misleading results of endocrine tests in patients suffering from liver diseases promted us to investigate the influence of liver function on the pharmacokinetics of dexamethasone (DEX). It was the aim of this study to find out whether routine parameters of liver function may be usefull in roughly predicting the clearance of dexamethasone. Methods : In 50 patients 1 iver function was rated on the basis of their plasma cholinesterase activity (CHE) and prothrombin time (PT). Blood samples were withdrawn $7,15,30,60,120,240,360,480$ and $960 \mathrm{~min}$ following an iv bolus injection of $2 \mathrm{mg}$ of dexamethasone-21-dihydrogenphosphate corresponding to $1,66 \mathrm{mg}$ of $\mathrm{DEX}$ for the determination of DEX pharmacokinetics by RIA.

Results : Computer assisted best fit analysis (2 compartment model) of the plasma DEX decay did not show any influence of liver function on the distribution half-life $\left(t \frac{1}{2}-\alpha\right)$ and on the initial volume of distribution of DEX, but a $56 \%$ increase in the terminal phase, "metabolic" half-life ( $\left.t \frac{1}{2}-\beta\right)$ with decreasing liver function. While the $t \frac{1}{2}-\beta$ increased from $167 \pm 12 \mathrm{~min}$ in patients with a CHE activity $>5.0 \mathrm{kU} / 1$ to $253 \pm 14 \mathrm{~min}$ in those with a CHE $\leq 1.0$ $\mathrm{kU} / 1$, the metabolic clearance rate (MCR) decreased from $226 \pm 29 \mathrm{ml} / \mathrm{min}$ to $111 \pm 180 \mathrm{ml} / \mathrm{min}$. In patients on phenytoin the $t \frac{1}{2}-\beta$ was reduced to $<100 \mathrm{~min}$. CHE activity $(r=-0.454)$ and $P T(r=-0.447)$ were significantly $(p<0.001)$ correlated with the $t \frac{1}{2}-\beta$ of DEX. We conclude that the dosage of dexamethasone given for diagnostic or therapeutic purpose needs to be adjusted in patients on phenytoin therapy and in patients with liver disease causing a CHE $\leq 2 \mathrm{kU} / \mathrm{l}$.

Dr. S. Kütemeyer, Abt. Klinische. Endokrinologie, Medizinische Hochschule, D-30625 Hannover, Germany

\section{A 52}

A PLACEBO CONTROLLED DOUBLE BLIND CLINICAL TRIAL OF 7.5 MG AND 15 MG OF MELOXICAM IN SHORT TERM TREATMENT OF PATIENTS WITH RHEUMATOID ARTHRITIS (RA)

E-M LEMMEL *

Introduction: Meloxicam (MEL) is a new non-steroidal antiinflammatory drug (NSAID) belonging to the enolic acid class. In animal studies it has been shown to have excellent anti-arthritic efficacy and an improved tolerability profile over other NSAIDs. Early preclinical studies have shown that MEL preferentially inhibits cyclooxygenase-2 (COX-2).

The aims of this three-week, parallel, multicentre trial were to assess the efficacy and safety of two different doses of MEL in comparison to placebo (PLA) in patients with active RA. The specific question was, whether COX-2 inhibition relates to therapeutic efficacy and safety in the clinical'setting.

Methods: 468 patients ( $337 \mathrm{~F}, 131 \mathrm{M}$, mean age 55 years) were randomised (MEL $7.5 \mathrm{mg}=159$, MEL $15 \mathrm{mg}=162, \mathrm{PLA}=147$ ) and analysed by an intention-to-treat analysis. All trial drugs were given orally once daily.

Results: 31 patients (21\%) in the PLA group, 11 patients $(7 \%)$ in the $7.5 \mathrm{mg}$ MEL group and 16 patients (10\%) in the $15 \mathrm{mg}$ MEL group discontinued the trial prematurely due to lack of efficacy or adverse events. $15 \mathrm{mg}$ MEL was significantly superior $(p<0.05)$ to PLA in 3 of the 4 primary endpoints: disease activity assessed by the investigator and by the patient and reduction of the tender/painful joint count. The difference between $7.5 \mathrm{mg}$ MEL and PLA reached statistical significance in 2 of the 4 primary endpoints: disease activity assessed by the patient and reduction of the tender/painful joint count. In none of the primary endpoints a statistically significant difference between $15 \mathrm{mg}$ and $7.5 \mathrm{mg}$ MEL occured. Global tolerance assessed by the patient and investigator at the last trial visit was similar in all three treatment groups. Adverse events were slightly more frequent with meloxicam than with placebo. In none of the patients gastric or duodenal ulcers, perforations or bleeds were observed.

Conclusion: The efficacy of meloxicam $7.5 \mathrm{mg}$ and $15 \mathrm{mg}$ per day was significantly superior to placebo in the treatment of patients with RA. There were no relevant differences regarding safety parameters between the 2 meloxicam doses and placebo. The preferential COX-2 inhibition may be the reason for the favorable efficacy and safety profile of meloxicam.

E-M Lemmel "for the Internstional Meloxicem Study Group

Staatliches Rheumakrankenhaus, Rotenbachtalstr. 5, D-76530 Baden-Baden 


\section{MORPHINE GLUCURONIDES INTERACT DIRECTLY WITH THE CEREBRAL $\mu$-OPIOID-REZEPTOR \\ S. Löser, J. Meyer, C. Desel, P. Runzheimer, U. Gundert-Remy}

Introduction: The major metabolites of morphine are morphine 3-0-B-D-glucuronide (M3G) and morphine 6-0-B-D-glucuronide (M6G). In humans plasma AUCs of M3G and M6G exceed those of morphine depending on form and route of application.

$\mathrm{M} 3 \mathrm{G}$ and M6G penetrate the blood-brain-barrier due to an unexpectedly high lipophilicity. M3G is an antagonist able to provoke withdrawl symptoms even in opioid naive animals. M6G is an agonist markedly more potent than morphine.

Methods: Pig brains were homogenized and the homogenate centrifuged to give a microsomal preparation free of nuclei and coarse debris. Aliquots were incubated at $37^{\circ} \mathrm{C}$ in buffer $(\mathrm{pH}$ 7.4) containing $0.5 \mathrm{nM}\left[{ }^{3} \mathrm{H}\right] \mathrm{DAMGO}$.

Results: The $\mathrm{IC}_{50}$ for morphine, $\mathrm{M} 3 \mathrm{G}$ and $\mathrm{M} 6 \mathrm{G}$ were $3.7 \mathrm{nM}$, $24 \mathrm{nM}$ and $1.2 \mu \mathrm{M}$, respectively. M6G and $\mathrm{M} 3 \mathrm{G}$, respectively, shifted the $\mathrm{IC}_{50}$ for morphine markedly to the right.

Discussion: Our results on the single substances confirm data from the literature indicating that $\mathrm{M} 3 \mathrm{G}$ and $\mathrm{M} 6 \mathrm{G}$ inhibit binding to the $\mu$-OR less potent than morphine.

From the fact that $\mathrm{M} 3 \mathrm{G}$ and $\mathrm{M} 6 \mathrm{G}$ shift the $\mathrm{IC}_{50}$ for morphine to the right we infer binding of $\mathrm{M} 3 \mathrm{G}$ and $\mathrm{M} 6 \mathrm{G}$ to the morphine binding site at the $\mu$-OR.

Dr. med. Stefan V. Löser; Abteilung f. Klinische Pharmakologie; Robert-Koch-Str. 40; D-37075 Göttingen

\section{A 55}

\author{
DRUg USAGE PaTterns AND COST ON SURGICAL INTENSIV CARE UNITS (SICU) OF THE \\ UNIVERSITY HOSPITALS FRANKFURT/MAIN AND JENA \\ J.-P. Marschner*, J.Tepper** and R. Schäfer**
}

Intensiv care units are the most expensive wards consuming $15-20 \%$ of the hospital budget.

Drug use reviews on SICU's of the university hospitals Frankfurt (22 beds) and Jena (25 beds) were compared after recording the indication related administration of pharmaceuticals and blood products over a 4 months investigation period using notebook-PC's. All substances were included, wich produced $60 \%$ and $80 \%$ of total pharmaceutical cost in the year before, respectively.

In Frankfurt and Jena 207 and 465 patients were registered, causing total cosi of DM 938.000,- and DM 1.145.000,- and causing cost per patient and day of average DM 796.and DM 513,-, respectively. In Jena most expensive diagnoses were severe trauma ( $388 \%$ of total cost; $n=66)$, gastro-intestinal bleeding $(14.9 \% ; n=16)$ and malignant growth $(14.3 \% ; n=100)$. In Frankfurt high cost diagnoses were liver transplantation (27\% of total cost; $n=2 !)$, severe trauma $(10.5 \% ; n=22)$ and coronary bypass crafting $(9.3 \% ; n=73)$. Although the patient populations were different, the percentage cost of the substance groups on total drug cost were the same in both SICU's: blood-products $57 \pm 1 \%$, antibiotic and chemotherapeutics $19 \pm 0,5 \%$, immuno-globulines 10,5 $2,5 \%$. Anyway, inside these groups drug usage patterns differed distinctly. For example, in Jena the high-cost antibiotics were tobramycin, cefuroxim, amoxicillin and AmBisome ${ }^{\circledR}$ causing $16.2 \%$, $12.3 \%, 8.1 \%$ and $8 \%$ of total antibiotic cost, respectively. Corresponding data for Frankfurt are AmBisome $39.8 \%$, Imiperiem $14.3 \%$, Cefotaxim $7,4 \%$ and Cefamandol $6.5 \%$. Severe sepsis was the most abundant complication occuring in both SICU's in 7 patients and producing cost of DM 208.695,- in Frankfurt and DM 173.676,- in Jena. In sepsis blood products were the most expensive substances with $52.9 \%$ (Frankfurt) and $38.9 \%$ (Jena) followed by antibiotics with $26.2 \%$ and $14.3 \%$ and inmunoglobulines with $17.1 \%$ and $36.8 \%$, respectively. Conclusion

- Recording the indication related drug adninistration drug usage patterns may be identified and targets for economical intervention may be found.

- Blood and blood-products must be included because they produce about $50 \%$ of total cost.

- Complications, especially sepsis, produce high cost, which should be included in the discussion with the health assurances concerning the payment system using diagnosis related groups.

* Dept. of Clin. Pharm. Univ. Hosp., Theodor-Stern-Kai 7, D-60590 Frankfurt/Main

** Inst. of Clinical Pharmacology, Univ. Hosp. Jena, Bachstrasse 18,D-07743 Jena
DRUG USAGE PATTERNS IN A MIXED HAEMOTOLOGICAL/GASTROENTEROLOGICAL WARD OF THE UNIVERSITY-HOSPITAL FRANKFURT/MAIN J.-P. Marschner

Indication-related drug administrations and cost were recorded on a mixed haematological/gastroenterological ward over a 6 months period using a notebook PC as previously described (Marschner et al., IntJClinPharmTher 1994, in press)

\begin{tabular}{|l|l|l|}
\hline Results: & haematology & gastroenterology
\end{tabular}

\begin{tabular}{|l|l|l|}
\hline number of patients & \multicolumn{1}{c|}{86} & \multicolumn{1}{c|}{147} \\
\hline average length of stay & \multicolumn{1}{|c|}{22.3 days } & \multicolumn{1}{c|}{12 days } \\
\hline total cost substances & \multicolumn{1}{|c|}{ DM 800.522,- } & \multicolumn{1}{c|}{ DM 143.153,- } \\
\hline most expensive dia- & 1.AML (n=14/40\%) & 1.carcinoma (n=25/16\%) \\
gnoses (number of & 2.NHL (n=11/ 17\%) & 2.after LTX (n=1/ 12\%) \\
patients/ \% total cost) & 3.anemia (n=5/ 12\%) & 3.hepatocirhosis (n=9/8\%) \\
\hline Most expensive & 1. blood products (32\%) & 1.antibiotics, antimyco- \\
substance-groups & 2. chemotherapeutics (21\%) & tics, virustatics (33\%) \\
(\% total cost) & 3. antibiotics, antimyco- & 2.blood products (24\%) \\
& tics, virustatics (16\%) & 3. immunoglob. (13\%) \\
\hline most expensive sub- & 1. thrombocytes (30\%) & 1. human albumin (14\%) \\
stances (\% total cost) & 2. G-CSF (14\%) & 2. ceftriaxon (9\%) \\
& 3. liposom. amphoter. B (7\%) & 3. imipenem (7\%) \\
\hline
\end{tabular}

- One haemophiliac with factor VIII inhibitor receiving Factor Eight Inhibitor Bypassing Activity and producing cost of DM 876.300,- was not included in the above shown results.

- Blood products, coagulation factors and antimicrobial agents are the most expensive substances, however their use could be more restricted.

- Chemotherapy represents also a high-cost factor, but altematives do not exist.

Dep. of Clin. Pharm., Univ. Hosp., Theodor-Stem-Kai 7, D-60590 Frankfurt/Main

A 56

PhaRMaCOECONOMTC ACTIVITIES OF ClINICAL PHARMAKOlogists AT THE UNIVERSITIY HOSPITAL FRANKFURT/MAIN J.-P. Marschner, P. Thürmann, S. Harder

In 1992 a Drug-Utilisation-Review-Group (DURG) was founded by Clinical Pharmacologists. The task of this group is to identify drug usage patterns, to record indication related drug administration including cost and to analyse these data. As a result recommendations concerning rational and economical use of pharmaceuticals and blood-products were given (e.g. $5 \mathrm{HT}_{3}$-receptor-antagonists, human albumin, G-CSF) The cost-development (million DM) of all substances during the last 11 years is shown in the table

\begin{tabular}{l|c|c|c|c}
\hline year & drugs & $\begin{array}{c}\text { blood and } \\
\text {-products }\end{array}$ & $\begin{array}{c}\text { coagulaion } \\
\text { factors }\end{array}$ & total \\
\hline 1982 & 15.7 & 6.1 & 4.6 & $\mathbf{2 6 . 4}$ \\
1990 & 22.2 & $\mathbf{8 . 3}$ & 9.9 & $\mathbf{4 0 . 4}$ \\
1991 & 24.1 & 10.0 & 9.9 & $\mathbf{4 4 . 0}$ \\
1992 & 26.0 & 11.2 & 8.8 & $\mathbf{4 6 . 0}$ \\
1993 & 23.6 & $\mathbf{4 . 8}$ & 3.9 & $\mathbf{3 2 . 3}$ \\
\hline
\end{tabular}

The most expensive substances are blood-products $(27 \%)$, antimicrobial agents $(27 \%)$ and immunoglobulines $(21 \%)$.

In conclusion, at the Universitiy Hospital Frankfurt/Main the activities of the Drug-Utilisation-Review-Group seem to be successful and are at least inpart responsible for the reduction of drug-cost of more than DM 10 Mio last year.

Dept. of Clinical Pharmacology, University Hospital Frankfurt/Main Theodor-Stern-Kai7, D-60590 Frankfurt/Main 
A 57

PHARMACOKINETIC/DYNAMIC (PKPD) ANALYSIS OF FENOTEROL INDUCED TACHYCARDIA AND HYPOKALEMIA IN HEALTHY WOMEN. STANDARD TWO STEP VS. POPULATION APPROACH

I. Meineke, Th. Bouillon, U. Langen, K. Günther, R. Hildebrandt, K. Warnke, U. Gundert-Remy

The aim of this study was to determine the extent and the time course of fenoterol induced tachycardia and hypokalemia during and after a continuous intravenous infusion with three different rates within the therapeutic range for tocolysis. Furthermore we compared the point estimators and precision of parameters obtained with a standard two step approach and a population model.

According to a randomized double blind multiple cross over design, 6 healthy females received an intravenous infusion of either placebo or fenoterol $(0.5 \mu \mathrm{g} / \mathrm{min}, 1 \mu \mathrm{g} / \mathrm{min}, 2 \mu \mathrm{g} / \mathrm{min})$ over 3 hours. The plasma concentration of fenoterol, heart rate, blood pressure, plasma potassium and plasma glucose were monitored during and up to 2 hours after the infusion. The plasma concentrations of fenoterol and potassium and the heart rate were fitted to an integrated PKPD model. Both individual parameter estimates and population estimates were obtained with NONMEM. Both effects correlated best with the concentration in the central compartment. The relationship between heart rate and concentration was adequately described by an $E_{\max }$ model. Modelling of the dose dependent hypokalemic effect of fenoterol required an negative sigmoid Emax model with an additional term allowing for passive diffusion of potassium from the intra- to the extracellular compartment. During the observation period, the concentration response relationship remained stable for both effects. As to be expected, the estimates of the population parameters were much more stable than those of the individual patients. It is concluded that the population method might be superior to the STS approach even in a data rich situation.

Department of Clinical Pharmacology, University of Göttingen, Robert Koch Str. 40, 37075 Göttingen, Germany

\section{A 59}

\section{CALCIUMANTAGONIST THERAPY: QUALITY CONTROL BY MEANS OF ANIMAL EXPERIMENTS (RATS) H.P. Metzger}

Calciumantagonists (CA) are lipophilic molecules which, however, have no common structural similarities. Nevertheless, $\mathrm{CA}$ are characterized by the ability to attach to various receptors and binding places in cardiac and smooth muscle preventing calcium overload, necrosis and cellular death. In order to study the physiological effects of CA on cerebral cortex of normal and Vit D3 calcified rats, i.v. infusion of CA have been applied. Cerebral blood flow (via hydrogen clearance) and oxygen supply (via surface oxygen tension) have been measured in normal and sclerotic Albino rats in order to differentiate cerebral and systemic effects. Miniaturized surface oxygen and hydrogen electrodes were placed on top of the exposed cerebral cortex of ketamine-xylazine anesthetized rats.

Nifedipen, verapamil, diltiazem and flunarizine induced hypotension in normal and Monckeberg type sclerotic rats. Nifedipen and verapamil showed comparable improvements in $\mathrm{CBF}$ and surface $\mathrm{PO}_{2}$, the initial hypotension recovered completely under nifedipen but not under verapamil. Compared with verapamil, the hypotension was even more pronounced under flunarizine (33:18\%). Nevertheless, in response to both CA CBF was improved to about $60 \%$. However, diltiazem did not increase CBF due to hypotension. Sclerotic rats showed a MAP-decrease from 148 to $91 \mathrm{~mm}$ $\mathrm{Hg}$, the $\mathrm{PO}_{2}$ histogram was left-shifted. Diltiazem did not improve the cortical supply of sclerotic animals.

Medizinische Hochschule Hannover, Physiologisches Institut, KonstantyGutschow-Str. 8, D-30625 Hannover

\section{A 58}

Discrepancy between in vivo/in vitro dissolution for IS-5-MN

P.-G. Merz, S. Rietbrock, A. Schrödter, S. Harder, H.-J. Weimann, D. Meister

IS-5-MN is absorbed completely in the gastrointestinal tract and lacks first pass metabolism. Controlled release formulations are predominantly used in clinical therapy. We investigated whether the in vitro-dissolution profile deternined the concentration time curves in vivo.

18 volunteers received 3 different controlled release formulations ( $A, B, C$, containing $60 \mathrm{mng}$ IS-5-MN) in a randomised cross-over design. Plasma samples were taken from 0 to 48 hours after application. One week wash-out phase was kept between investigations. IS-5-MN were determined in plasma using a GC-method. In vitro dissolution of $A, B, C$ was investigated by using the rotating bottle method according NF XIV

Mean absorption time (MAT) was calculated as the difference of MRT and $\mathrm{kel}_{\mathrm{el}}^{-1}$, the mean dissolution time (MT diss ) was calculated as proposed by Brockmeier (1). Additionally half value duration (HVD) and plateau time (PT) are reported.

\begin{tabular}{llll}
\multicolumn{2}{l}{ Table: In vivo/in vitro pharmacokinetic parameters } & \\
& A & B & C \\
AUC(ng/ml*h) & 6589 & 7493 & 7507 \\
$\mathrm{C}_{\max }(\mathrm{ng} / \mathrm{ml})$ & 500 & 521 & 628 \\
$\mathrm{t}_{\text {max }}(\mathrm{h})$ & 5.0 & 4.9 & 7.1 \\
$\operatorname{MAT}(\mathrm{h})$ & 4.91 & 5.57 & 5.94 \\
$\mathrm{HVD}(\mathrm{h})$ & 11.3 & 13.2 & 9.9 \\
$\operatorname{PT}(\mathrm{h})$ & 19.9 & 21.4 & 20.9 \\
$\operatorname{MT}_{\text {diss }}(\mathrm{h})$ & 4.25 & $\mathbf{4 . 1 8}$ & 6.19
\end{tabular}

The difference of the dissolution profiles between the product is not reflected in the parameters MAT, HVD and PT. Although preparation C has the longest MTdiss it has the largest $C$ max value and shortest HVD. The origin of this apparent discrepancy between in vivo/in vitro profiles deserves further elucidation

(1) Acta Pharm. Technol. 32 (4), 164-174 (1986)

Dr. P.-G. Merz, University Clinic, Department of Clinical Phanmacology, TheodorStern-Kai 7, D-60590 Frankfurt, Germany

A 60

INTRACORONARY DRUG APPLICATION FOR EVALUATION OF SYSTOLIC AND DIASTOLIC LV FUNCTION - FOCUS ON ENOXIMONE

V. Mitrovic, K. Berwing, R. Strasser, M. Schlepper

The influence of intracoronary enoximone at a dose of $0.075 \mathrm{mg} / \mathrm{kg} / 10 \mathrm{~min}$ on global and regional wall motion, myocardial perfusion (contrast echo) and diastolic LV function during pacing-induced ischemia was investigated in 18 pts. with significant LAD stenoses.

Results: Enoximone did not change either heart rate at rest $\left(79 \pm 9\right.$ vs $\left.80 \pm 9 \mathrm{~min}^{-1}\right)$ or blood pressure (LVSP: $159 \pm 7$ vs $162 \pm 5 \mathrm{mmHg}$ ). In the postpacing ischemic period, LVEDP fell from a mean of 28.9 to 18.4 mmHg after enoximone ( $<<0.001)$, dp/dtmax increased from 1050 to $1369 \mathrm{mmHg} / \mathrm{s} \quad(\mathrm{p}<0.001)$ and regional EF from $47 \%$ to $58 \%$ ( $p<0.01$ ) with global EF remaining unchanged $(45 \%$ vs $47 \%)$. ST segment depression was reduced significantly from 2.3 to $1.5 \mathrm{~mm}(\mathrm{p}<0.01)$. Enoximone induced an increase in myocardial perfusion by $129 \% \quad(p<0.001)$ in the stenosis-depending myocardial areas with shortening of the wash-out half-time of the echo contrast medium from a mean of 14 to $5 \mathrm{~s} \quad(\mathrm{p}<0.001)$. The isovolumetric relaxation (ECHO) was shortened by $13 \% \quad(p<0.05)$, the $E$ wave by $5 \%$, and $d p / d t m i n$ was increased by $17 \% \quad(\mathrm{p}<0.01)$.

Conclusions: Intracoronary application of enoximone leads to an improvement in both systolic and diastolic LV function without concomitant peripheral effects due to regression of myocardial ischemia.

V. Mitrovic, Max Planck Institute for Physiological and Clinical Research, Kerckhoff-Klinik GmbH, Bad Nauheim. 
A 61

CARNITINE DEPLETION IN CHILDREN TREATED WITH PIVALOYLSUBSTITUTED B-LACTAM ANTIBIOTICS I. Möller and M. Kurowski

Pivaloyl-substituted B-lactamantibiotics belong to a new group of prodrugs with an improved bioavailability following oral administration. After metabolic cleavage the pivalic acid and the free B-lactam are eliminated separately. Pivalic acid is subjected to enzymatic coupling with endogenous carnitine leading to carnitinereduced under the treatment which may lead to neurological side effects in patients with metabolic predisposition. We showed, that the pattern of other acylcarnitineesters excreted with the urine was not changed significantly after administration of a pivaloyl-substituted cephalosporine in healthy subjects.

In order to compare the pattern of excreted carnitineesters we analyzed urine samples of pediatric patients treated with cefetamet-pivoxil.

The analysis of carnitineesters in the urine was achieved by HPLC following precolumn derivatization. As an internal standrad we used undecanoyl-carnitine ester, which does not occur in human plasma or urine. After the extraction using ion exchange columns the samples were incubated with p-bromo-phenacyl reagent. The mixture of derivatives was separated on a reversed phase column applying a gradient of different buffers. With this method the whole spectrum of carnitineesters can be quantitatively analyzed. The percentage of the pivalic acid ester eliminated with the urine in pediatric patients did not differ from that observed in healthy subjects, therefore an increased risk in this patient group cannot be inferred.

Institut für Klinische Pharmakologie, Universitätsklinikum Charité, HumboldtUniversität zu Berlin, Schumannstraße 20, D-10098 Berlin; pivaloylester, which can be found in large amounts in the urine. Free carnitine is

A 62

Pharmacokinetics and bioavailability of Bupranolol-TTS and oral Bupranolol in patients with impaired liver function compared to healthy volunteers K.-H. Molz", W. Cawello*t, G. Haug-Pihale ${ }^{* * *}$, R. Bonn ${ }^{* *}$ W. Hammes ${ }^{* *}$, A. Weil ${ }^{* * *}$ and G. Popescu*t+

Bupranolol is nearly completely absorbed after oral administration, but more than $90 \%$ of the parent compound are metabolized by first pass through the liver.

It can be expected that transdermal application of the substance will bypass the high first pass metabolism resulting in higher plasma concentrations or lower therapeutic doses, respectively. A reduced capacity of metabolizing liver enzymes might mimic this effect. The study was performed to investigate if metabolisation by hepatic enzyme systems results in liver function dependent pharmacokinetics. Special interest was to be given to possible differences between oral and transdermal application. In an open sequential single dose- study including 10 patients with impaired liver function and 10 age/sex/weight- matched healthy volunteers a bupranolol transdermal therapeutic system (containing $30 \mathrm{mg} / 24 \mathrm{~h}$ ) and bupranolol tablets $(100 \mathrm{mg})$ were administered to each participant separated by a washout period of a week. Phenotyping for mephenytoin and sparteine was done to exclude poor metabolizers. Blooo samples for the quantification of bupranolol plasma concentrations were drawn before and $1,2,3,6,9,12,16,23,24$ (before patch removal), $25,27,30,36,48,60$ and 72 hours after patch application as well as before tablet administration and $0.5,1,1,5,2,3,4,6,8$, $10,12,16,24,30,36,48$ and 60 hours post dose. Urine samples were collected in 5 (TTS) and 6 (tablets) intervals after dosing. Blood pressure and heart rate were measured before and 1,3,6,12 and 24 hours after dosing, ECG's were recorded before and 3,6 and 24 hours after dosing.

The pharmacokinetic results indicate only minor differences between patients and healthy controls after patch applications. For example the main parameter $\mathrm{AUC}(0-\infty)$ were $65.8 \pm 26.3 \mathrm{ng} / \mathrm{m} / \mathrm{h}$ (mean $\pm \mathrm{sd}$ ) in healthy controls and $57.8 \pm 18.1 \mathrm{ng} / \mathrm{ml} \cdot \mathrm{h}$ in patients. Completely other situation was given in comparison of data from oral administration: AUC $(0-\infty)$ decreased dramatically to $5.7 \pm 3.7 \mathrm{ng} / \mathrm{ml} / \mathrm{h}$ in healthy controls and increased to $473.3 \pm 611.6 \mathrm{ng} / \mathrm{m} / \mathrm{h}$ in patients.

*) Dept. of Clinical Pharmacology, JWG- University Frankfurt/M *) Schwarz Pharma AG, Monheim **7) present address: APEX Applied Pharmcology, Munich (study performed at: LAB, Munich)

\section{A 64}

Urinary Nitrate Excretion in Cardiac Transplanted Patients: A Marker for Graft Rejection?

A. Mügge*, S. Kurucay*, R. Böger, S. Bode-Böger, H. J. Schäfers+, J.C. Frölich, and P.R. Lichtlen*.

\section{dependent Relaxation in Isolated Porcine Coronary} Arteries

A. Mügge, S. Kunz, and P.R. Lichtlen.

Vascular complications are a common finding in patients with diabetes mellitus. It has been reported that elevated glucose impairs acetylcholine- but not nitruprusside-mediated relaxation of rabbit aorta in vitro suggesting an abnormal endothelium-mediated vasodilator mechanism (Cohen, Circulation 1993; 87 (suppl. V): 67).

The purpose of the study was to investigate whether this phenomenon 1. implies general impairment of the nitric oxidemediated relaxation (or only specific interference with muscarinic receptors), and 2 . can be also demonstrated for coronary arteries. Porcine coronary arteries were cut in rings and were set up in organ baths for isometric tension recordings. Rings were randomized and incubated with different glucose concentrations $(5.5,22.0$, or 44.0 $\mathrm{mM}$ ) for 6 hours according to Cohen and coworkers. Rings were preconstricted with prostaglandin F2 $\alpha(0.5-3 \mu \mathrm{M})$; the nitric oxidemediated relaxation was induced by either substance $P(0.01-10$ $\mathrm{nM})$, bradykinin $(0.1-100 \mathrm{nM})$, or calciumionophor A23187 (1 $1000 \mathrm{nM}$ ), the endothelium-independent relaxation by nitroglycerin ( 1 - $3000 \mathrm{nM}$ ). In addition, the effects of glucose were studied on acetylcholine- $(0.01-10 \mu \mathrm{M})$ and serotonin- $(0.001-10 \mu \mathrm{M})$ induced vascular responses. Results: Surprisingly, elevated glucose concentrations ( 22 and $44 \mathrm{mM}$ ) had neither an effect on the potency nor the efficacy of any of the agonists tested.

It is concluded that this previously reported impairment of endothelium-mediated vasodilation of rabbit aorta by elevated glucose concentrations may not be important in other species or types of arteries.

Division of Cardiology, Hannover Medical School, 30625 Hannover, Germany
Nitric oxide production may be induced by cytokine-mediated immune responses. We tested the hypothesis that graft rejection in cardiac transplanted patients is associated with an increased production of nitric oxide. The study group consisted of 83 patients in whom one or several myocardial biopsies (total 194 biopsies) were obtained to assess for graft rejection. At the day of biopsy, urine was collected for a time period of at least 4 hours (10\% isopropanol was added for antimicrobial activity). Nitrate was measuerd in urine samples by gaschromatography. Nitrate excretion was expressed as the quotient of nitrate and creatinine content ( $\mu \mathrm{mol}$ nitrate/mmol creatinine). Since nitric oxide is oxidized in biologic systems to nitrite and finally nitrate, it was assumed that nitrate excretion reflects total nitric oxide release. Graft rejection was classified according to the Hannover classification system (A0/1= no/minor rejection, A2A4=moderate/severe rejection).

Results: Nitrate excretion showed a large interindividual variation ( 9 to $502 \mu \mathrm{mol}$ nitrate/mmol creatinine). Altough not significant, the nitrate

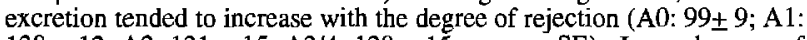
$128 \pm 12 ; \mathrm{A} 2: 131 \pm 15 ; \mathrm{A} 3 / 4: 128 \pm 15 ;$ mean $\pm \mathrm{SE}$ ). In a subgroup of patients $(n=32)$ who underwent several biopsies with and without rejection, moderate/severe rejection was significantly associated with increased nitrate excretion (A0/A1: $111 \pm 13$ vs. A2-A4: $161 \pm 30$, $\mathrm{p}<0.05)$.

Conclusion: The urinary nitrate excretion is increased in patients with moderate/severe graft rejection. Because of large variation in excretion, this marker may be not suitable for rejection diagnosis.

Divisions of Cardiology*, Clinical Pharmacology and Thoracic Surgery ${ }^{+}$, Hannover Medical School, 30625 Hannover, Germany 
A 65

EFFECTS OF VARIOUS ANTIDEPRESSANTS ON $5-H T$ UPTAKE IN HUMAN PLATELETS

B. Müller, B. Müller-0erlinghausen, L. Franke, H.-J. Schewe, J. Schley, K. Thjes-Flechtner, R. Uebelhack

Platelets are widely used as an accepted model

for the study of central neurotransmitter function in humans. However, only few comparative investigations on the influence of tricyclic antidepressants have been performed under in vivo conditions in patients. We analysed the changes of $V_{\max }$ and $K_{m}$ as well as the uptake under halfsaturation conditions in platelet rich plasma and washed platelets after 3 weeks of treatment with amitriptylin, nortriptilyn, maprotilin, and clomipramin in 50 depressed patients. The correlation of uptake-inhibition and amitriptyin/ nortriptylin serum concentrations will be demanstrated. Potential effects of lithium augmentation in non-responders have also been studied.

Dr. Beatrice Müller

Psychiatrische Klinik, Charité

Medizinische Fakultät der

Humboldt-Universität

Schumannstr. 20/2l

D-10117 Berlin

\section{A 66}

TISSUE KINETICS OF MODEL DRUGS IN VIVO IN MAN MEASUREMENT BY MICRODIALYSIS

M Müller*, R Schmid**, C Wasicek*, B v.Osten*, I Gerngroß*, HG Eichler* Depts, of Clinical Pharmacology and Medical and Chemical Laboralory Diagnosis, University of Vienna, Vienna, Ausiria)

Measurement of drug concentrations in tissues would be useful for clinica pharmacokinetic studies but appropriate experimental methods are not available at present. The aim of this study was to assess the scope and limitations of the microdialysis technique for human tissue pharmacokinetic studies.

Studies were conducted in 13 healthy male volunteers. Microdialysis probes were inserted into the medial vastus muscle and the periumbilica subcutaneous adipose layer. Thereafter, volunteers received either paracelamol (2000mg p.o.) or gentamicin (160mg, iv bolus). Drug concentrations were followed in plasma, muscle and subcutanous tissue Calibration of the microdialysis probes was carried out in vitro and in vivo, employing the retrodialysis method.

For both model compounds complete concentration versus time profiles in muscle and subcutanous tissue could be obtained. Major pharmacokinetic paramelers $\left(t_{12-a b s}, t_{12+e}, c_{\max }, t_{\max }, A U C, A U I C\right)$ were calculated for tissues tissue/plasma concentration ratios could be derived. Reproducibility of tissue drug concentration measurements was high.

In conclusion, we have shown that microdialysis sampling is a suitable too for measuring drug concentrations in human muscle and subcutanous tissues. Microdialysis is readily applicable, relatively non-invasive and reproducible. This technique may become a valuable addition for pharmacokinetic characterization of selected drugs.

Department of Clinical PharmacologyNienna University Hospital A-1090 Wien, Währinger Gürtel 18-20

A 68

INHIBITION OF COLLAGEN-INDUCED PLATELET AGGREGATION BY DT-TX 30 A COMBINED THROMBOXANE -SYNTHETASE INHIBITOR AND -RECEPTOR ANTAGONIST, IN MAN EX VIVO. T.H. Müller, H. Narjes, J. Krause.

-RECEPTOR ANTAGONISM, SELECTIVELY PREVENTS THE FORMATION OF LARGE THROMBI IN MAN EX VIVO. T.H. Müller, K. Rühr, H. Narjes, J. Krause.

The combination of thromboxane $A_{2}$ /prostaglandin endoperoxide (EPO) receptor antagonism with thromboxane synthetase inhibition (TRASI) is designed to both abolish the EPOs' prothrombotic role and direct EPOs from activated platelets to adjacent cells for the generation of antithrombotic prostaglandins Thus, we have investigated the effect of the potent TRASI DT-TX 30 on thrombus formation in models of vascular injury (of the media versus selective deendothelialization) in man ex vivo.

Healthy volunteers were treated with an oral dose of vehicle (placebo; $n=10$ ) or DT-TX $30(25,50,100,200,400 \mathrm{mg} ; n=6$ per dose). Blood was taken before and 1,2, 4 and $24 \mathrm{~h}$ after the ingestion, anticoagulated and allowed to flow over a thrombogenic cell-free subendothelial matrix (CFM) or a layer of human venous smooth muscle cells (SMC) for $10 \mathrm{~min}$. The "en face" area of platelets/thrombi deposited was determined by microscopic morphometry. In the absence of cells of the vessel wall (CFM) the thrombus formation was inhibited by $32 \pm 15 \%( \pm S D)$ after $50 \mathrm{mg}, 43 \pm 28 \%$ after $100 \mathrm{mg}, 31 \pm 1 \%$ after $200 \mathrm{mg}$ and $57 \pm 29 \%$ after $400 \mathrm{mg}$ DT-TX 30 versus $5 \pm 21 \%$ after placebo. The subclass of the large thrombi $(=7 \%$ of all platelets/thrombi but incorporating $>90 \%$ of the platelet mass) was much stronger affected by the DT-TX 30 treatment: the mean area was reduced by $61 \pm 27 \%$ after $25 \mathrm{mg}, 69 \pm 20 \%$ after $50 \mathrm{mg}$, $78 \pm 9 \%$ after $100 \mathrm{mg}, 53 \pm 25 \%$ after $200 \mathrm{mg}$ and $71 \pm 8 \%$ after $400 \mathrm{mg}$ DT-TX 30 versus $-16 \pm 40 \%$ after placebo.

In the presence of cells of the vessel wall (SMC) the overall thrombus forma tion was reduced by up to $42 \pm 21 \%$ after only $25 \mathrm{mg}, 36 \pm 31 \%$ after $50 \mathrm{mg}$, $59 \pm 20 \%$ after $100 \mathrm{mg}, 72 \pm 5 \%$ after $200 \mathrm{mg}$ and $81 \pm 6 \%$ after $400 \mathrm{mg}$ DT$\mathrm{TX} 30$ versus $2 \pm 12 \%$ after placebo.

In summary, DT-TX 30 showed a unique antithrombotic profile of selectively inhibiting the formation of large thrombi and cooperating with vascular smooth rnuscle cells in man ex vivo.

Pharmacological Research, Dr. K. Thomae GmbH, D-88397 Biberach, Germany
DT-TX 30 , a molecule combining potent and specific thromboxane synthetase inhibition with prostaglandin endoperoxide/thromboxane $A_{2}$ receptor antagonism, has been examined in healthy male subjects. Collagen-induced platelet aggregation in platelet rich plasma prepared from venous blood was measured photometrically before and up to 24 hours after a single oral dose of $25,50,100$, 200 or $400 \mathrm{mg}$ DT-TX 30 in a placebo-controlled, double-blind study. Platelet aggregation was induced in the ex vivo samples by collagen in concentrations between 0.5 and $10 \mu \mathrm{g} / \mathrm{ml}$ to evaluate platelet aggregation in relation to the strength of the proaggregatory stimulus. The $\mathrm{EC}_{50}$, i.e. the concentration of collagen required for a half-maximal aggregatory response (defined as the maximal change of the optical density), was determined. In the placebo-treated control group, the mean $\mathrm{EC}_{50}$ was $365 \pm 55 \mathrm{ng} / \mathrm{ml}$ collagen ( $\pm S E ; n=10$ ) before treatment. It then varied between $362 \pm 41$ and $417 \pm 83 \mathrm{ng} / \mathrm{ml}$ collagen after treatment. The ratio of the post- to the individual pre-treatment $E C_{50}$ values was $1.08 \pm 0.10(n=10)$ at $0.5 h, 1.05 \pm 0.11$ at $1 \mathrm{~h}$ $1.13 \pm 0.14$ at $2 h, 1.1 \pm 0.20$ at $4 h, 1.07 \pm 0.07$ at $8 h$ and $1.02 \pm 0.06$ at $24 h$. This indicates that the sensitivity of the platelets to collagen was not affected by the placebo treatment.

Oral treatment with DT-TX 30 , however, strongly inhibited the aggregatory response of the platelets to collagen stimulation. The $\mathrm{EC}_{50}$-ratio was increased to a maximum of $4.5 \pm 0.85$ ( 1 h p.a.; $n=6$ ) by $25 \mathrm{mg}, 8.0 \pm 1.9$ ( 1 h p.a.; $n=6$ ) by $50 \mathrm{mg}, 9.9 \pm 1.6(0.5$ h p.a.; $n=6)$ by $100 \mathrm{mg}$. $11.1 \pm 1.9$ (0.5 h p.a.; $n=5)$ by 200 $\mathrm{mg}$ and $22.7 \pm 4.4$ ( $2 \mathrm{~h}$ p.a.; $n=6$ ) by $400 \mathrm{mg}$ DT-TX 30 . A substantial inhibition of collagen-induced platelet aggregation was observed still $8 \mathrm{~h}$ after the administration ( $E C_{50}$-ratio of $3.8 \pm 0.6(n=6)$ for $100 \mathrm{mg}$ and $7.8 \pm 1.3(n=6)$ for $400 \mathrm{mg}$ DT-TX 30).

A single oral dose of DT-TX 30 inhibits collagen-induced platelet aggregation in both a dose-dependent and reversible manner in man ex vivo.

Pharmacological Research, Dr. K. Thomae GmbH, D-88397 Biberach, Germany 
ENDOGENDUS DRLG-L TKE FACTORS IN A POLISH POPULATION

A. Mrozikiewicz,Z.Lowicki, J.Kowal, P.M.Mrozikiewicz

The detection of endogenous opioids suggested the opinion that in case of the presence in the organism of a receptor for an exogenous substance there is probably a similar endogenous substance.The occurrence in the blood of persons, who were not treated with cardiac glycosides, of endogenous digoxin-like or ouabain-like factors confirms that opinion. In our study we took up the research of other drug-like factors in the blood serum of healthy people.

In two hundered and twenty-five healthy volunteers (110m,115f) non-smokers not receiving any treatment before or during the test and aged between 18 and 49 y(mean age $36 y$ ) the occurrence of drug-like factors in blood serum was studied. The examinations were carried out with the use of the fluorescence-polarization-immunoassay (FPIA)-TD Abbott. The presence of the following endogenous drug-like factors in the blood serum was evaluated: quinidine,phenytoin, carbamazepine, theophylline, cyclosporine and gentamicin.

The presence of endogenous phenytoin-like, theophyllinelike and cyclosporine-like factors has been demonstrated. The drug-like factors were not found in the case of quinidine, carbamazepine and gentamicin. The phenytoin-like factor was found in $91,1 \%$, theophylline-like factor $95,1 \%$ and cyclosporine-like factor in $96,9 \%$ of examined volunteers.The mean value of the drug-like factors were as follow : pheny toin $0,18^{+} 0,05 \mu \mathrm{g} / \mathrm{ml}$, theophylline $0,16^{ \pm} 0,11$ $\mathrm{\mu g} / \mathrm{ml}$ and cyclosporine $12,41 \pm 4,24 \mathrm{ng} / \mathrm{ml}$. The supposition may be proponued that organism produces drug-like substances according to its needs.

Department of Clinical Pharmacology,University of Medical Sciences, Długa 1/2,6l-848 Poznari,Poland

\section{A 71}

POLYMORPHIC ARYLAMINE $N$-ACETYLTRANSFERASE (NAT2) GENOTYPES: CORRELATION WITH PHENOTYPIC ACTIVITY

P.M. Mrozikiewicz, I. Cascorbi, J. Brockmöller, and I. Roots

Recently the gene structure of NAT2 was elucidated and now the NAT2 genotyping methods may substitute the NAT2 phenotyping procedures in clinical and epidemiological investigations. The aim of this study was to compare various NAT2 genotypes with NAT2 phenotypic activity. NAT2 genotyping was performed in 176 children of Polish origin applying allele specific polymerase chain reaction (mutation at position $341 \mathrm{nt}$ of NAT2 coding sequence) and restriction fragment length polymorphism with restriction enzymes $M s p \mathrm{~V} / A l u \mathrm{I}, F o k \mathrm{I}, K p n \mathrm{I}, T a q \mathrm{I}, D d e \mathrm{I}$, and $B a m H \mathrm{I}$ for mutations at positions $191,282,481,590,803$, and $857 \mathrm{nt}$, respectively. NAT2 phenotyping relied on the conventional sulfadimidine method. The genotype nomenclature of Grant (Pharmacogenetics 1993, 3, 45 - 50) was used.

The genes coding for rapid acetylation were present in $37.5 \%$ of the cases, genes coding for slow acetylation were detected in $62.5 \%$. The frequency of specific $N A T 2$ alleles were: R1, $20.7 \%$; R2, $1.2 \%$; S1a, $30.4 \%$; S1b, 3.1 $\%$; S1c, $6.3 \%$; S2, $34.9 \%$; S3, $1.4 \%$; and S4, $2.0 \%$. There was no mutation found at $19 \mathrm{I}$ nt. In 166 cases $(94.3 \%)$ we have stated NAT2 genoand phenotype concordance, but in 10 cases (5.7\%), genotype and phenotype deviated from each other. Seven individuals were genotyped as S1aS2, one as S1aS1c, and one as S1aS4 but were phenotypically rapid acetylators. One child was genotyped as R1S1a but proved a slow acetylator.

We can confirm that in about $94 \% N A T 2$ genotyping allows to properly predict NAT2 phenotype. Discrepancies may derive, i. a., from yet unknown mutations which we try to detect by DNA-sequencing.

Institute of Clinical Pharmacology, Charité, Humboldt-University of Berlin, Schumannstr. 20/21, D-10098 Berlin, Germany
THE ACETYLATION AND OXIDATION PHENOTYPES IN A POLISH POPULATION

A.Mrozikiewicz,D.Kiełczewska-Mrozikiewicz,Z.Lowicki, P.M.Mrozikiewicz, E.Chnara

The acetylation and oxidation phenotypes were studied in 448 healthy volunteers $(235 \mathrm{~m}, 213 \mathrm{f})$ aged between 18 and 46 years (mean 36y) in the Wielkopolska region in Poland.

The acetylation phenotype was studied with the use of sulphadimidine which was given in a dose of $44 \mathrm{mg} / \mathrm{kg} \mathrm{b.w}$. per os.Sulphadimidine was determined by a spectrophotometric method. The border value of M.R. was $75 \%$ in urine.

The oxidation phenotype was studied with the use of soarteine which was given in a dose of $1,5 \mathrm{mg} / \mathrm{kg} \mathrm{b.w.per} \mathrm{os.}$ Sparteine was determined by the Gas Chromatographic method in urine. If M? was 20 <MR $<340$ these are values for intensive metabolism, if MR was $0,22<M R<12$ these are values for poor metabolism.

The determinated phenotypes were bimodally distributed. Our studies have shon that 259 healthy volunteers $(57.8 \%$ ) were slow and $189(42,2 \%)$ were fast metabolizers. Intensive oxidation phenotype could be ascertained in 423 volunteers $(94,4 \%)$ and poor oxidation phenotype in 25 volunteers $(5,6 \%)$.

These findings are comparable with the values typical for the Caucasian population.

Department of Clinical Pharmacology,University of Medical Sciences, Długa 1/2, 61-848 Poznań, Poland

\section{A 72}

NISOLDIPIN AND NITROGLYCERIN PREVENT DIGOXIN-INDUCED CONSTRICTION OF EPICARDIAL CORONARY ARTERIES IN PATIENTS WITH CORONARY ARTERY DISEASE. C.W.T. Nolte, S. Jost, A. Mügge, W-G. Daniel, P. Lichtlen

Several studies demonstrated that cardiac glycosides reduce diameter of epicardial coronary arteries. In patients (PTS) with coronary artery disease (CAD) this vasoconstrictive side effect of glycosides may cause ischemic complications in the presence ot high-grade stenoses. This study evaluated quantitatively the effect of an i.v. injection of digoxin on diameter of epicardial coronary arteries in 20 PTS with CAD. Eleven PTS (group 1) were treated with aspirin $100 \mathrm{mg} / \mathrm{d}$, nine PTS (group 2) were treated with aspirin and $10 \mathrm{mg}$ nisoldipin 2 hours prior to angiography. Coronary angiograms were taken in identical projections before $(0)$ and $5,10,15$ and 30 minutes after i.v. injection of $0.8 \mathrm{mg}$ digoxin; at $35 \mathrm{~min} 0.1 \mathrm{mg}$ of nitroglycerin (NTG) was given. The mean diameters of normal segments and the minimum diameters of stenoses were analysed with CMS (Medis, Leiden). A total of 149 normal and 28 stenotic segments were analysed. Figure shows the change of coronary diameter (\% predrug-value; mean \pm SE) for group I (left) and II (right):

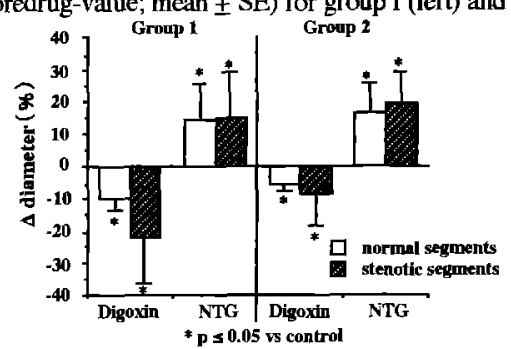

Conclusions: 1.Application of digoxin i.v. a in clinically common dosage induces constriction of normal and stenotic coronary arteries. 2. Nisoldipin prevents digoxin-induced vasoconstriction, specially in stenotic coronary arteries. 3. Digoxin-induced vasoconstriction is reversal with NTG. 4. PTS with CAD should be treated with NTG or nisoldipine before administration of digoxin in order to prevent vasoconstrictive side effects.

Department of Cardiology, Hannover Medical School, 30625 Hannover 
A 73

TALINOLOL METABOLISM IN HUMAN - STRUCTURE, POLARITY AND URINARY RECOVERY OF THE METABOLITES R. Oertel, K. Richter, B. Trausch, A. Berndt, W. Kirch

Talinolol (1-(4-cyclohexylureido-phenoxy)-2-hydroxy-3-tert.-butylaminopropan; AWD, Dresden) is frequently used as a cardioselective $B$-adrenoceptor antagonist. Talinolol metabolites in urine were detected by HPLC and GC/MS with previously characterized reference compounds and were quantified by HPLC with a normal phase silica column (Oertel et al., Br. J. Clin. Pharmacol. 37 (1994) 496). Less than one per cent of administered dose was recovered in urine as hydroxylated talinolol. Other metabolites could be excluded. In serum after therapeutic doses talinolol metabolites were not traceable. However, in a suicidal patient with a parent compound serum concentration of $1400 \mathrm{ng} / \mathrm{ml}$ (manifold higher as after usual therapeutic dose) two hydroxy metabolites at concentrations near the detection limit $(10 \mathrm{ng} / \mathrm{ml})$ were found. Obviously only a small amount of the talinolol dose is metabolized in human.

In this study the relation between structure, polarity and urinary recovery of the metabolites was examined. Four different isomers of mono-hydroxylated talinolol were identified in urine of volunteers after a single dose of talinolol. Eight isomers are possible: six hydroxy-cyclohexyl-compounds and two hydroxy-phenoxy-compounds. There was a low degree of specificity of biotransformation seen with respect to the point of attack on the cyclohexyl ring. Hydroxylation of the phenyl ring could be excluded in human.

Using HPLC methods very small quantities of reference compounds are sufficient to estimate and compare the polarity and hydrophily of similar compounds. Long retention times in a normal phase system and short retention times in a reversed phase (RP) system are found for polar and hydrophilic compounds. The shortest retention times of all hydroxylated talinolol compounds in the nonmal phase system as well as the longest retention times in the RP system were found for the main metabolites 4-trans- and 3-cis-hydroxycyclohexyl-talinolol. Accordingly, the main metabolites are the most polar and hydrophilic mono-hydroxylated talinolol isomers.

Institut für Klinische Pharmakologie, Medizinische Fakultät Carl Gustav Carus, Technische Universität Dresden, Fiedlerstr. 27, 01307 Dresden, Deutschland

\section{A 75 \\ ROLE OF PROTEIN ISOPRENYLATION IN CANCERO- GENESIS: INHIBITORS OF FARNESYLATION}

\author{
Monique Paubert-Braquet \\ BIO-INOVA Research Laboratories, 48/52, Rue de la Gare, F-78370 Paisir, \\ France
}

Increased cell proliferation induced by ras-oncogenes is mediated by growth factors. Growth factors bind to cell membrane surface receptors and activate tyrosine kinases leading to protein phosphorylation. This triggers posttranslational modification of the function of low molecular mass GTP binding Ras proteins, e.g. p21ras, including heterotrimetric $G$ proteins. These proteins carry a $\mathrm{C}$-terminal amino acid sequence, $\mathrm{CAAX}$ where $\mathrm{C}$ is cysteine, which is the target of isoprenylation by famesyl protein transferases (FPPTases) and geranyl-geranyl protein transferases (GGPTases). The amino acids of this sequence determine whether the Ras protein is substrate for FPTases or GGPTases. This biochemical pathway is related to mevalonate metabolism, therefore, cholesterol biosynthesis shares several steps with isoprenylation. The active compounds include a series of isoprenoid inter-mediates, such as geranyl pyrophosphate (C-10), farnesyl pyrophosphate (FPP, C-15) and geranyl-geranyl pyrophosphate (GGPP, C20) which are critical for cell proliferation. Inhibitors of isoprenylation may (i) compete with FPP to its binding site on the alpha subunit of the enzyme, (ii) inhibit the $\mathrm{Zn}_{\mathrm{n}}$ protease of FPTase beta subunit, and (iii) interfere with the binding of the CAAX peptide to its binding site on the beta subunit. The inhibitors include microbial products like manumycin, gliotoxin, acetylgliotoxin and pepticin-namins, FPP analogues, tetrapeptides and related peptidomimetics that may compete for the CAAX sequence, products of plant origin like limonene as well as synthetic compounds. All these compounds have been known to retard cell proliferation. and their effect can be abolished by mevalonic acid. Inhibitors of HMG-CoA reductase, such as lovastatin, which have been developed as antihyperlipidemic drugs, may also effective as anticancer agents. The recognition of the importance of mevalonate metabolism in cancerogenesis provides possibility to test simple chemical compounds against tumor growth, and gives promise for pharmacological exploitation of inhibitors of isoprenylation and $\mathrm{HMG}-\mathrm{CoA}$ reductase inhibitors for cancer chemotherapy.
A 74

EFFECTS ON PLATELET FUNCTIONS OF SINGLE ORAL DOSES OF LYSINE CLONIXINATE AND ACETYLSALICYLIC ACID

D. Pallapies, A. Muhs, L. Bertram, G. Rohleder*, P. Nagyiványi* and B. A. Peskar

Lysine Clonixinate is a non-steroidal antiinflammatory drug with marked analgesic effects. It is used for treatment of acute pain such as postoperative, dental or menstrual pain. We have determined the biosynthesis of thromboxane $(\mathrm{TX}) \mathrm{B}_{2}$ and prostaglandin $(\mathrm{PG}) \mathrm{F}_{2 \alpha}$ in clotting whole blood ex vivo as well as collagen-induced platelet aggregation before and $0.25,0.5$ (only $\mathrm{TXB}_{2}$ and $\mathrm{PGF}_{2 \alpha}$ biosynthesis), 1, 2.5, 6, 24 and 48 hours after oral intake of $125 \mathrm{mg}$ Lysine Clonixinate. The results were compared with data obtained after oral intake of $500 \mathrm{mg}$ acetylsalicylic acid (ASA). While both $\mathrm{TXB}_{2}$ and $\mathrm{PGF}_{2 \alpha}$ biosynthesis measured radioimmunologically were inhibited significantly ( $p<0.05$ and $p<0.01$, respectively) 2.5 hours, but not 6 hours after Lysine Clonixinate, inhibition by ASA was much greater and still highly significant $(p<0.01)$ after 48 hours. The mean concentrations of Lysine Clonixinate and of ASA inhibiting $\mathrm{TXB}_{2}$ biosynthesis in vitro by $50 \%\left(\mathrm{EC}_{50}\right)$ were $3.2 \pm 0.5 \mu \mathrm{M}$ and $6.2 \pm 0.9 \mu \mathrm{M}$, respectively. Aggregation of $0.5 \mathrm{ml}$ aliquots of platelet-rich plasma induced by $1 \mu \mathrm{g} / \mathrm{ml}$ collagen was inhibited by Lysine Clonixinate significantly $(\mathrm{p}<0.01)$, but not completely for up to 24 hours, while aggregation induced by $3 \mu \mathrm{g} / \mathrm{ml}$ collagen was inhibited for up to 6 hours only $(p<0.01)$. Platelet aggregation induced by both collagen concentrations was inhibited by ASA almost completely $(p<0.01)$ for at least 48 hours. The $\mathrm{EC}_{5_{0}}$ for in vitro inhibition of submaximal collagen-induced platelet aggregation was $59 \pm 16$ $\mu \mathrm{M}$ for Lysine Clonixinate and $97 \pm 21 \mu \mathrm{M}$ for ASA. It remains to be investigated, whether other mechanisms than inhibition of cyclooxygenase contribute to the analgesic activity of Lysine Clonixinate. The profile of side effects including only moderate inhibition of platelet function by Lysine Clonixinate as compared to ASA might be an advantage with regard to its use as an analgesic.

Department of Pharmacology and Toxicology, Ruhr-Universität, Universitätsstr. 150, D-44780 Bochum, Germany

*Roemmers S.A.I.C.F., Buenos Aires, Argentina

\section{A 76}

HEMODYNAMIC, RENAL AND ENDOCRINE EFFECTS OF DOPAMINE AND EPININE IN HEALTHY VOLUNTEERS

U.Poller, K.Pönicke, M.Elter-Schulz*), A.Daul*), F. Jockenhövel*) and $0 .-$ E. Brodde, Institute of Pharmacology, University of Halle, and *)Departm. of Internal Medicine, University of Essen, Germany

Dopamine (DA) and epinine (EPI, the active metabolite of ibopamine) are DA- and $\alpha$ - and $\beta$-adrenergic receptor $(R)$ agonists. To study whether $D A-R$ mediated effects can be separated from $\alpha$ - and $\beta-A R$ effects we assessed in 10 male volunteers effects of i.v. DA and EPI $(0.5 ; 1.0 ; 2.0$ and $4.0 \mu \mathrm{g} / \mathrm{kg} / \mathrm{min}$ for $15 \mathrm{~min}$ each) on changes in serum prolactin (PRL, $D A-R$ mediated) blood pressure ( $P$ ) and heart rate (HR, $\alpha$ - and $\beta-A R$ mediated), natriuresis (urinary excretion of sodium), diuresis (urine flow rate) and plasma noradrenaline (NA) levels. In the 0.5 and $1.0 \mu \mathrm{g}$ doses DA and EPI did not affect Psyst, Pdiast and HR, but significantly decreased PRL (DA: from $4.2 \pm 0.5$ to $2.7 \pm 0.4 \mathrm{ng} / \mathrm{ml}$; EPI: from $6.3 \pm 1.1$ to $4.4 \pm 0.8 \mathrm{rg} / \mathrm{ml}, \mathrm{p}<0.01)$. In the $4 \mu \mathrm{g}$ dose $D A$ and $E P I$ increased Psyst by $20 \mathrm{~mm} \mathrm{Hg}$, Pdiast by 4 and $8 \mathrm{mn} \mathrm{Hg}$, and HR by 8 and 11 beats/min but further decreased $\dot{P} R L$. In addition, both DA and EPI significantly increased diuresis and natriuresis; in contrast, only $D A$, but not EPI, dose-dependently increased plasma $N A$ levels, an effect that was not inhibited by $\beta-A R$ antagonists. We conclude that in 0.5 and $1.0 \mu \mathrm{g}$ doses (plasma levels of 20-70 nmol/i) DA and EPI act only at DA-R. In higher doses, however, DA and EPI can activate $\alpha$ - and $\beta-A R$ whereby EPI has a stronger $\alpha$-AR component than DA. Moreover, part of DA-effects are indirect $v i$ a release of endogenous NA whereas EPI-effects do abviously not include an indirect component. 
A 77

\section{EFFECT OF LOW DOSE CICLETANIN ON PROSTACYCLIN SYNTHESIS AND BLOOD PRESSURE IN HYPERTENSIVE PATIENTS \\ J. Radermacher, R.Müller-Bartels, F. Bartels, H. Baumgarten, K. Thon, D. Tsikas and J.C. Frölich,}

20 patients with essential hypertension were treated with cicletanin ( 100 $\mathrm{mg} / \mathrm{d}$ ) for 12 weeks. Compliance was verified by measuring urinary cicletanin excretion. Before entering the study antihypertensive medication had been withdrawn for at least 2 weeks (wash out phase). The study was preceeded by a placabo phase of 1 week duration. Blood pressure measurements and urine collections for measurements of 2,3dinor-6-ketoProstaglandin F1 $\alpha$ (a stable prostacyclin metabolite) were performed at the start and end of placebo phase, after 1 week of treatment with cicletanin and in monthly intervalls thereafter. Cicletanin decreased systolic and diastolic blood pressure, the effect becoming significant at 4 weeks.

\begin{tabular}{l|c|c|c} 
& Wash out & Placebo & Cicletanin \\
\hline Systolic BP [mmHg] & $169.1 \pm 2.4$ & $160.2 \pm 3.3^{* * *}$ & $150.6 \pm 3.9 * *$ \\
Diastolic BP [mmHg] & $99.1 \pm 2.0$ & $95.5 \pm 2.2$ & $89.3 \pm 2.4 * *$ \\
Pulse [bpm] & $73.8 \pm 2.0$ & $72.9 \pm 2.0$ & $71.6 \pm 2.4$ \\
Urine [m1/d] & $1580 \pm 169$ & $1321 \pm 120$ & $1381 \pm 64$ \\
dn-6keto PGF1 $\alpha$ [pg/ml] & $111 \pm 14$ & $113 \pm 8$ & $137 \pm 15^{*}$
\end{tabular}

depicted as average of all treatment periods

Urinary excretion of the prostacyclin metabolite 2,3dinor-6 keto PGFl $\alpha$.increased by $21 \%$. Hypertensive patients and control subjects ( $\mathrm{n}=13 ; 2,3$ dinor-6-keto-PGFla: $120 \pm 19 \mathrm{pg} / \mathrm{ml}$ ) did not differ significantly in urinary exctetion of 2,3dinor-6 keto PGF1 $\alpha$. Neither systolic nor diastolic blood pressure showed a significant correlation with 2,3dinor-6 keto-PGF1 alpha excretion (systolic BP: $R=0,12, p=0,21$; diastolic BP: $\mathrm{R}=0,0007, \mathrm{p}=1,0$ ).

These data show that cicletanin is effective in reducing blood pressure. Increased prostacyclin production is probably not responsible for the observed reduction of blood pressure.

Institute of Clinical Pharmacology and Dept. of Nephrology; Hannover Medical School, Konstanty Gutschow Str. 8, 30625 Hannover, Germany

\section{A 79}

DOSE-DEPENDENT EFFECT OF ASPIRIN ON CAROTID ATHEROSCLEROSIS C. Ranke, A. Creutzig, H. Hecker, K. Alexander

Antiplatelet treatment with aspirin is well established as secondary prophylaxis after a transient ischemic attack or minor ischemic stroke, but the effect of aspirin treatment on the course of carotid atherosclerosis is unknown. We tried to investigate the effect of aspirin on the initial stages of carotid atherosclerosis.

Patients were recruited from a prospective, randomized, double blind clinical trial to compare two doses of aspirin ( $900 \mathrm{mg} \mathrm{vs} 50 \mathrm{mg}$ daily) with respect to restenoses after lower limb angioplasty. Of the 383 patients admitted to the angioplasty trial, 27 patients showing 104 small carotid atheroma ( $<50 \%$ lumen narrowing) were examined at entry and after 1 year of aspirin treatment using a high-resolution ultrasound duplex system. Disease progression and regression were defined by a change of maximal plaque area (as measured by longitudinal ultrasound sections) of more than 2 standard deviations of the method.

The change in plaque area was significantly different for the treatment groups: average plaque size remained'unchanged after treatment with 900 $\mathrm{mg}$ aspirin daily but increased markedly after treatment with $50 \mathrm{mg}$ aspirin daily ( $p=0.011$ ). There were significantly more lesions in the $50-\mathrm{mg}$ group showing progression than in the 900-mg group (23 plaques [47\%] vs 13 plaques [24\%], $p=0.025)$. Ultrasonic disappearance of a lesion was observed only in the $900-\mathrm{mg}$ group in 9 cases ( 7 soft plaques, 2 ulcerative plaques, $p=0.018$ ). The 6 patients on $50 \mathrm{mg}$ aspirin who continued smoking during the study showed significantly more progression as compared to the 7 non-smokers in the $50-\mathrm{mg}$ group (17 plaques [59\%] vs 6 plaques $[30 \%], p=0.038$ )

The results of our study indicate that aspirin treatment slows carotid plaque growth in a dose-dependent fashion, with a dose of $900 \mathrm{mg}$ daily more efficient than $50 \mathrm{mg}$ a day.

Dr. C. Ranke, Division of Angiology, Hannover Medical School, KonstantyGutschow-Str. 8, 30625 Hannover, Germany.

\section{A 78}

CLINICAL-PHARMACOLOGICAL ASPECTS OF THE NICERGOLINE BIOAVAILABILITY

H. Rameis

In the past the realization of trials on the pharmacokinetics of Nicergoline in human beings break down according to analytical difficulties. From animal studies with labelled compounds it is known, that Nicergoline is rapidly absorbed from the gastrointestinal tract and two main metabolites (MDL, 1-MMDL) can be detected. The mean elimination half-life for Nicergoline is given with $2,5 \mathrm{~h}$, for MDL $12-17 \mathrm{~h}$ and for 1-MMDL with 4-6 h. The compound is excreted mainly by the kidney. Due to known problems of the application of labelled drugs in human beings there are two approaches for the determination of these compounds: first the detection by monoclonal antibodies by using a RIA-method, secondly a HPLC-analysis. Although there are promising in-vitro results of the immunological method, quantitative analyses of serum samples show deceptive results. The HPLCassay reveales that in human serum samples after oral administration of Nicergoline only the metabolites MDL and 1-MMDL can be detected. Further analytical development lower the limit of detection which should be $1 / 10$ of $c_{\text {axa }}$. With an improved HPLC-method it will be demonstrated that only the measurement of the metabolite MDL is suitable to give sufficient results in pharmacokinetic trials and in studies on bioavailability with formulations of Nicergoline.

Correspondence: Univ. Dozent Dr. H. Rameis, Wiener Arbeitsgruppe für Klinische Pharmakologie und Therapie, A-1050 Wien, Franzensgasse 22

\section{A 80}

THE APPLICATION OF POPULATION KINETICS IN THE TREATMENT OF NEONATAL PATIENTS WITH GENTAMICIN U. Renz and M. Kurowski

Gentamicin is frequently applied in neonatal patients for the treatment of severe infections. The use is associated with high incidences of oto- and nephrotoxicity. Ototoxicity occurs in $1-1.5 \%$ of the treated patients. It can be avoided, if the trough levels remain under $2 \mu \mathrm{g} / \mathrm{ml}$ between the administered doses. If the nephrotoxic effect, which occurs in $2-10 \%$ of the treated patients, can also be reduced under these circumstances is not yet clear. Recently it has been suggested to administer gentamicin only once daily in order reach the desired trough levels. This applies especially to children, in which the terminal half-ilife can be protonged to approximately 9 hours. This dosage regimen assures a sufficient effectivity due to the marked postantibiotic effect, but should reduce the incidence of the toxic effects.

In order to test this hypothesis we pertorm a case-control study with neonatal children treated with gentamicin. The cases of nephrotoxicity during the previous 12 months are identified from the hospital records. For these patients the plasma level time curves are obtained with the use of a population based pharmacokinetics programme, which considers the measured plasma concentrations and the administered doses. Plasma concentrations were measured routinely in the process of therapeutic drug monitoring. From these curves the duration of times with concentrations lower than $2 \mu \mathrm{g} / \mathrm{ml}$ during the last 3 days prior to the diagnosis are estimated. For the cases matched controls were identified according to age, age of gestation and other factors affecting the renal function e.g. comedication. Different analyses are carried out according to the definition of exposure. The results will be discussed with regards to the modification of the dosage schedule for gentamicin and the application of population kinetics in order to reduce the adverse effects.

Institut für Klinische Pharmakologie, Universitätsklinikum Charité, HumboldtUniversität zu Berlin, Schumannstraße 20, D-10098 Berlin; 
A 81

ECONOMIC CONSEOUENCES OF THEOPHYLLINE TDM

A.-K. Riethling, E.-M. Hehl, F. Henschel

Economic evaluation of drug therapy is an important task of Clinical Pharmacology. Drug costs amount to a relatively small percentage of total health care costs. Some drugs may help to avoid more expensive therapeutic procedures. Drugs with small therapeutic ratio need a therapeutic drug monitoring (TDM) to optimize therapeutic results and to avoid side effects. TDM may enhance the costs of drug therapy and the question arises, whether the additional costs are justified from the economic point of view. The aim of the study was to investigate the effectiveness of theophylline TDM in chronic obstructive pulmonary disease.

Methods: 30 outpatients suffering from chronic obstructive pulmonary disease and receiving theophylline as a basic medication were included in this study. During the one-year observation period the parameters of pulmonary function were examined four times $11 \mathrm{st}, 3 \mathrm{rd}$, 6th and 12th month) by the same physician and theophylline trough levels were estimated to individualize the dosage. The clinical outcome was assessed by intraindividual comparison.

Results: Impaired parameters of pulmonary function were improved. Hospital admissions were reduced. During the one-year observation period 4 out of 30 patients had 6 hospital admissions with totally 64 days. Under the conditions of theophylline therapy without TDM during the year before 7 of them had 13 hospital admissions with 197 days of stay in hospital.

Discussion: The results agree with a previous study on inpatients. There it was observed, that parameters of pulmonary function significantly were improved due to TDM-supported theophylline therapy in comparison to a group receiving theophylline without TDM. Despite the additional costs theopylline TDM contributes not only to improved clinical outcome but also to decreased costs for the care of patients with chronic obstructive pulmonary disease.

Adress: University of Rostock, Institute of Pharmacology and Toxicology Department of Clinical Pharmacology, Schillingallee 70, D-18055 Rostock

\section{A 83}

STUDIES OF THE MECHANISMS INVOLVED IN PSEUDOCHOLINESTERASE ACTIVITY REDUCTION DURING CARDIOPULMONARY BYPASS

AFE Rump, M Theisohn, G Aydincioglu, M Yilmaz, W Biederbick, J Schierholz, "C Diefenbach, " M Abel, "U Börner, $W$ Buzello and W Klaus.

Pseudocholinesterase-activity (PChE) is an important determinant of the elimination kinetics of drugs like mivacurium. Therefore, the time course of PChE was investigated in 16 patients undergoing cardiosurgery with cardiopulmonary bypass (CPB) in normo-or hypothermia . Anesthesia was induced and maintained with midazolam, propofol and fentanyl using mivacurium as a muscle relaxant By starting $\mathrm{CPB}, 2 \mathrm{I}$ of priming fluid were added to circulation volume. From collected blood samples, PChE (U/) was determined photometrically according to Ellman (1961)(butyrylthiocholine, dithiobisnitrobenzoate, $405 \mathrm{~nm}, \mathrm{pH}=7.0,37^{\circ} \mathrm{C}$ ). Total plasma protein concentration ( $g \%$ ) was measured according to Lowry, and the specific PChE was calculated as the quotient of PChE and protein concentration $(\mathrm{U} / \mathrm{g})$. Serum heparin-activity was defermined in 4 patients (Berichrome Heparin test kit). Moreover, the influence of heparin and aprotinin, both contained in the CPB priming solution, on PChE in vitro was examined using fresh serum from healthy volunteers $(n=3)$. Results: The induction of anesthesia had no significant influence on PChE or protein concentration $(p>0.05)$. CPB induced a significant decrease of $\mathrm{PChE}(-37 \%)(p<0.05)$ and protein concentration $(-24 \%)(p<0.05)$ and a less pronounced numerical reduction the specific PChE ($15 \%)(p>0.05)$. The reduction of PChE and protein concentration was not significantly affected by ending CPB $(p>0.05)$, and the values remained low over the remaining operation time. There was no significant difference in PChE, measured at $37^{\circ} \mathrm{C}$ in vitro, or protein concentration between the normothermic and hypothermic group ( $p>0.05$ ). Furthermore, there was no correlation between serum heparin-activity and PChE reduction. PChE in the plasma of healthy volunteers was not significantly affected by either heparin up to $100 \mathrm{U} / \mathrm{ml}$ or aprotinin up to $10000 \mathrm{U} / \mathrm{ml}(p>0.05)$. Conclusion: (1) PChE is reduced by CPB as a consequence of hemodilution. (2) The pharmacological agents used in the present anesthetic technique do not inhibit PChE at therapeutic serum concentrations.

Institut für Pharmakologie and * Klinik für Anästhesiologie und Intensivmedizin, Universität Köln, Gleuelerstrasse 24, 50931 Köln
A 82

PHARMACOKINETICS OF MITOMYCIN C IN THE CHEMOEMBOLISATIONTREATMENT OF LIVER METASTASES

AFE Rump, S Botvinik-Helling, M Theisohn, W Biederbick, J Schierholz, * R Fischbach, ${ }^{\star}$ W Heindel, ${ }^{\star}$ K Lackner and W Klaus.

In cancer treatment arterial blood flow reduction by embolisation followed by intra-arterial chemotherapy may be advantageous by achieving high and prolonged drug concentrations in the tumor and lower systemic drug exposure. Pharmacokinetics of mitomycin-C (MMC) were investigated in 4 colorectal cancer patients (body weight: $55-92 \mathrm{~kg}$ ) with liver metastases undergoing chemoembolisation. After hepatic artery branch catheterization and microspheres injection (Polyvinylalcohol, circumference: 150-250 $\mu \mathrm{m}$, ITC-Contour Rehaforum Medical) $20 \mathrm{mg} \mathrm{MMC}$ dissolved in $20 \mathrm{ml}$ physiological $\mathrm{NaCl}$ solution were infused in 5-8 min, followed by Ethiblock application. Serum MMC-concentrations were determined from peripheral venous blood samples by reverse-phase HPLCsystem with ultraviolet detection $\left(\mathrm{C}_{18}\right.$-column, Elution: phosphate-buffer $(0.01 \mathrm{M}$ $\mathrm{pH}: 6.5)$ ) : methanol, $\mathrm{V}: \mathrm{V}=70: 30,365 \mathrm{~nm}$ ). Pharmacokinetic parameters were computed using non- compartmental or two-compartment model analysis assuming linear kinetics (Top Fit 2.0 Software). Results: On the average, maximum serum concentrations were observed at $T_{\text {max }}=7.7 \mathrm{~min}$ following the beginning of MMC-infusion and amounted to $C_{\max }=1095 \mathrm{ng} / \mathrm{ml}$ (range: 562 $1790 \mathrm{ng} / \mathrm{ml}$ ). Mean steady state distribution volume was $0.56 \mathrm{l} / \mathrm{kg}$ with a central compartment volume of $0.22 \mathrm{l} / \mathrm{kg}$. Concentration-time curves could be described by a distributional phase $\left(T_{1 / 2}=8.5 \mathrm{~min}\right)$ followed by a terminal elimination phase $\left(T_{1 / 2}=72.4 \mathrm{~min}\right)$. Mean total clearance amounted to $8.6 \mathrm{ml} / \mathrm{min} . \mathrm{kg}$. The area under the concentration time curve was $33 \mu \mathrm{g} \cdot \mathrm{ml}^{-1}$.min.

Conclusion: Pharmacokinetic parameters for MMC-disposition in this study do not substantially differ from those reported for similar MMC-amounts administered as intravenous bolus. Systemic MMC exposure does not seem to be reduced following the embolisation procedure used compared to intravenous application.

Institut für Pharmakologie und * Klinik für Radiologie, Universität Köln, Gleuelerstraße 24, 50931 Köln

A 84

MITOMYCIN-C CONCENTRATION IN HUMAN OCULAR AQUEOUS HUMOR AFTER TOPICAL ADMINISTRATION DURING TRABECULECTOMY AFE Rump, M Theisohn, W Biederbick, J Schierholz, S Botvinik-Helling, "M Diestelhorst, "GK Krieglstein and W Klaus.

The concentration of the antitumor antibiotic mitomycin $\mathrm{C}$ (MMC), used in ophtalmic surgery for its antiproliferative effects, was measured in the aqueous humor of 7 glaucoma patients undergoing trabeculectomy. Sponges soaked with MMC-solution (100 ul of MMC- solution $0.2 \mathrm{mg} / \mathrm{ml}: 20 \mathrm{mg}$ ) were applied intraoperatively under the scleral flap for $5 \mathrm{~min} .100$ to $200 \mathrm{ul}$ of aqueous humor were drawn with a needle $10 \mathrm{~min}$ following the end of topical MMC- treatment Samples were assayed for MMC using a reverse-phase HPLC-system with ultraviolet detection ( $\mathrm{C}_{18}$-column, Elution: Phosphate-buffer $(0.01 \mathrm{M}$ $\mathrm{pH}: 6.5)$ :methanol, $\mathrm{V}: \mathrm{V}=70: 30,365 \mathrm{~nm}$ ). Swabs were extracted in phosphatebuffer $(0.1 \mathrm{M}, \mathrm{pH}: 7.0)$ before HPLC-analysis. Extemal calibration was used for MMC quantitation. Quantitation limit was $10 \mathrm{ng} / \mathrm{ml}$. In all aqueous humor samples MMC-concentration was below $10 \mathrm{ng} / \mathrm{ml}$. MMC in the swabs amounted to $37 \%$ of the MMC amount applied. Conclusion: After intraoperative topical application MMC concentration in the aqueous humor of patients is very low. The substantial loss of MMC from the swabs used for the topical MMC-treatment suggests (1) rapid systemic absorption of MMC and/or (2) a loss through irrigation of the operative field following topical MMC-application.

Institut für Pharmakologie und * Klinik für Augenheilkunde, Universität Köln, Gleuelerstrasse 24, 5093 Köln 


\section{Drug consumption review on surgical intensive care units}

Raik Schäfer, Jürgen Tepper, Annemarie Hoffmann Institut für Klinische Pharmakologie der Friedrich-Schiller-Universität Jena

Due to runaway costs of the national health service which are reflected as well in growing expenditures for drugs at the University Hospital of Jena investigation of indication related drug administration patterns becomes more and more interesting. This holds especially true for intensive care units (ITU's) which are determined by similar high costs for technical equipment as for drugs (1) although any economical considerations seem to be questionable due to ethical reasons (2).

Over a 4 month period indication related drug administrations of 2 surgical ITU's of the University Hospital Jena have been recorded and analyzed by using a PC-notebook. Total expenditures for all 465 included patients add up to DM 1.144.773 regarding these drugs and blood products which caused $80 \%$ of total costs in 1993 . The 10 leading substances ( Antithrombin III, Human Albumin $20 \%$, Prothrombine complex, ...) represent $67 \%$ of total costs including blood products, antibiotics and $\mathrm{lg} M$ enriched intravenous immunglobine. Therefore the indication of particulary these drugs became more interesting for further investigations.

Already during the study actual discussions with the treating medical staff have been made leading to new developed therapy recommendations. Providing same high standard of medical treatment a remarkable cost saving of some drugs by more critical and purposeful use could already be achieved as a first result. However, the results of the study underline impressivly the benefit of such investigations for improvement of drug treatment. The simple replacement of expensive drugs ( e.g. prothrombine complex) by higher quantities of cheaper ones of the same indication group ( e.g. fresh frozen plasma (3) ) does not necessarily mean less expenditures in all cases but may cause unsiderable side effects.

(1) Mann HJ, Wittbrodt ET 1993 Identifying drug usage patterns in the intensive care unit. PharmacoEconomics 4(4): 235-239

(2) Rothmann DJ Shulkin DJ 1993 The rising cost of pharmaceuticals. Am J Hosp Pharm 50(8) Suppl. 4: 8-12

(3) Hiller E, Heim MU 1989 indikationen fur die Therapie mit frischgefrorenem Plasma. Dt med Wschr 114: 1371-1374

\section{A 87 \\ RELEVANCE OF PS2-PROTEIN, EGFR AND CATHEPSIN D IN ASSOCIATION WITH ESTABLISHED PROGNOSTIC FACTORS IN BREAST CANCER \\ R.Schmidt ${ }^{1}$, D.Sorger ${ }^{2}$, F.Walter ${ }^{3}$, M.Schönfelder ${ }^{3}$, and R.Preiss ${ }^{t}$}

Estrogen(ER) and Progesterone(PR) receptor status as well as lymph node involvement are important factors in predicting prognosis and sensitivity to hormone and chemotherapy in patients with breast cancer. Prognostic relevance of pS2-protein, EGFR and Cathepsin D is currently under debate. Especially pS2 and EGFR expression appears to provide additional information regarding the responsiveness of the tumour tissue to Tamoxifen. The aim of the present study was to investigate the relationships between these parameters and established prognostic factors in breast cancer. In a prospective study pS2 and Cathepsin D were assayed immunoradiometrically in the tumour cytosol of 122 patients, EGFR was measured by ELISA. Relating the level of these factors to the lymph node involvement, menopausal status as well as tumour size, no significant association could be established. In our findings ER and PR are significantly correlated with the expression of pS2 but none is correlated with the cathepsin D status. EGFR was shown to be inversely correlated with the content of ER. A significant association between Cathepsin D and pS2 could be established in patients with early recurrence. At a median follow-up of 15-24 months, recurrence was more common in patients with tumours having negative status for $\mathrm{pS} 2$, independent of receptor status. In conclusion, because of the relative independence on the ER and PR status and other prognostic factors and the influence on the recurrence behaviour, demonstrated here, and their role in promoting tumour dissemination and changing hormone therapy sensitivity, all three factors represent markers of prognostic relevance.

Departments of Clinical Pharmacology ${ }^{1}$, Nuclear Medicine ${ }^{2}$ and Surgery ${ }^{3}$, University of Leipzig, FRG
COMPARISON OF MUSCULAR BLOOD FLOW OF THE LEG BETWEEN INTRAARTERIAL AND INTRAVENOUS PROSTAGLANDIN E1 IN PERIPHERAL ARTERIAL DISEASE, ASSESSED BY [15-0]-H2O-PET. S. Schellong, W. Burchert, J.vd Hoff, C. Roth, H. Hundeshagen, K. Alexander.

Background: PGE1 has been shown to be efficacious in the treatment of critical leg ischemia. Despite of an almost complete first pass metabolism in the lung the clinical effects of intraarterial and intravenous PGE1 do not differ significantly. In addition, it is not fully understood which of the various pharmacological actions of PGE1 is the main factor; by most authors, however, it is thought to be the increase of cutaneous and muscular blood flow. By means of [15-O]H2O-PET, we studied muscular blood flow (MBF) of the leg in patients with peripheral arterial disease comparing intraarterial and intravenous PGE1. Patients and methods: 8 patients $(3 \mathrm{f}, 5 \mathrm{~m}$; mean age $59 \mathrm{y}$ ) with PAD were studied, (5 atherosclerosis, 3 thromboangiitis obliterans). At the first day, $5 \mu$ g PGE1 were infused intraarterially within 50 minutes; PET scanning of the lower leg was performed at minutes 0,25 und 50. At the following day, 40 $\mathrm{gg}$ PGE1 were infused intravenously within 2 hours; PET scanning was performed at minutes 0,30,60 and 120. Results: In the infused leg the increase of MBF caused by intraarterial PGE1 averaged $79 \pm 59 \%$ at minute 25 and $100 \pm 85 \%$ at minute 50 ; in the not infused leg there was no effect. The increase rate in the infused leg was highly variable but did not correlate with sex, age, disease or clinical outcome. For intravenous PGE1 the change of MBF at any time averaged almost $0 \%$. Conclusion: Unlike intraarterial PGE1, intravenous PGE1 does not increase the muscular blood flow of the leg. A comparable clinical effect provided, increase of muscular blood flow may not be considered the main way of action of PGE1 in critical leg ischemia.

Department of Angiology, Department of Nuclear Medicine, Medical School Hannover, D-30625 Hannover, FRG.

\section{A 88 \\ PHARMACOECONOMIC RESEARCH - ETHICAL ASPECTS R. Schüppel}

Pharmacoeconomic studies, conducted either separately from or together with clinical trials are increasing in both number and meaning. In a period of limited health care budgets, political and medical decision makers alike run the risk of accepting the results of such studies without critical reflection. Careful evaluation of those studies by state-of-the-art methods is one way out of the trap. Another could be to refer to ethical considerations.

The problem in this context is, that the discussion concerning ethical aspects of pharmacoeconomic research, at least in Europe, is just in its beginning. Therefore, no widely accepted standards are available. But they are essential to answer four main questions:

1. Who should perfom a pharmacoeconomic study?

2. Which objectives should be considered?

3. What kind of study should be performed (e. g. cost-effectiveness, cost-utility, cost-benefit analysis)?

4. Which consequences will be drawn from the results?

Based on the case study-orientated "moral cost-benefit model" ( $R$. Wilson, Sci. Tech. Human Values 9: 11-22, 1984), a three-step decision and evaluation model is proposed to handle bioethical problems in pharmacoeconomic studies:

1. Moral risk analysis

2. Moral risk assessment

3. Moral risk management.

Possible practical consequences for decision making in research policy, study design and assessment of results are discussed.

Universität Ulm - Klinikum, Abt. Psychosomatik, Robert-Koch-Str. 8, D-89070 UIm 
A 89

EFFECTB OF RETOCONAZOLE ON ACTH, CORTIBOL AND 11DEOXYCORTIBOL BECRETION IN COBHING'S DIBEASE. T.H. Schürmeyer, C. Gutgesell and A. von zur Mühlen

Ketokonazole is known to decrease pituitary ACTH secretion in vitro and inhibits adrenal 11-hydroxylase activity. To work out the clinical significance of both effects analysis of episodic secretion of ACTH, cortisol (F) and 11-deoxycortisol (DF) was performed in patients with cushing's syndrome (CS) requiring adrenostatic therapy.

Methods : Ketokonazole was started in 11 patients with CS (9 ACTH-secreting pituitary adenomas [CD], 2 adrenal adenoma [AA]). In 9 of them ( $8 \mathrm{CD}, 1 \mathrm{AA}$ ) blood samples were obtained for 24 hours at $10 \mathrm{~min}$ intervals (144 samples/patient) before and again under treatment (mean dose $1000 \mathrm{mg} / \mathrm{d}$, >6 weeks). Hormone levels were measured by RIA and secretion patterns analysed by means of PULSAR, CLUSTER and DESADE. 2 patients were investigated only once because treatment was stopped due to side effects. Results : The table shows the hormone levels of 8 patients with $C D$ before (A) and under treatment (B) $[x \pm$ sem] ACTH (pg/ml) $\mathrm{F}(\mu \mathrm{g} / \mathrm{dl}) \quad \mathrm{DF}(\mathrm{ng} / \mathrm{ml})$

mean (A) $89 \pm 29 \quad 21.3 \pm 2.0 \quad 9.6 \pm 0.9$

$\begin{array}{lrlr}\text { (B) } & 119 \pm 27 & 15.1 \pm 1.7 & 16.0 \pm 3.0\end{array}$

$\operatorname{maxima}(\mathrm{A}) \quad 171 \pm 54 \quad 37.9 \pm 5.5 \quad 15.1 \pm 1.5$

(B) $250 \pm 56 \quad 25.2 \pm 4.2 \quad 28.3 \pm 5.9$

No change in the patterns of secretion occurred.

We conclude that the observed $34 \%$ increase of plasma ACTH and the $58 \%$ decrease of F/DF ratio demonstrate that inhibition of adrenal 11ß-hydroxylase activity is the primary mode of action of ketoconzole in vivo. Even at high doses ACTH and F secretion patterns could not be normalized.

PD Dr. T.H. Schürmeyer, Abt. Klin. Endokrinologie, Medizinische Hochschule, D-30625 Hannover, Germany

\section{A 91}

SICCA SYNDROME FOLLOWING ORAL ADMINISTRATION OF A BETA-BLOCKER

M Siepmann, J Barth, w Kirch

A sicca syndrome has been described very seldom after systemic administration of beta-blockers. We recently observed a 51 years old male patient who was treated with bisoprolol $5 \mathrm{mg}$ once daily since 12 months. Before administration of the betablocker he had temporarily complained about a feeling of dryness, a foreign body sensation of the eyes and reddening of the conjunctivae. The symptoms which were originally only slightly pronounced began markedly to worsen about six months following administration of bisoprolol. Application of artificial tear fluid did not really improve the symptoms, whereas cessation of treatment with bisoprolol led to disappearance of them within three weeks. Subsequently the administration of a lower dose of bisoprolol $12.5 \mathrm{mg}$ daily because of elevated blood pressure values and corresponding symptoms) was tolerated by the patient without reoccurrence of pronounced sicca symptoms during the next months.

In conclusion a sicca syndrome following oral therapy with beta-blockers has been reported rarely. The symptoms may reach from slight conjunctivitis sicca to a full blown mucocutaneous syndrome as described with practolol or metipranolol. A patient's predisposition may enhance the development of a sicca syndrome.

Dr. Martin Siepmann, Klinische Pharmakologie und Therapie, Medizinische Fakultät Carl Gustav Carus, Technische Universität Dresden, Fiedlerstraße 27, 01307 Dresden

\section{A 90}

\section{ANTI-INFLAMMATORY TREATMENT CONCEPTS FOR POSTOPERATIVE PAIN AND SWELLING PROPHYLAXIS FOLLOWING DENTO-ALVEOLAR SURGERY - RESULTS FROM 5 CLINICAL, INTRAINDIVIDUAL DOUBLE - BLIND STUDIES}

\section{S. SCHULTZE-MOSGAU 1), R. SCHMELZEISEN 1), J.C. FRÖLICH 2) \\ 1) Department of Oral and Maxillofacial Surgery, Hanover Medical School 2) Institute for Clinical Phannacology, Hanover Medical School}

The improvement of pain and swelling conditions by means of drugs is an important method of achieving an enhanced perioperative quality of life in cases of dentoalveolar surgery. In 5 prospective, randomised, double-blind studies the influence of various concentrations of local anaesthetics and accompanying analgesic and antioedematous drugs was investigated in the case of osteotomies. All of the studies were carried out according to a standardised study procedure. A comparison of the local anaesthetics articaine $4 \%$ und articaine $2 \%$ (Study 1) demonstrated the superior effect of articaine $4 \%$ with respect to onset relief on pain, period of effectiveness and ischaemia. Recordings of the cheek swelling in the remaining studies were made both sonogtaphically and with tape measurement, while the documentation of the pain was carried out by means of visual analogue scales on the day of operation and on the first and third post-operative days. The perioperative, exculsive administration of $2 \times 6 \mathrm{mg}$ Dexamethasone (Study 2) resulted in a significant reduction in the swelling ( $58 \%$ ) while the exclusive administration of $3 \times 400 \mathrm{mg}$ Ibuprofen (Study 3 ) was accompained by a marked decrease in pain (64\%) but no significant reduction of swelling in comparison to the placebo group. The combination of $3 \times 400 \mathrm{mg}$ Ibuprofen und $32 \mathrm{mg}$ Methylprednisolone (Study 4) yielded a decrease in pain of $67.7 \%$ and a reduction in swelling of $58 \%$. A comparison between a mono-drug Ibuprofen and a combination drug ASS/Paracetamol (Study 5) resulted in no significant difference in the reduction of swelling and pain and therefore highlighted no advantages for the combined drug. A mono-drug should therefore be given priority as an analgesic. The combination of Ibuprofen und Methylprednisolone offers the greatest reduction in pain and swelling. Using the results of the randomised studies, a phased plan for a patient-oriented, anti-inflammatory therapy to accompany dento-alveolar surgery is presented.

Dr. Stefan Schultze-Mosgau, Klinik für Mund-, Kiefer- und Gesichtschinurgie (Direktor: Prof. Dr. Dr. J.-E. Hausamen), Medizinische Hochschule Hannover, Konstanty-Gutschow-Str. 8, D-30625 Hannover, Deutschland

\section{A 92}

PHARMACOKINETICS OF IBOPAMINE - AN ORAL DOPAMINE AGONIST- IN PATIENTS WITH NORMAL AND IMPAIRED RENAL FUNCTION

M Siepmann, U Ebert, w Kirch

Ibopamine is an orally active derivative of dopamine which is rapidIy converted to epinine (Nmethyldopamine) by esterasis hydrolysis.

Pharmacokinetic data for Ibopamine have hitherto been determined in patients with renal failure only following single oral dosing of this dopamine agonist. In a placebo controlled study 20 patients with congestive heart failure (NYHA class II) were treated orally for seven days with $100 \mathrm{mg}$ ibopamine t.i.d. 10 subjects had a normal renal function (mean inulin clearance (GFR) $91 \pm 3,4 \mathrm{ml} / \mathrm{min}$ ), 10 patients suffered from chronic renal insufficiency (GFR $36 \pm 3,9 \mathrm{ml} / \mathrm{min} ; \mathrm{X} \pm \mathrm{SEM}$ ). Pharmacokinetic parameters of epinine, the maximum plasma concentration, the time to reach maximum plasma concentration and the area under the curve from 0 to 6 hours were unaltered in impaired renal function when measured on the first or on the seventh treatment day. However plasma concentrations in both groups were significantly higher on the first treatment day than after one week of ibopamine administration. In this context antipyrine clearance as a parameter of oxidative liver metabolism which might have been induced by ibopamine revealed no differences between placebo and ibopamine values. In conclusion kinetic and dynamic behaviour of ibopamine was not altered by impaired renal function.

Dr. Martin Siepmann, Klinische Pharmakologie und Therapie, Medizinische Fakultät Carl Gustav Carus, Technische Universität Dresden,Fiedlerstraße 27, 01307 Dresden 
MONOCLONAL ANTIBODIES AND THEIR USE FOR MEASURING HUMAN PROTEIN C

E. Staboulidou, H.P. Metzger

Human Protein C (HPC) is a Vitamin K-dependent in the liver produced glycoprotein with anticoagulant properties. When active Protein $C$ splits the coagulation factors Va and VIIIa by means of limited proteolysis (Kisiel et al 1977). Its concentration in normal plasma is $2-6 \mu \mathrm{g} / \mathrm{ml}$. HPC's biological importance became evident when a congenital Protein $\mathrm{C}$ deficiency, which results in difficult recurrent thromboembolic diseases was discovered (Griffin et al 1981)

The recognition of a congenital HPC deficiency, as well as the connection between acquired Protein $\mathrm{C}$ deficiency and the appearance of thromboembolic complications by means of highly accurate and sensitive ascertained methods is therefore of great practical importance for the clinic.

Murine monoclonal antibodies (moAbs) against HPC were formed. Antibody producing hybridomas were tested by an ,indirect ELISA“ against soluble antigens. The plates were coated with purified HPC up to 50 ng/100ul. The peroxydase-system was used to identify antibodies. The antibodies were tested with the remaining Vitamin K-dependent proteins for cross-reactivity, as well as with HPC deficiency plasma for disturbances by other plasma proteins. The above described experiment represents a sensitive and specific method for measuring the HPC concentration with moAbs.

Medizinische Hochschule Hannover, Physiologisches Institut, KonstantyGutschow-Str.8, D-30625 Hannover

\section{A 95}

INDUCIBLE NITRIC OXIDE SYNTHASE IS EXPRESSED IN VENTRICULAR MYOCARDIUM FROM PATIENTS WITH SEPSIS

B. Stein, *U. Förstermann, H. Scholz, M. Thoenes

There is evidence that nitric oxide (NO) plays a role in cardiovascular disease like hypertension, myocardial ischemia and septic cardiomyopathy. NO stimulates the guanylyl cyclase leading to an increase in cGMP content. We investigated by immunoblotting the expression of the inducible nitric oxide synthase (iNOS) in left ventricular myocardium from failing human hearts due to idiopathic dilative cardiomyopathy (IDC, $\mathrm{n}=10$ ), ischemic cardiomyopathy (ICM, $\mathrm{n}=7$ ), Becker muscular dystrophy $(n=2)$ and sepsis ( $\mathrm{SH}, \mathrm{n}=3)$ compared to non-failing human hearts (NF, $n=4)$. Cytokine-stimulated mouse macrophages were used as positive controls. SDS-polyacrylamide gel electrophoresis $(7.5 \%)$ was perfomed with homogenates of left ventricular myocardium and mouse macrophages respectively. Proteins were detected by enhanced chemiluminescence using a mouse monoclnal antibody raised against iNOS. Furthermore, we measured the cGMP content in these hearts by radioimmunoassy. $A$ band at about $130 \mathrm{kDa}$ was observed in two out of three hearts from patients with sepsis and in stimulated mouse macrophages. No iNOS-protein expression was detected in either non-failing human hearts $(n=4)$ or failing human hearts due to IDC, IHD or BMD. In ventricular tissue from patients with sepsis cGMP content was increased to $230 \%(72 \pm 17 \mathrm{fmol} / \mathrm{mg} \mathrm{ww}, \mathrm{n}=3)$ compared to non-failing hearts ( $100 \%$ or $31 \pm 6.9 \mathrm{fmol} / \mathrm{mg} \mathrm{ww}, \mathrm{n}=4$ ). In left ventricular tissue tissue from patients with heart failure due to IDC, IHD and BMD cGMP content did not differ from that in non-failing hearts. It is concluded that an enhanced iNOS protein expression may play a role in endotoxin shock, but is unlikely to be involved in the pathophysiology of end-stage heart failure due to IDC, IHD and BMD. (Supported by the DFG.)

Abteilung Allgemeine Pharmakologie, Universitäts-Krankenhaus Eppendorf, Universität Hamburg, Martinistraße 52, D-20246 Hamburg, *Pharmakologisches Institut Mainz, Obere Zahlbacher Straße 67, 55101 Mainz, FRG
TABLETS WITH pH DEPENDENT DISSOLVING COATING AS A TOOL TO INVESTIGATE LOCAL DRUG ABSORPTION IN THE GUT.

A. H. Staib, C. Huschka, ${ }^{\star} K$. Lehmann, ${ }^{*} H$. U. Petereit, M. Zaigler, U. Fuhr.

Assessment of local drug absorption differences ("absorption window") in the human gastrointestinal tract is relevant for the development of prolonged release preparations and for the prediction of possible absorption changes by modification of gastrointestinal motility. Current methods are either invasive and expensive (catheterization of the intestinum. HF-capsule method) or do not deliver the drug to a precisely defined localization.

We evaluated the delay of drug release from tablets coated with methacrylic acid copolymer dissolving at different $\mathrm{pH}$ values as an alternative method. Three coated preparations of caffeine tablets (onset of drug release in in vitro tests at $\mathrm{pH} 5.5,6.0$ and 7.0 ) and an uncoated tablet (control) were given to six healthy male volunteers in a randomized order. Caffeine was used because of its rapid and complete absorption and good tolerability. Blood samples were drawn up to $24 \mathrm{~h}$ postdose (coating pH 7.0 up to $30 \mathrm{~h}$ postdose), and caffeine concentrations were measured by HPLC. AUC, time to reach measurable caffeine concentrations $\left(T_{\text {lag }}\right), T_{\max }, C_{\max }$ and mean absorption time (MAT) values for coated preparations were compared to the reference tablet (mean \pm SD of $n=6$ ):

$\begin{array}{lcccc}\text { Preparation } & \text { control } & \text { coating pH 5.5 } & \text { coating pH 6.0 } & \text { coating pH 7.0 } \\ \text { AUC }_{0 \text { _(mg/th) }} & 28 \pm 7 & 30 \pm 6 & 30 \pm 10 & 25 \pm 8 \\ \mathrm{~T}_{\text {lag }} \text { (h) } & 0.3 \pm 0.0 & 1.3 \pm 1.0 & 2.1 \pm 0.2 & 3.3 \pm 0.6 \\ \mathrm{~T}_{\max } \text { (h) } & 1.0 \pm 0.6 & 2.0 \pm 1.3 & 4.0 \pm 0.3 & 5.6 \pm 1.5 \\ \mathrm{C}_{\max } \text { (mg/l) } & 4.1 \pm 0.4 & 3.8 \pm 0.5 & 3.4 \pm 0.4 & 2.6 \pm 0.8 \\ \text { MAT (h) } & - & 1.4 \pm 1.1 & 2.7 \pm 0.4 & 4.4 \pm 1.1\end{array}$

The relative bioavailibility for the coated preparations did not differ from the reference, suggesting complete release of caffeine. All coatings delayed caffeine absorption onset. The $\mathrm{T}_{\text {lag }}$ for the $\mathrm{pH} 5.5$ preparation suggests that release started immediately after the tablet had left the stomach. The mean delay of $2.1 \mathrm{~h}$ for the $\mathrm{pH} 6.0$ coating was highly reproducible and should reflect small intestine release. The $\mathrm{pH} 7.0$ coating delayed absorption to the highest extent, however the drug was probably released before the colon was reached.

Dept. Clin. Pharmacology, University Hospital, Th.-Stern -Kai 7, 60590 Frankfurt; ${ }^{\star}$ Roehm GmbH, Abt. Pharmapolymere, Kirschenallee, 64293 Darmstadt; Germany

\section{A 96}

ENHANCED URINARY NITRATE EXCRETION IN RATS WITH ADJUVANT ARTHRITIS

D.O. Stichtenoth, Frank-M. Gutzki, Dimitrios Tsikas, Norma Selve* and J.C. Frölich

Nitric oxide (NO), synthesized by the inducible form of No synthase, has been implicated as an important mediator of specific and non-specific immune response. Little is known about the in vivo synthesis of No in inflammatory joint diseases. Therefore we have studied the excretion of the major urjnary metabolite of No, nitrate, in rats with adjuvant arthritis, a well established model of polyarthritis. In addition we assessed the urinary excretion of cyclic GMP, which is known to serve as second messenger for the vascular effects of No, synthesized by the constitutive form of NO synthase, affecting blood vessels, platelet aggregation and neurotransmission.

in 24 h urines of 12 male sprague daw ley rats at day 20 after induction of adjuvant arthritis we measured nitrate excretion by gas chromatography and cyclic GMP by radioimmunoassay. For control we determined the same parameters in $24 \mathrm{~h}$ urines of non-arthritic rats of the same strain and age.

We found a significant ( $p<0.001$, two-tailed, unpaired t-test), more than 3-fold increase of urinary nitrate excretion in arthritic rats (mean $541 \pm$ SD $273 \mu \mathrm{mol} / \mathrm{mmol}$ creatinine) as compared to non-arthritic rats ( $169 \pm 39$ umol/mmol creatinine). Urinary cyclic GMP excretion was slightly, but not significantly lower in arthritic rats $(510 \pm 44$ nmol/mmol creatinine) than in controls (747 $\pm 33 \mathrm{nmol} / \mathrm{mmol}$ creatinine). There were no major differences in food or water intake which could account for these results.

The increased urinary nitrate excretion accompanied by normal cyclic GMP excretion suggests that No production by the inducible form of NO synthase is enhanced in rats with adjuvant arthritis.

Institute of Clinical Pharmacology, Hannover Medical School, D-30623 Hannover, Germany and * Research Center Grünenthal GribH, Zieglerstr. 6, D-52078 Aachen, Germany 
A 97

URINARY NITRATE EXCRETION IS INCREASED IN PATIENTS WITH RHEUMATOID ARTHFITIS AND REDUCED BY PREDNISOLONE D.O. Stichtenoth, J. Fauler, H. Zeidler* and J.C. Frölich

Nitric oxide (NO) has been shown to be a major messenger molecule regulating blood vessel dilatation, platelet aggregation and serving as central and peripheral neurotransmitter; furthermore NO is a crucial mediator of macrophage cytotoxicity. NO production can be assessed reliably by determination of its main metabolites nitrite and nitrate in serum, reflecting NO synthesis at the time of sampling, or in $24 \mathrm{~h}$ urine, reflecting daily NO synthesis. Farrell et al. (Ann Rheum Dis 1992; 51: 1219) recently reported elevated serum levels of nitrite in patients with rheumatoid arthritis (RA) We report here total body nitrate production and the effect of prednisolone in patients with RA.

Nitrate excretion in 24 h urines of 10 patients with RA as defined by the 1987 revised criteria of the American Rheumatism Association was measured by gas chromatography at 2 times: First before start of a antiinflammatory therapy with prednisolone, when the patients had high inflammatory activity as indicated by mean CRP serum concentrations of $71 \pm \mathrm{SD} 61 \mathrm{mg} / \mathrm{l}$ and elevated ESR with a mean of $62 \pm 28$ after 1 hour. Secondly 2-4 weeks after start of prednisolone therapy in a dosage of 0.5 $\mathrm{mg} / \mathrm{kg}$ body weight, when the patients showed clinical and biochemical improvement (CRP $6 \pm 5 \mathrm{mg} / \mathrm{l}, \mathrm{p}<0.05$, ESG $32 \pm 17$, p<0.001, two-tailed paired $\mathrm{t}$-test). For comparison $24 \mathrm{~h}$ urines from 18 healthy volunteers were obtained.

Before start of prednisolone therapy the urinary nitrate excretion in patients with RA (mean $223 \pm$ SD $126 \mu \mathrm{mol} / \mathrm{mmol}$ creatinine) was more than twofold higher $(p<0.001$, two-tailed unpaired t-test) than in healthy volunteers $(83 \pm$ $63 \mu \mathrm{mol} / \mathrm{mmol}$ creatinine). The urinary nitrate excretion decreased significantly $(p<0.001$, two-tailed, paired t-test) to $162 \pm 83 \mu \mathrm{mol} / \mathrm{mmol}$ creatinine under therapy with prednisolone, when inflammatory activity was reduced considerably. Despite the decrease the urinary nitrate excretion was still twofold higher ( $p<0.05$, two-tailed, unpaired t-test) in patients with RA than in the control group.

Our data suggest that the endogenous NO production is enhanced in patients with RA. Furthermore the results indicate that this elevated NO synthesis could be reduced in accordance with suppression of systemic inflammation by prednisolone therapy.

Institute of Clinical Pharmacology and "Department of Rheumatology, Hannover Medical School, D-30623 Hannover, Germany

\section{A 99}

DRUG BUDGET AT A UNIVERSITY HOSPITAL: COSTS DISTRIBUTION AND TRENDS.

M.Theisohn", HJ Volk"*, A.Voßen", W.Klaus"

Drug budget considerably increased (100\%) since 1986, more than the global expenses of the university hospital. This may be caused by the use of innova- tive drugs and therapies: ondansetron (antiemtic), ambisome (antimykotic), growth factors, immunosupressives in organ transplantations, blood products and drugs to influence coagulation (antithrombin III, factor VIII etc.). Trend analysis of the expenses at the various departments may be a basis for a ratio- nal and economic use of the drug budget.

Total drug expenses amounted to 30 mill. DM in 1993. 10 mill.DM (33\%) were used in surgical departments with intensive care units (ICU) (general surgery, kardiovascular surgery, neurosurgery, gynecology, anaesthesiology) of which $40 \%$ are needed by the ICU and $25 \%$ in the operating rooms. Surgical departments without ICU but similar patient numbers (ophthalmology, ENT, orthopedics and urology) get only $10 \%$ of the budget ( $30 \%$ needed for the operating rooms). The medical departments spent 10 mill.DM of which ICU needs only $10 \%$ whereas the oncology (OncU) and antiinfective units uses more than $50 \%$. Similar relation could be seen in the child hospital (2.4 mill.DM, $8 \%$ ) where $25 \%$ were spent for ICU and $40 \%$ for OncU. The departments of dermatology and neurology get $10 \%$, the depart- ments of radiology, nuclear medicine and radiation therapy only $8 \%$ of the budget. Antiinfective drugs (antibiotics, antimycotics, virustatics) are most expensive ( $21 \%$ of budget) followed by drugs used for radiological procedures $(8 \%)$, heparine type anticoagulants $(7.4 \%)$, narcotics $(6.1 \%)$, cytostatics $(5 \%)$, human albumin $(3.2 \%)$, growth factors $(3 \%)$, coagulation factors $(2.5 \%)$, immunoglobulines $(2.2 \%)$, immunsupressive drugs $(2 \%)$, antiemetics $(1 \%)$ and tissue adhesives $(2.3 \%)$.

Increasing the knowledge about the costs of medical items and the rational and economical use may stop the overproportional increase of the drug budget.

Department of Pharmacology", Hospital Pharmacy", University of Cologne, Gleuelerstr. 24, 50931 Köln, Germany

\section{A 98}

PRESCRIPTIONS OF DRUGS PREPARED IN PHARMACIES IN AN EAST GERMAN REGION

W. Sziegoleit, C. Krörck

Most drugs used in therapy are finished products of the pharmaceutical industry. But now as ever the physicians are entitled to prescribe drugs which have to prepare in a pharmacy for a particular patient. Little information is available on the frequency and patterns of these prescriptions. We had occasion to analyse the prescriptions of drugs which were prepared in 6 pharmacies in North Thuringia (East Germany) from October to December 1993 at the expense of a large health insurance company (Allgemeine Ortskrankenkasse). The selected pharmacies are localised in 6 cities. We found 2172 prescriptions of drugs made up in phannacies among a total number of 58472 reviewed drug prescriptions. This is $3.7 \%$ of the total. Most of these prescriptions were performed by dermatologists $(56.6 \%$ ), general practitioners $(21.9 \%)$, paediatrists $(7.9 \%)$ and otolaryngologists $(4.1 \%)$ According to this, the most frequently prescribed groups of drugs were dematics $(62.8 \%)$, followed by disinfectants $(14.1 \%)$. Ointments $(54.8 \%)$ and solutions (17.8\%) were the most frequent drug forms. Prescriptions were written in either Latin $(82.6 \%$ ) or German (17.4\%). Our results show that even now drugs prepared in pharmacies are used in the ambulatory pharmacotherapy to a low degree, especially in the treatment of skin diseases.

Prof. Dr. W. Sziegoleit, Martin-Luther-Universität, Institut für Pharmakologie und Toxikologie, Magdeburger Str. 4, D-06097 Halle

\section{A 100}

RELATIVE BIOAVAILABILITY OF ACETYLSALICYLIC ACID (ASA) FROM ENTERIC COATED TABLETS (100 AND $300 \mathrm{MG)} \mathrm{IN} \mathrm{COMPARISON} \mathrm{TO}$ THE STANDARD PLAIN TABLET WITH 100 AND 300 MG ASA

P. Thomann* E. Wölke*, J. Degen*, M. Seiberling*, G. Latta** D. Karabelnik***, B. Meyer***

"Innovex(Biodesign), Freiburg, **BAYER AG, Leverkusen ***ANAWA Laboratorien, Wangen/Zürich

\section{Introduction and Methods}

Enteric coated tablets with $100 \mathrm{mg}$ and $300 \mathrm{mg}$ acetylsalicylic acid (ASA) have been developed which should avoid the known gastrointestinal adverse events by a controlled drug release mainly in the duodenum after having passed the stomach. A 4-way cross-over study in 24 healthy male subjects, aged from 19-39 years, was conducted to investigate the pharmacokinetics, bioavailability, safety, and tolerance of ASA and its metabolites salicylic acid and salicyluric acid following enteric coated tablets in comparison with plain tablets. ASA and its metabolites were deternined by a sensitive, specific, and validated HPLC method. Pharmacokinetic parameters were determined by non-compartmental analysis. Bioequivalence was assessed by $90 \%$ confidence intervals.

Results and Conclusion

\begin{tabular}{|c|c|c|c|}
\hline \multicolumn{2}{|c|}{ relative bioavailability } & point estimator [\%] & $90 \%$ confidence interval \\
\hline 100mg & ASA & 94.7 & $79-113$ \\
& salicylic acid & 96.9 & $92-102$ \\
& salicyluric acid & 84.7 & $77-94$ \\
\hline \multirow{3}{*}{$00 \mathrm{mg}$} & ASA & 73.1 & $61-87$ \\
& salicylic acid & 92.9 & $88-98$ \\
& salicyluric acid & 93.5 & $84-104$ \\
\hline
\end{tabular}

Following the administration of enteric coated tablets, a delayed absorption can be observed for both the $100 \mathrm{mg}$ dose and the $300 \mathrm{mg}$ dose. This is likely due to a delaved release of the active substance from the enteric-coated tablets in the small intestine after gastric passage. Considering the mean residence times (MRT), there is a difference of at least $2.8 \mathrm{~h}$ following the enteric coated tablets compared to the plain tablets for ASA and the two metabolites measured. This difference represents the sum of residence time in the stomach plus the time needed to destroy the coating of the tablet when it left the stomach. In general, the maximum observed concentrations of both enteric coated formulations occurred 3-6 h post dose. 


\section{A 101}

PHARMACOKINETICS OF ANTI-HBS AFTER AN INTRAVENOUS INFUSION OF IMMUNOGLOBULIN G (BT 507) IN 12 HEALTHY MALE VOLUNTEERS

P. Thürmann, Ch. Sonnenburg-Chatzopoulos

The pharmacokinetics of a novel immunoglobulin $\mathrm{G}$ (IgG) preparation (BT507, Biotest, Dreieich, FRG) have been determined in 12 healthy, male anti-HBs-negative volunteers. For this preparation only plasma from HIV-, HBV-and HCV-negative donors was used, the quality control for the product was in accordance with the EC-guideline for virus removal and inactivation procedures. Each volunteer received a single, intravenous infusion of $100 \mathrm{ml} \mathrm{BT507}$ containing $5 \mathrm{~g} \mathrm{IgG}$ and anti-HBs $\geq 5,000 \mathrm{IU}$. Anti-HBs was used as a simply measurable and representative marker for the IgG. Blood samples for determination of anti-HBs (AUSAB EIA, Abbott, FRG) were drawn before and directly after the infusion, after 1,3,6,12 and 24 hours, on day 3,5,8,15,22 $29,43,57,71,85$ and 99. Additionally, total protein, IgG, IgA, IgM and e3/C4 complement were measured and blood hematology and clinical chemistry parameters determined. The pharmacokinetic parameters of anti-HBs were calculated using the TOPFIT ${ }^{\mathrm{P}}$ PC program assuming a 2-compartment model.

\begin{tabular}{|c|c|c|c|c|c|c|}
\hline $\begin{array}{l}\text { mean } \\
\text { sd }\end{array}$ & $\begin{array}{c}\mathrm{C}_{\max } \\
(\mathrm{mU} / \mathrm{ml}) \\
1,778 \\
204\end{array}$ & $\begin{array}{l}t_{\max } \\
\text { (h) } \\
1.4 \\
1.2\end{array}$ & $\begin{array}{l}\text { AUC } \\
\text { (mU/ml*days) } \\
28,867 \\
5,637\end{array}$ & $\begin{array}{l}\mathrm{t} 1 / 2 \mathrm{el} \\
\text { (days) } \\
22.1 \\
3.7\end{array}$ & $\begin{array}{l}\mathrm{Cl}_{\text {tot }} \\
(\mathrm{ml} / \mathrm{min}) \\
0.130 \\
0.034\end{array}$ & $\begin{array}{l}V d_{\text {ss }} \\
(1) \\
5.4 \\
0.7\end{array}$ \\
\hline
\end{tabular}

3 months after the application of BT507 all subjects were negative for HIV, HCV and HBV. No relevant changes occured in total Ig, complement factors and safety laboratory variables. The calculated half-life of anti-HBs of 22 days corresponds to that of natural IgG (about 21-23 days). Conclusion: Since pharmacokinetic characteristics of IgG represent both the entirety or a cleavage of the molecule, the results of this study suggest an almost completely preserved integrity of the IgG molecule in the preparation BT507.

Dr.med. Petra Thürmann, Dept. of Clinical Pharmacology, University Clinic, Theodor-Stern-Kai 7, 60590 Frankfurt, FRG

\section{A 103 \\ RENAL ELIMINATION OF TALINOLOL ENANTIOMERS Beate Trausch, R. Oertel, K. Richter, T. Gramatté, W. Kirch}

Talinolol (Cordanum $^{\circledR}$ ), the mostly used $\beta_{1}$-adrenoceptor antagonist in Eastern Germany, is a racemic drug [R/S-1-(4-Cyclohexyl-ureido-phenoxy)2-hydroxy-3-tert.-butylamino-propane]. The S-enantiomer has a greater affinity to the $\beta_{\mathrm{L}}$-receptors $(1: 20)$ and a 100 -fold higher efficiency than the R-form.

The elimination of the talinolol enantiomers was studied in 12 healthy volunteers (age: $23-32$ years, body weight: $55-84 \mathrm{~kg}$ ) given a single oral dose (50 mg) or an intravenous infusion ( $30 \mathrm{mg}$ ) of the racemic drug. Three volunteers were phenotypically poor metabolisers and nine were extensive metabolisers of the debrisoquine-type of hydroxylation. The R- and Senantiomers of talinolol were analysed in urine by a HPLC method after enantioselective derivatisation. The concentrations of the enantiomers within every sampling period as well as the amounts of $\mathrm{S}$ - and R-enantiomer eliminated within $36 \mathrm{~h}$ were compared with the t-test for paired samples (two-sided significance level: $\mathrm{p}<0,05$ )

After intravenous infusion $7516 \pm 1485 \mu \mathrm{g} \mathrm{S}$-talinolol and $7540 \pm 1492 \mu \mathrm{g}$ $\mathrm{R}$-talinolol were recovered unchanged in urine within the observation time. This corresponds to a S/R-ratio of $1,00 \pm 0,02$. The mean total amount $(=\mathrm{S}$ - + R-enantiomer) eliminated was on average $50 \%$ of the administered dose. After oral administration $26 \pm 7 \%$ of the dose were eliminated within $36 \mathrm{~h}$. The amounts of talinolol enantiomers recovered were equally (Senantiomer: $6416 \pm 1624 \mu \mathrm{g}$; R-enantiomer: $6492 \pm 1674 \mu \mathrm{g}$; S/R-ratio $0,99 \pm 0,03$ ). The ratios of $\mathrm{S}$ - to R-concentrations at every sampling interval and of every volunteer were assessed between 0,82 and 1,11 (mean: 1,00 after infusion and 1,01 after oral administration, respectively). There was no significant difference for any of the parameters calculated. No dependence on metaboliser phenotype was observed.

An enantioselective pharmacokinetics of talinolol can be excluded.

Institut für Klinische Pharmakologie, Medizinische Fakultät Carl Gustav Carus, Technische Universität, Fiedlerstr. 27, 01307 Dresden, Germany

\section{A 102 \\ PHARMACOECONOMIC EVALUATIONS: CLINICALLY RELEVANT ENDPOINTS P. Thürmann}

Pharmacoeconomic evaluations (PE) describe the relationship between a certain health care input (costs) for a defined treatment and the clinical outcome of patients measured in common natural units (e.g. blood pressure reduction in $\mathrm{mmHg}$ ), quality of life (QoL) gained, lifes saved or even in money saved due to the improvement in patients functional status. This implies that the efficacy of a treatment has been measured and proven in clinical trials. In addition, in order to transfer data obtained in clinical trials to the clinical setting, an epidemiological database for diseases and eventually drug utilization may be required. The evaluation of the efficacy depends on the disease to be treated or prevented and the mode of treatment. For acute, e.g. infectious diseases, the endpoint can be defined easily by the cure rate, but for PE the time (length of hospital stay) and other factors (e.g. no. of daily drug administrations) have to be considered. In the case of chronic diseases, e.g. hypertension or hypercholesterolaemia, surrogate endpoints (blood pressure or serum cholesterol reduction) and information on side effects may be acceptable for the approval, but cannot be used for a meaningful PE. The latter should include the endpoints of the disease, i.e. cardiovascular events (requiring hospitalisation and additional treatment) and mortality. Furthermore, the QoL has to be measured and considered for chronic treatment. Several questionaires have been developed to measure the overall QoL or the health related QoL. Especially the latter may be a more useful tool to detect and quantify the impact of a treatment on QoL. Combining the clinical endpoint mortality and QoL by using QALYs (quality-adjusted lifeyears) may be a useful tool to determine the value and costs of a given drug treatment but cannot be applied to all treatments under all circumstances.

Dr.med. Petra Thürmann, Dept. of Clinical Pharmacology, University Clinic, Theodor-Stern-Kai 7, 60590 Frankfurt, FRG

\section{A 104}

PLATELET AGGREgATION AND SENSITIVTTY TO PROSTAGLANDIN E1 IN RECOMBINANT HIRUDINAND HEPARIN- ANTICOAGULATED BLOOD.

\author{
M. Viigimaa, D. Tsikas and J. C. Frölich
}

Hirudin is the most potent known natural inhibitor of thrombin and is presently gaining popularity as an anticoagulant since recombinant forms have become available. The aim of the present study was to compare platelet aggregation, sensitivity to prostaglandin E1 (PGE1) and thromboxane $\mathrm{A} 2$ (TxA2) release in r-hirudinized and heparinized blood. Platelet aggregation was measured turbidimetrically using a dual channel aggregometer (LAbor, Germany) in blood samples of healthy volunteers anticoagulated with r-hirudin W015 (Behring) and heparin (20 $\mu \mathrm{g} / \mathrm{ml}$ blood each). Aggregation was induced by arachidonic acid (AA; $0.5,1.0$ and $2.0 \mathrm{mM})$ and ADP $(1.0 \mu \mathrm{M})$. PGEl in concentrations 10,20 and $40 \mathrm{ng} / \mathrm{ml}$ was used. Plasma $\mathrm{TxB} 2$ content was measured by gas chromatography/mass spectrometry. This study showed a significantly lower AA-induced platelet aggregation in r-hirudinized plasma. Three minutes after the aggregation induction by $0.5 \mathrm{mM} \mathrm{AA}$ the plasma $\mathrm{TxB} 2$ concentration was $23.0 \mathrm{ng} / \mathrm{ml}$ in blood anticoagulated with rhirudin and $108.4 \mathrm{ng} / \mathrm{ml}$ in heparin- anticoagulated blood. The extent of the ADP- induced aggregation was nearly the same in rhirudinized and heparinized plasma. Platelet sensitivity to PGE1 was significantly higher in r-hirudinized blood. Thus, AA-induced platelet aggregation is significantly lower and sensitivity to PGE1 higher in r-hirudin-anticoagulated blood in comparison with heparin-anticoagulated blood.

University of Tartu, Puusepa Str. 8, Tartu EE 2400, Estonia 
A 105

RECIRCULATORY MODEL OF SORBITOL KINETICS M. Weiss, G. H. Hübner, W. Teichmann, I. G. Hübner.

Sorbitol was used as a model substance to investigate the dynamics of the initial distribution process following bolus intravenous injection of drugs. To avoid a priori assumptions on the existence of well-mixed compartments data analysis was based upon the concept of residence time density in a recirculatory system regarding the pulmonary and systemic circulation as subsystems. The inverse Gaussian distribution was used as an empirical model for the transit time distribution of sorbitol across the subsystems. Distribution kinetics was evaluated by the relative dispersion of transit (circulation) times. The distribution volumes calculated from the mean transit times were compared with the modelindependent estimate of the steady-state volume of distribution. Kinetic data and estimates of cardiac output were obtained from 10 patients after percutaneous transluminal coronary angioplasty. Each received a single $0.8 \mathrm{~g}$ iv bolus dose of sorbitol. Arterial blood samples were collected over 2 hours. While the disposition curve could be well fitted by a tri-exponential function the results indicate that distribution kinetics is also influenced by the transit time through the lungs, in contrast to the assumption of a wellmixed plasma pool underlying compartmental modelling. A significant correlation was found between estimated $C L$ and cardiac output. This result reflects a linear dependence of hepatic perfusion on cardiac output in the observed range ( $\mathrm{CO}$ between 4150 and $7248 \mathrm{ml} / \mathrm{min}$ ).

Sekt. Pharmakokinetik des Pharmakol. Inst. und Klinik für Innere Medizin III der Martin-Luther-Universität Halle-Wittenberg 06097 Halle/Saale

\section{A 107}

CHOLINERGIC TRANSMISSION IN HUMAN AIRWAYS AND NEURONAL EFFECTS OF [B-ADRENOCEPTOR AGONISTS

I. Wessler, T. Reinheirner, KD. Höhle ${ }^{\star}$ and K. Racké ${ }^{\star \star}$

Acetylcholine plays an important role in regulating various functions in the airways In human lung less is known about regional differences in cholinergic innervation and about receptor-mediated regulation of acetylcholine release. In the present study the tissue content of endogenous acetylcholine and the release of newly-synthesized ['H]acetylcholine were measured in human lung. Human tissue was obtained at thoracotomy from patients with lung cancer. Moreover, in isolated rat tracheae with intact extrinsic vagal innervation possible effects of B-adrenoceptor agonists on evoked $\left[{ }^{3} \mathrm{H}\right]$ acetylcholine release were studied. Endogenous acetylcholine was measured by HPLC with EC-detection; evoked $\left[{ }^{3} \mathrm{H}\right]$ acetylcholine release was measured after a preceding incubation of the tissue with $\left[{ }^{3} \mathrm{H}\right]$ choline

Human large (main bronchi) and small (subsegmental bronchi) airways contained similar amounts of acetvlcholine $(300 \mathrm{pmol} / 100 \mathrm{mg})$, whereas significantly less acetylcholine was found in lung parenchym $(60 \mathrm{pmol} / 100 \mathrm{mg})$. Release of $\left[{ }^{3} \mathrm{H}\right]$ acetylcholine was evoked in human bronchi by transmural electrical stimulation (four $20 \mathrm{~s}$ trains at $15 \mathrm{~Hz}$ ). Oxotremorine, an agonist at muscarine receptors, inhibited evoked [ $\left.{ }^{3} \mathrm{H}\right]$ acetylcholine release indicating the existence of neuronal inhibitory receptors on pulmonary parasympathetic neurones. Scopolamine shifted the oxotremorine curve to the right suggesting a competitive interaction (pA2 value: 8.8 : slope of the Schild plot not different from unity). However, a rather sluggish Schild plot was obtained for pirenzepine. Scopolamine but not pirenzepine enhanced evoked $\left[{ }^{3} \mathrm{H}\right]$ acetylcholine release. The present experiments indicate a dense cholinergic innervation in human bronchi: release of acetylcholine appears to be controlled by facilitatory and inhibitory muscarine receptors.

In isolated mucosa-intact rat tracheae isoprenaline ( $100 \mathrm{nM})$ inhibited $\left[{ }^{3} \mathrm{H}\right]$ acetylcholine release evoked by preganglionic nerve stimulation. Isoprenaline was ineffective in mucosa-denuded tracheae or in the presence of indomethacin. Thus, $\beta$ adrenoceptor agonists appear to inhibit acetylcholine release in the airways by the liberation of inhibitory prostanoids from the mucosa.

Department of Pharmacolgy, University of Mainz, Obere Zahlbacher Str. 67, 55101

Mainz

*St. Hildegardis Hospital, Clinic for Surgery, 55101 Mainz

**Department of Pharmacology, University of Frankfurt. 60590) Frankfurt
A 106

DETERMINATION OF AZATHIOPRINE METABOLITES AS A POSSIBLE CAUSE OF ANAEMIA IN RENAL TRANSPLANT RECIPIENTS UNDER ENALAPRIL COMEDICATION.

S. Weller, P. Thürmann, E.-H. Scheuermann, J. Gossmann, N. Rietbrock

Anaemia has been reported in renal transplant (NTX) recipients treated with azathioprine (AZA) and angiotensin converting enzyme-inhibitors (ACE-I). An abnormal AZA metabolism with increased 6-thioguanine nucleotide (TGN) levels in erythrocytes is a possible cause of severe megaloblastic anaemia (Lennard et al, Br J Clin Pharmacol 1984).

Methods: 15 NTX patients receiving AZA $(1,9 \pm 0,54 \mathrm{mg} / \mathrm{kg} / \mathrm{d})$, prednisolone $(0,12 \pm 0,06 \mathrm{mg} / \mathrm{kg} / \mathrm{d})$ and enalapril (ENA) $(0,16 \pm 0,07 \mathrm{mg} / \mathrm{kg} / \mathrm{d})$ for more than 6 months were studied prospectively. Blood samples were taken before and $3 \mathrm{~h}$ after administration of AZA on 2 visits during ENA treatment and 10 weeks after ENA had been replaced by other antihypertensives (X). TGN in erythrocytes, 6-mercaptopurin (MP) and 6-thiouric acid (TUA) in $3 \mathrm{~h}$ post dose plasma (p.) und $24 \mathrm{~h}$ urine (u.) samples were analyzed by HPLC using a mercurial cellulose resin for selective absorption of the thiol compounds. Pharmacodynamic variables were hemoglobin $(\mathrm{Hb})$, erythropoietin (EPO) and creatinine clearance (Ci).

\begin{tabular}{|c|c|c|c|c|c|c|c|c|}
\hline \multirow[t]{2}{*}{ Results. } & \multicolumn{2}{|c|}{ MPp. [ng/ml] } & \multicolumn{2}{|c|}{ MPu. $[\mu g]$} & \multicolumn{2}{|c|}{ TUAp. [ng/ml] } & \multicolumn{2}{|c|}{ TUAu. [ $\mu g]$} \\
\hline & ENA & $x$ & ENA & $X$ & ENA & $x$ & ENA & $x$ \\
\hline mean & 14.8 & 15.3 & 141 & 112 & 301 & 348 & 1778 & 1328 \\
\hline \multirow[t]{3}{*}{ sd } & 9.9 & 9.1 & 71 & 97 & 158 & 178 & 912 & 748 \\
\hline & \multicolumn{2}{|c|}{ 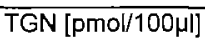 } & \multicolumn{2}{|c|}{$\mathrm{Hb}[\mathrm{g} / \mathrm{d}]$} & \multicolumn{2}{|c|}{$\mathrm{EPO}[\mathrm{mU} / \mathrm{ml}]$} & \multicolumn{2}{|c|}{$\mathrm{Cl}[\mathrm{m} / / \mathrm{min}]$} \\
\hline & ENA & $\mathrm{x}$ & ENA & $\mathrm{X}$ & ENA & $\mathrm{X}$ & ENA & $x$ \\
\hline mean & 277 & 304 & $\overline{12.7}$ & 13.6 & 14.0 & 20.0 & 61.9 & 59.3 \\
\hline sd & 171 & 194 & 2.2 & 1.2 & 12.3 & 13.9 & 21.1 & 19.9 \\
\hline
\end{tabular}

Conclusions: The determined AZA metabolites remained almost unchanged after withdrawal of ENA whereas $\mathrm{Hb}$ and EPO values increased significantly $(p<0,03)$. Anaemia may have been caused by decreased EPO formation due to ACE-I in addition to ineffective erythropoiesis caused by AZA metabolites (Howarth, J Clin Pathol 1993).

Stefan Weller, Dept. of Clinical Pharmacology, University Clinic

Theodor-Stern-Kai 7, 60590 Frankfurt, FRG

A 108

INHIBITION OF NON-ENZYMATIC FRUCTATION OF HUMAN SERUM ALBUMIN BY VARIOUS DRUGS

W.Wörner, V.Jakus, N.Rietbrock

The occurrence of the non-enzymatic reactions between glucose and structural proteins is well known (Vlassara H et al. (1994) Lab Invest 70: 138-151). The reaction between proteins and fructose (i.e. fructation), however, can also occur. Like glucose-protein adducts the fructose analogies are able to form so-called advanced glycation endproducts (AGE). The inhibition of early and advanced products of fructation may be important for the prevention of diabetic late complications (McPherson JD et al. (1988) Biochemistry 27: 1901-1907). We investigated the in vitro fructation of human serum albumin (HSA) and its inhibition by selected drugs. HSA was fructated by incubation with $20 \mathrm{mmol} / 1$ fructose in $0 . \mathrm{I} \mathrm{mol} / 1$ phosphate buffer, $\mathrm{pH}=7.4$, at $37^{\circ} \mathrm{C}$ for 21 days. The rate of fructation was measured by the following methods:

- a colorimetric method based on deglycation of glycated proteins by hydrazine (Kobayashi K et al.(1994) Biol Pharm Bull 17: 365-369),

- affinity chromatography with aminophenyl-boronate-agarose,

- fluorescence measurement for the determination of AGE.

We used aminoguanidine, penicillamine, captopril and alpha-lipoic acid(20 $\mathrm{mmol} / \mathrm{l})$

to sludy the inhibition of HSA fructation.

After three weeks incubation the formation of early glycation products was inhibited by aminoguanidine $(15 \%)$ and captopril $(3 \%)$ whereas penicillamine and alpha-lipoic acid showed minimal inhibition. Aminoguanidine inhibited the formation of AGE by $42 \%$, penicillamine by $37 \%$, alpha-lipoic acid by $11 \%$ and captopril by $37 \%$.

These results inay suggest a potential use of the investigated drugs in the prevention of the formation of protein-frucrose adducts.

Dr.pharm. Wolfgang Worner. Dept.Clinical Pharmacology, University Hospital Frankfurt, Theodor Slern Kai 7.60590 FrankfurdMain FRG 


\section{A 109}

A new African vegetable substance in the treatment of neurodermitis and other skin diseases (Karitê; Butyrospermum Parkii)

W. Wörner, Y.Keita, W.Etrich

Karité "butter" is used traditionally in West Afrịcan Manding culture as a cosmetic to protect the skin against the sun. Gas chromatography was used to analyze the ingredients of Karitê butter from Guinea. We found $3 \%$ palmitic acid, $42 \%$ stearic acid, $42 \%$ oleic acid and $8 \%$ linaleic acid and $0.1 \%$ of other fatty acids with higher chain lengths like arachidonic acid. Some of these are essential fatty acids (vitamine F). Furthermore Karité contains vitamine A and $D$ as well as triterpene alcohols and phytosterines. An original extract was used to prepare a skin cream. This preparation was tested in 25 volunteers (18 women, 7 men; age 20-55 y.). The cream contained at least 50\% Karité, glycerol, emulsifiers and no preservative agent except for sorbic acid. 24 of the volunteers very well tolerated the cream and thought it effective. The skin became more tender and elastic. Good results were obtained when the volunteers suffered from very dry skin. Two of them who were known to be allergic against the most available skin creams had no problems in using our Karité cream. Pure Karité butter was used for four months to treat an African infant with neurodermitis. After this time the symptoms had markedly improved whereas previous therapy trials with other usual topical medicaments had been unsuccessful. These pre-studies had shown that dermatologic preparations containing Karité may be a good alternative in the treatment of therapyresistent skin diseases and may in some cases be able to replace corticoid treatment.

Abteilung für Klinische Pharmakologie am Klinikum der Johann Wolfgang Goethe-Universität D-60590 Frankfurt an Main

\section{A 111}

IN VIVO VS. IN VITRO COMPARISON OF INHIBITORY DRUG EFFECTS ON THE HUMAN CYTOCHROM P450 ISOFORM CYP1A2.

\section{$M$. Zaigler and U. Fuhr.}

The human cytochrome P450 isoform CYP1A2 determines the level of a variety of drugs metabolized by the enzyme, including caffeine (CA) and theophylline $(\mathrm{TH})$. More than 50 compounds are potential or proven inhibitors of this enzyme. Some of them were reported to be substrates or inhibitors to CYP1A2 in vitro, others caused pharmacokinetic interactions with drugs metabolised by CYP1A2. We characterized a series of these compounds with.. respect to their effect on CYP1A2 in human liver microsomes in relation to published pharmacokinetic interactions in vivo. CYP1A2 activity in vitro was measured as CA 3-demethylation at the high affinity site in human liver microsomes, using 15 min incubation at $37^{\circ} \mathrm{C}$ with 125 - $2000 \mu \mathrm{M}$ caffeine, an NADPH generating system, and inhibitor concentrations covering 1.5 orders of magnitude. Apparent $K_{1}$ values were estimated using nonlinear regression analysis.

For inhibitory effects on CYP1A2 activity in vivo, the absorbed oral dose causing $50 \%$ reduction in $\mathrm{CA}$ or $\mathrm{TH}$ clearance $\left(E D_{50}\right)$ was estimated from all published interaction studies using the $E_{\max }$ model.

All drugs tested were competitive CYP1A2 inhibitors in vitro, suggesting dose

\begin{tabular}{|c|c|c|c|c|}
\hline inhibitor & $\begin{array}{c}\mathrm{K}_{\mathrm{I}} \\
(\mu \mathrm{M}) \\
\text { in vitro }\end{array}$ & $\begin{array}{c}\mathrm{ED}_{50} \\
\text { (mmol) } \\
\text { to CA }\end{array}$ & $\begin{array}{l}\mathrm{ED}_{50} \\
\text { (mmol) } \\
\text { to TH }\end{array}$ & good agreement (table) was \\
\hline methoxsalen & 0.24 & 0.18 & - & \\
\hline fluvoxamine & 0.47 & - & 0.23 & efrects on prarmacokineucs \\
\hline propafenone & 42 & - & 0.72 & with $K$ yalues $<50$ uM \\
\hline mexiletine & 63 & 1.45 & 1.22 & With $\mathrm{K}_{\mathbf{I}}$ \\
\hline pipemidic acid & 130 & 1.35 & 1.76 & ractions (change $35->100 \%$ \\
\hline enoxacin & 140 & 0.38 & 0.70 & for usual dosing schedules). \\
\hline ciprofloxacin & 200 & 2.78 & 2.82 & Inhibitors with $\mathrm{K}_{4}$ values \\
\hline cimetidine & 717 & 2.03 & $5 . \overline{32}$ & $>1000 \mu \mathrm{M}$ did not reduce \\
\hline lomefloxacin & 1100 & - & 22.6 & netabolic clearance depen- \\
\hline ofloxacin & 1500 & no effect & 15.0 & ing on CYP1A2 activity. \\
\hline
\end{tabular}

Dept. Clin. Pharmacology, University Hospital, Th.-Stem-Kai 7, 60590 Frankfurt, FRG
A 110

EFFECTS OF RECOMBINANT HIRUDIN (r-HIRUDIN; HBW 023) ON COAGULATION AND PLATELET ACTIVATION IN VIVO: COMPARISON TO UNFRACTIONATED HEPARIN AND A LOW MOLECULAR WEIGHT HEPARIN PREPARATION (FRAGMIN ${ }^{(3)}$ )

M Wolzt, S Eichinger, B Schneider, H Heinrichs, $K$ Lechner, HG Eichler, PA Kyrle

Depts. of Clinical Pharmacology and of Medicine I, Division of Hematology and Hemostaseologie, Institute of Medical Statistics and Documentation, Vienna University Hospital, Vienna, Austria and Behringwerke AG, Marburg. Germany

In a double-blind randomized cross-over study we have investigated in 15 healthy male volunteers the effects of recombinant hirudin (r-hirudin, HBW 023 , $0.35 \mathrm{mg} / \mathrm{kg}$ bodyweight s.c.), unfractionated heparin (UFH, $150 \mathrm{IU} / \mathrm{kg}$ bodyweight s.c.) and a low molecular weight heparin preparation (Fragmin ${ }^{(8)} 75 \mathrm{lU} / \mathrm{kg}$ bodyweight s.c.) on coagulation and platelet activation in vivo by measuring specific coagulation activation peptides [prothrombin fragment $1+2(F 1+2)$, thrombin antithrombin III complex (TAT), $\beta$-thromboglobulin ( $\beta-T G$ )] in bleeding time blood (activated state) and in venous blood (basal state). In bleeding time blood, r-hirudin and the heparin preparations significantly inhibited the formation of both TAT and F1+2 However, the inhibitory effect of r-hirudin on F1+2 generation was short-lived and weaker compared to UFH and LMWH and the TAT/F1+2 ratio was significantly lower after r-hirudin than both UFH and LMWH Thus, in vivo when the coagulation system is in an activated state r-hirudin exerts its anticoagulant effects predominantly by inhibiting thrombin (lla), whereas UFH and LMWH are directed against both Xa and lla. A different mode of action of UFH and LMWH was not detectable. In venous blood, r-hirudin caused a moderate reduction of TAT formation and an increase (at 1 hour) rather than decrease of $F 1+2$ generation. Formalion of TAT and F1+2 was suppressed at various time points following both UFH and LMWH. There was no difference in the TAT/F $1+2$ ratio after $r$-hirudin and heparin. Thus, a predominant effect of $r$ hirudin on lla (as found in bleeding time blood) was not deteclable in venous blood. In bleeding time blood, r-hirudin (but neither UFH nor LMWH) significantly inhibited $\beta$-TG release. In contrast, both UFH and LMWH caused an increase of $\beta-T G 10$ hours afler heparin application. Our observation of reduction of platelet function after r-hirudin compared to delayed platelet activation following UFH and LMWH suggests an advantage of r-hirudin over heparin, especially in those clinical situations (such as arterial thromboembolism) where enhanced platelet activity has been shown to be of particular importance.

Department of Clinical Pharmacology/Nienna University Hospital A-1090 Vienna, Währinger Gürlel 18-20 